\title{
Focus Marking in Kikuyu
}

\author{
Florian Schwarz \\ Humboldt-Universität zu Berlin / ZAS Berlin
}

\section{Kurzbeschreibung der Arbeit}

Im Kikuyu, einer in Kenia gesprochenen Bantusprache, wird Fokus systematisch durch Wortstellung markiert. In dieser Arbeit werden die verschiedenen Varianten der Markierung von Fokus in Frage-Antwortsequenzen dargestellt. Nach einem Überblick über in der Literatur vorhandene Diskussionen des Phänomens wird auf der Grundlage von mit einem Muttersprachler erhobenen Daten eine syntaktische Analyse von Fokuskonstruktionen mit der Partikel ne vorgeschlagen. Ferner werden neue Daten zur Fokussierung verschiedener Satzteile, z.B. der VP, des ganzen Satzes und des Wahrheitswerts, präsentiert. Ziel der Arbeit ist somit, die deskriptive Datenbasis zu Fokuskonstruktionen im Kikuyu zu erweitern und einen theoretischen Beitrag zu ihrer Analyse im Rahmen der generativen Grammatik zu liefern.

Die Arbeit wurde im Sommer 2003 als Magisterarbeit an der Humboldt-Universität zu Berlin, Institut für deutsche Sprache und Linguistik, angenommen.

\begin{abstract}
In Kikuyu, a Bantu language spoken in Kenya, focus is marked systematically by means of word order. In this study, the different possibilities for marking focus in question answer sequences are presented. After an overview of the discussions of the phenomenon in the literature, a syntactic account for focus constructions with the particle $n e$ is proposed. This account is based on original data that was gathered with a native speaker. In addition, new data on focusing different parts of the sentence, e.g. the VP, the entire sentence, or the truth-value, are presented. The aim of this study thus is to broaden the descriptive basis for focus constructions in Kikuyu and to provide a theoretical contribution to their analysis in the framework of generative grammar.
\end{abstract}

\section{Abbreviations}

The following abbreviations are frequently used throughout this study:

\begin{tabular}{|c|c|c|c|c|c|}
\hline APPL & $=$ & Applicative & PP & $=$ & Pronominal Prefix \\
\hline ASP & $=$ & Aspect & & & (in interlinear translations) \\
\hline ASS & $=$ & Associative & Sg. & $=$ & Singular \\
\hline CAUS & $=$ & Causative & SM & $=$ & Subject Marker \\
\hline COP & $=$ & Copula & $\mathrm{T}$ & $=$ & Tense \\
\hline DEM & $=$ & Demonstrative & TopP & $=$ & Topic Phrase \\
\hline FM & $=$ & Focus Marker & VS & $=$ & Verb Stem \\
\hline $\mathrm{FP}$ & $=$ & Focus Phrase & & & \\
\hline FV & $=$ & $\begin{array}{l}\text { Final Vowel } \\
\text { (of the verbal complex) }\end{array}$ & & & \\
\hline HAB & $=$ & Habitual & & & \\
\hline INF & $=$ & Infinitive & & & \\
\hline $\mathrm{LOC}$ & $=$ & Locative & & & \\
\hline $\mathrm{OM}$ & $=$ & Object Marker & & & \\
\hline
\end{tabular}




\section{Contents}

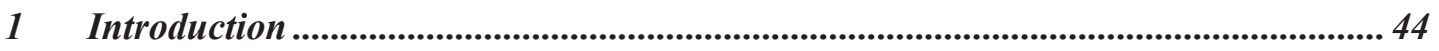

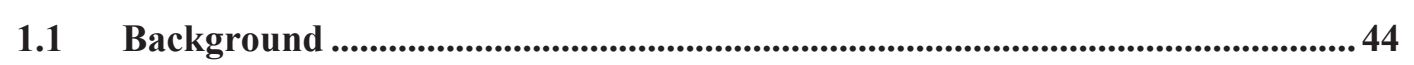

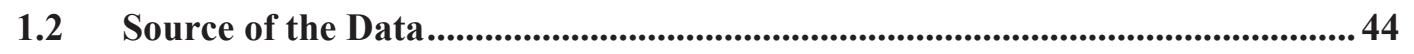

1.3 Some Kikuyu Basics and Notational Conventions ................................................... 44

1.4 Structure ....................................................................................................................................4 47

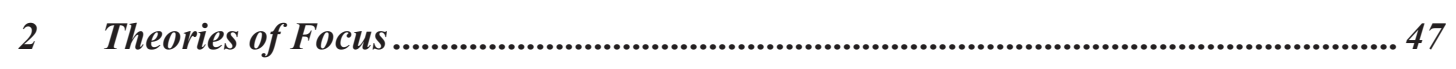

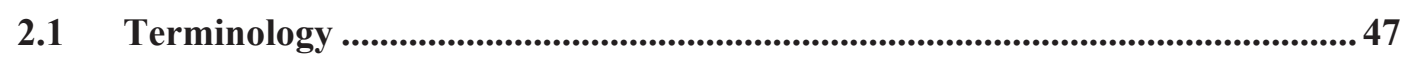

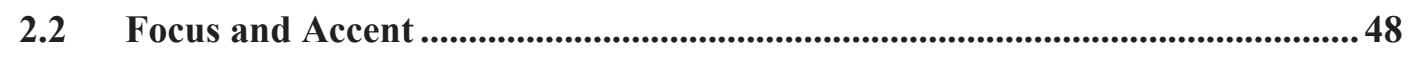

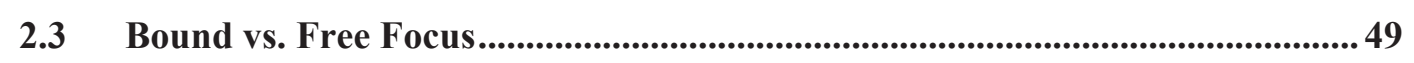

2.4 The Meaning of Focus ....................................................................................... 49

2.5 Syntactic Focus Constructions...................................................................5

2.6 Fieldwork on Focus - Question-Answer Congruence ...........................................5 52

3 The Morphosyntax of Focus in Kikuyu ..............................................................53

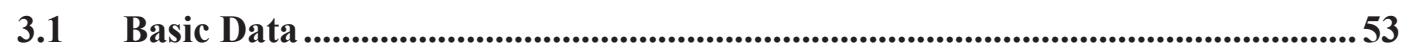

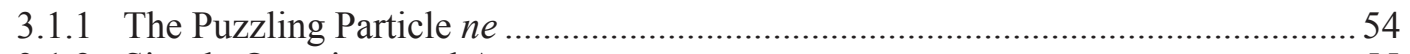

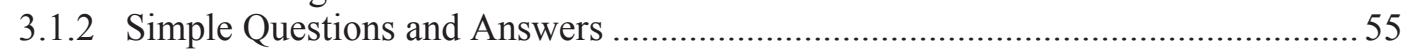

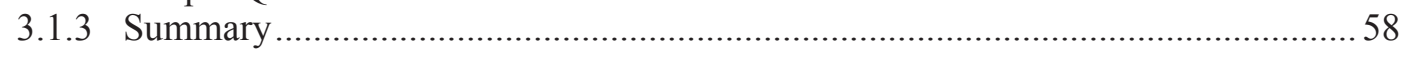

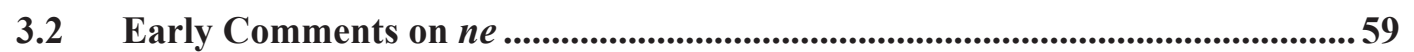

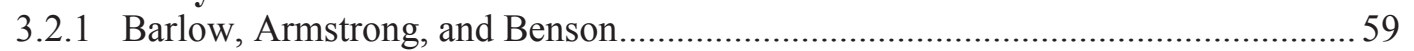

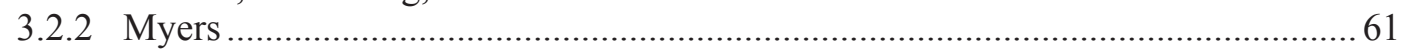

3.3 Clements vs. Bergvall - Focus Marker or Cleft? ..............................................62 62

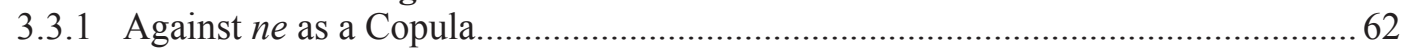

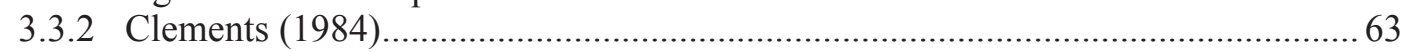

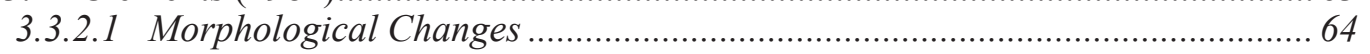

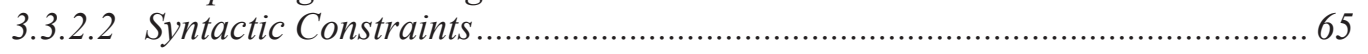

3.3.2.3 Analysis of preposed Focus constructions and wh-questions..........................66 66

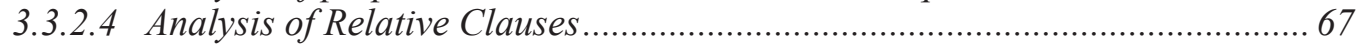

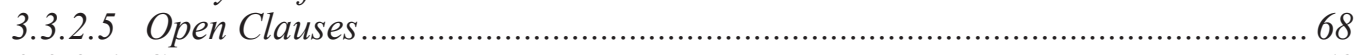

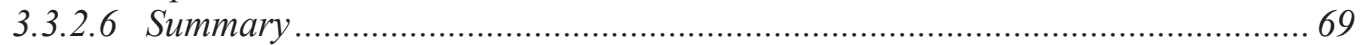

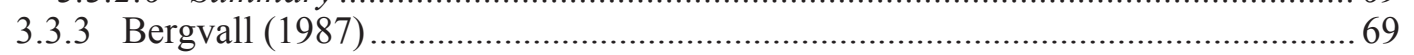

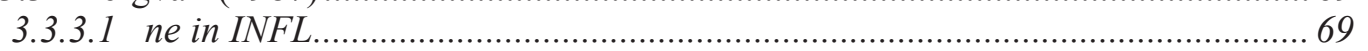

3.3.3.2 Cleft-Analysis of Preposed ne-Focus........................................................... 70

3.3.3.3 Pleonastic Subjects and Clefts in Dependent Clauses................................... 71

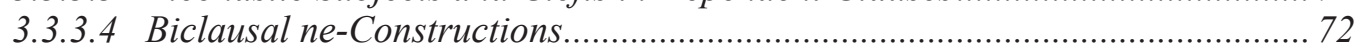

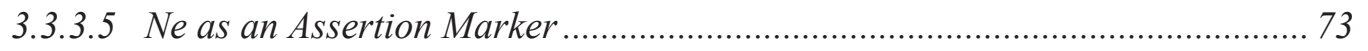

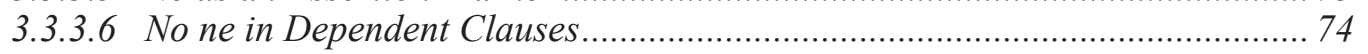

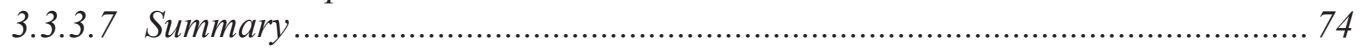

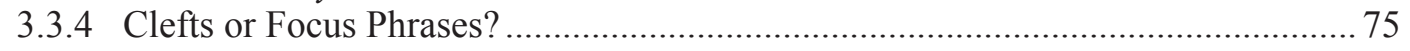

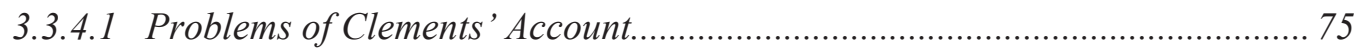

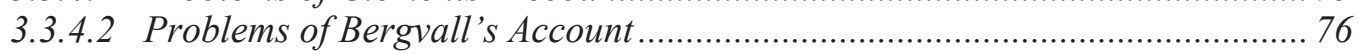

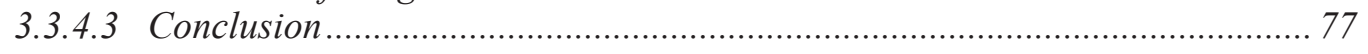

$4 \quad$ New Evidence and a New FP-Analysis............................................................................ 77

4.1 Arguments Against Analyzing Focal ne-Constructions as Clefts ........................ 77 


\section{CONTENTS}

4.1.1 Topicalization and Focus Constructions.................................................................. 78

4.1.1.1 Simple Topicalizations and/or Left Dislocations.......................................... 78

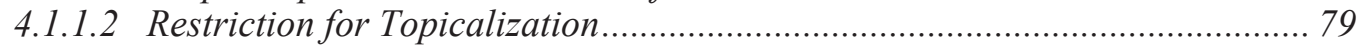

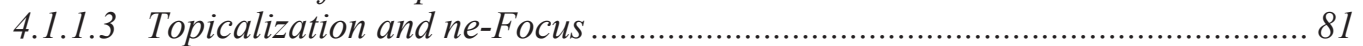

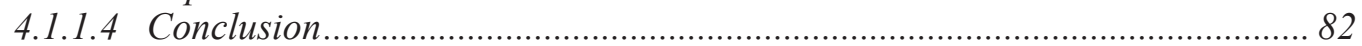

4.1.2 Locative Focus and an Alternative Focus-Construction......................................... 82

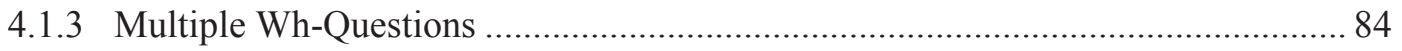

4.2 A New Account of Focus Constructions in Kikuyu ...............................................85 85

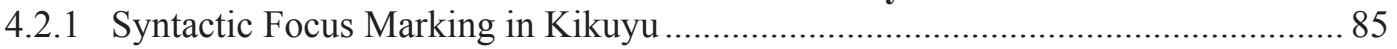

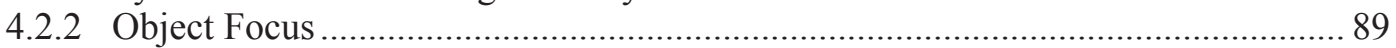

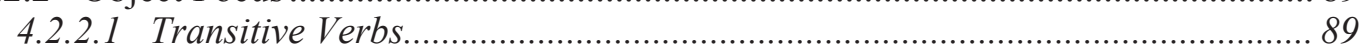

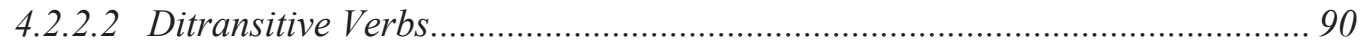

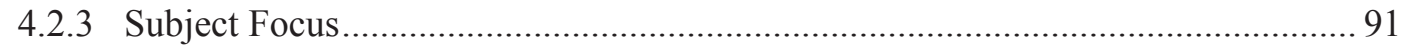

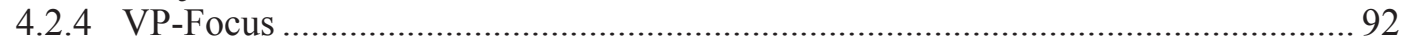

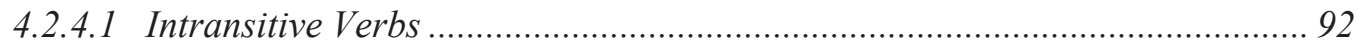

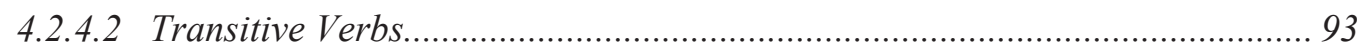

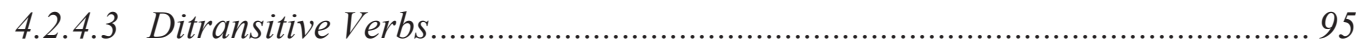

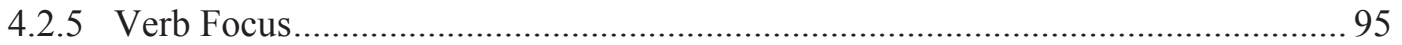

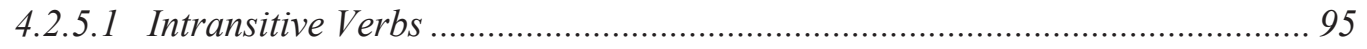

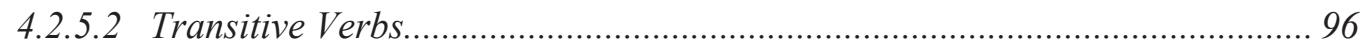

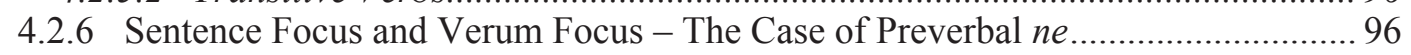

4.2.7 Focus and Copula Constructions - A Possible Reanalysis ........................................ 100

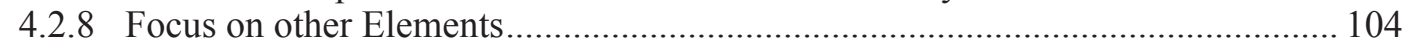

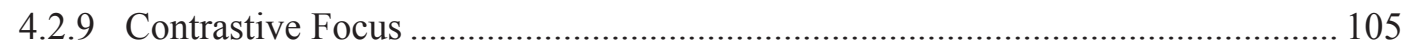

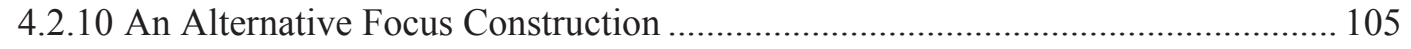

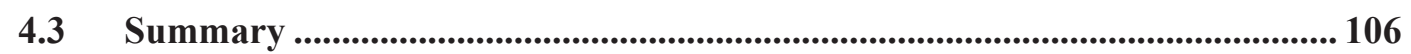

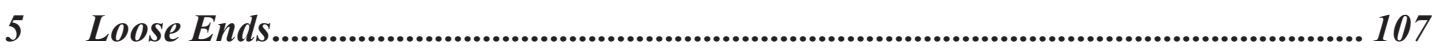

5.1 Further Issues for the New Analysis ....................................................................... 107

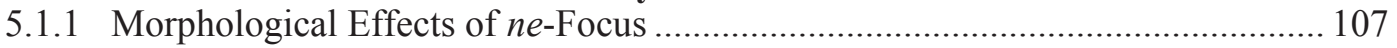

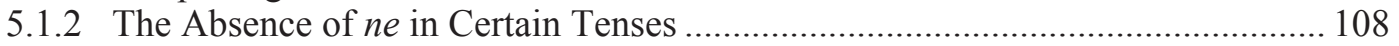

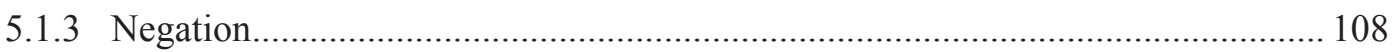

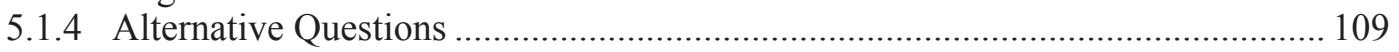

5.2 Semantic Issues ......................................................................................................... 109

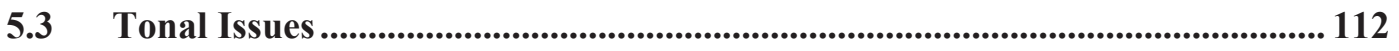

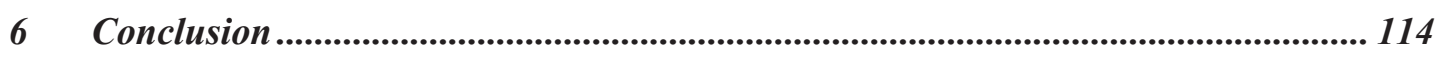

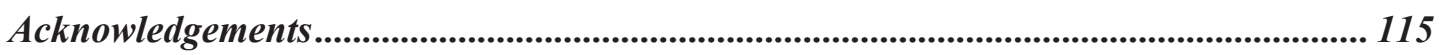

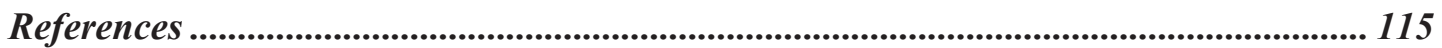




\section{Introduction}

\subsection{Background}

Languages employ different means to express categories of information structure, such as topic and focus. Recently, there has been increasing theoretical interest in how this is done and substantial amounts of research on typologically different languages have been carried out. The present study would like to contribute to this research by taking a close look at how information structure is expressed in the Bantu language Kikuyu. In particular, it presents data collected with a native speaker of Kikuyu that illustrates how focus is marked in Kikuyu sentences. The first goal of this work then is to present an overview of focus constructions in Kikuyu, and thereby to broaden the empirical basis for research on information structure in different languages. The second goal is to discuss theoretical analyses for these data. Previous descriptions and proposals of analysis are presented, and an attempt is made to develop a refined theoretical account. The general background for these theoretical considerations is that of generative grammar in the Chomskyan tradition.

In the next sections, I provide information about the source of the data, some basic facts about Kikuyu, and an overview of the structure of the following chapters.

\subsection{Source of the Data}

Most of the data discussed in the following chapters has been collected with the help of an informant, Sam Kinuthia (age: 36), a native speaker of Kikuyu. He grew up in the town of Kandani in the central Kenyan province of Murang'a. Apart from Kikuyu, he also is fluent in Swahili, English, German, and Russian, and works as a translator for German legal courts. The data gathering meetings took place at the Humboldt University and at the ZAS in Berlin. Communication during the meetings took place in German and English. Data presented in the following that lacks a reference is original data collected with the informant.

Further data that has been included stems from the linguistic literature on Kikuyu, which is not very extensive. There are a few traditional, descriptive works: Barlow's Studies in Kikuyu Grammar and Idiom (1951), a resourceful and detailed descriptive grammar including a textbook section with lessons for learning Kikuyu; Benson (1964), a Kikuyu-English dictionary; and Armstrong (1940), a very detailed descriptive account of The phonetic and tonal structure of Kikuyu. The main source of examples, here as well as in recent literature on Kikuyu, is Barlow's grammar. More recent work that is relevant for this study mainly consists of a number of articles by N. Clements (Clements (1984), (1984a)) and V. Bergvall (Bergvall (1983), (1986), (1987), (1987a)). Both have collected data of their own, some of which will be introduced in the sections on their work. The recent descriptive work by Mugane (1997) also is a helpful resource for an overview of Kikuyu.

\subsection{Some Kikuyu Basics and Notational Conventions}

Kikuyu is spoken in the central-southern regions of Kenya (Mugane 1997: 1), and belongs to the Bantu language family. In the classification system of Guthrie (1967) it is part of Zone E and labeled E51. In this section, I give a brief overview of a few central features of the grammatical structure of Kikuyu, which is primarily aimed at readers that are not familiar with Bantu languages. I also introduce some conventions for the presentation of the data. For more detailed information, the reader is referred to the available grammars, in particular to Barlow (1951) and Mugane (1997).

Concerning the phonological representation, I use a modified version of the IPA-system that is similar to the one used in Bergvall (1987). The modifications have been made to make the data more easily accessible to the informant. The correspondences between the notation used here and the Kikuyu orthography are as follows: 


\section{INTRODUCTION}

a. Vowels

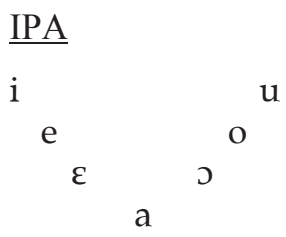

b. Consonants

\begin{tabular}{lll}
\multicolumn{2}{l}{ Modified IPA } & \\
\cline { 1 - 2 } $\mathrm{mb}$ & $\mathrm{t}$ & $\mathrm{k}$ \\
$\mathrm{\beta}$ & $\mathrm{nd}$ & $\mathrm{ng}$ \\
$\mathrm{m}$ & $\mathrm{n}$ & $\mathrm{\gamma}$ \\
& & $\mathrm{ny}$ \\
& & $\mathrm{c}$ \\
& $\mathrm{r}$ & $\mathrm{y}$
\end{tabular}

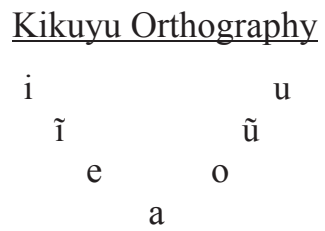

Kikuyu Orthography

$\begin{array}{llll} & \mathrm{t} & \mathrm{k} & \\ \mathrm{mb} & \mathrm{nd} & \mathrm{ng} & \\ \mathrm{b} & \mathrm{d} & \mathrm{g} & \\ \mathrm{m} & \mathrm{n} & \text { ny } & \mathrm{ng} \\ & & \text { nj } & \\ & & \mathrm{c} & \mathrm{h} \\ & \mathrm{r} & \mathrm{y} & \mathrm{w}\end{array}$

The voiced stops are prenasalized, although it is not always easy to actually hear this nasalization. Since this is reflected in Kikuyu orthography, I kept the [n] and [m] preceding the voiced stops in my notation. Ny and nj are also retained to stay close to the orthography.

There are several rules of vowel coalescence in Kikuyu. These are important here as far as they obscure the morphological structure at times, for example when a subject marker is merged with a tense prefix. The following is a list of the most important ones of these processes (Clements 1984: 41):

$$
\begin{array}{ll}
\text { a. } & \text { au } \rightarrow \text { i } \\
\text { b. } & \text { a } \rightarrow \text { } \rightarrow \supset \\
\text { c. } & \text { ae } \rightarrow \varepsilon \varepsilon \\
\text { d. } & \text { o } \rightarrow \text { wo } \\
\text { e. } & \text { ou } \rightarrow \text { uu }
\end{array}
$$

Kikuyu is a tone language, i.e. there are lexical items that are only distinguished by tone. The following is an example from Mugane (1997: 14):

$$
\begin{array}{lll}
\text { a. îra 'underestimate' } \\
\text { b. iră 'snow' } \\
\text { c. ira 'yesterday' }
\end{array}
$$

Vowels without a tone marker bear low tone, vowels marked ['] bear high tone, and vowels marked ["] bear rising tone. According to Ford (1975) and Clements (1984b: 281) there are two underlying tones in Kikuyu, High and Low, as well as a phonemic downstep. The tonal phonology of Kikuyu is extremely complex. A Theoretical account within autosegmental phonology is provided by Clements (1984a), and there are several other earlier theoretical works, for example Pratt (1972), Ford (1975), Clements and Ford (1979) and (1981). Also, as already mentioned, Armstrong (1940) provides detailed descriptions of tonal phenomena.

Tone is not a central topic in this work, although there are interesting questions related to the interaction of focus and tone. Some considerations in this regard are presented in section 5.3 in chapter 5. I did try to find possible interactions between focus and tone, but I could not determine any clear correlations between tonal phenomena, such as tone sandhi, and focus (which, of course, does not mean that there are none). Therefore, this topic is only treated marginally in this work, and tone is not marked except in examples from the literature that do indicate tone. ${ }^{1}$

1 A further complication for research on tone is that there seem to be differences between dialects. Hence it is not clear whether the findings by Clements and Ford can be fully generalized, and it seems like 
A central feature of Kikuyu morphology is the verbal complex that can take several affixes, including a subject marker and an optional object marker, temporal and aspectual prefixes and suffixes, as well as applicative and causative morphemes. The following list of morphemes, taken from Bergvall (1987: 21), illustrates the richness of verbal morphology:
a. Assertion or Focus Marker (FM): ne
b. $\quad$ Subject Marker (SM)
c. $\quad$ Tense Marker (T): -a-, -ra-, -ko-, - $\varnothing-,-$-re-, -ka-
d. Object Marker (OM)
e. Reflexive Marker (REFL): -e-
f. $\quad$ Verb Stem (VS)
g. Applicative suffix (APPL): -er-
h. $\quad$ Aspect Marker (ASP): -ir-, -ay-, -et-
i. $\quad$ Causative Marker (CAUS): -i-
j. $\quad$ Passive suffix (PASS): -wo (and variants)
k. $\quad$ Final Vowel (FV): Indicative -a or Subjunctive $-\varepsilon$

This list is given in the order in which the morphemes appear in the verbal complex, and the underlined morphemes are normally obligatory. The exact status and function of the verb initial particle ne will be a central issue in the following chapters. Bergvall (1987) argues that it is a marker of assertion, and I (along with Clements (1984)) will argue that it is a focus marker.

As most other Bantu languages, Kikuyu has a complex noun class system that consists of 17 classes (Mugane 1997: 26). They roughly represent semantic groups like humans (class 1 and $2-$ there is a singular and a plural class for each group) or abstract concepts (class 14). Nouns come with a class prefix, and the subject is marked on the verb with a concord marker that depends on the class of the subject noun. While the subject marker appears both with and without an overt NP in subject position, the object marker can only appear when there is no overt full object NP. Therefore, the object marker can be regarded as fully pronominal.

The basic word order in the Kikuyu sentence is SVO (Mugane 1997: 141). A simple sentence with a transitive verb usually looks like the following:

$$
\begin{array}{llll}
\text { a. } & \text { Kamau } & \text { (ne)-osn-ir- }-\varepsilon & \text { Njeri } \\
& \text { K. } & \text { (FM)-(SM)-see-ASP-FV N. } & \text { N. } \\
& \text { Kamau saw Njeri. }
\end{array}
$$

Kikuyu examples are given in the format of (5), with an interlinear translation and a (sometimes rough) English translation. Proper names are indicated by their initial in the glosses. The particle $n e$, which is labeled $F M$ for focus marker, is optional, although its presence or absence does make a difference in meaning. Just what this difference is will be discussed in chapters 3 and 4. The subject marker for class 1 (to which Kamau as a proper name for humans belongs) normally is $-a$-, but it is merged here with the initial vowel of the verb stem, following the vowel coalescence process described above in (2b). In such cases, I will put '(SM)' in brackets, since the subject marker is not as clearly visible.

In more complex sentences, the word order generally follows the pattern Subject $<$ Indirect or Direct Object (Human) $<$ Direct Object (Nonhuman) $<$ Target Locative $<$ Manner Adverbial $<$ Setting Locative < Time Adverbial (Bergvall 1987a: 39-40). Although it may seem at first sight that the word order in Kikuyu is fairly rigid, there are several possibilities for word order

there was at least some data from my informant that did not match their findings. Since questions related to the interaction of focus and tone require an in-depth understanding of the tonal phonology, it seemed beyond the scope of this work to include a detailed theoretical discussion of such questions. 


\section{INTRODUCTION}

variation, as will be seen in the discussion of the data in the following chapters. These variations are of central concern, and will be discussed in detail in chapter 3 and 4, where further details about Kikuyu syntax will be presented.

\subsection{Structure}

The following chapters are organized as follows. In Chapter 2, I give a brief overview of some important concepts in the theory of focus. In Chapter 3, I present the basic Kikuyu data that illustrates focus marking in questions and answers, and I discuss previous proposals for the analysis of these data. In particular, I compare the accounts by Clements (1984) and Bergvall (1987). This leads to the question whether preposed focus constructions with the particle $n e$ are best analyzed as cleft-sentences (Bergvall) or rather as examples of a syntactic focus phrase (Clements). In chapter 4, I present some new data that speak against the cleft-analysis. These data are related to topicalized elements in combination with preposed focused elements, as well as to locatives in focus and multiple wh-questions. On the basis of this data, I develop a revised version of the focus phrase analysis. Finally, I present a wider range of data with different parts of the sentence in focus, which seem to fit into the proposed analysis. In chapter 5, I discuss further issues and open questions in relation to the analysis proposed in chapter 4 . These include further syntactic issues, but also semantic and tonal ones. Chapter 6 gives a summary of the main results.

\section{Theories of Focus}

Focus, as a term in the theory of information structure, generally refers to the most prominent part of a sentence. The way in which this prominence is realized differs across languages. In generative theory, focus has been studied extensively in languages that use pitch accents to mark focus, beginning with Chomsky (1970) and Jackendoff (1972). From the 1980s on, there also has been extensive research on languages that have a structural position in the sentence to mark focus, in particular on Hungarian (cf. Szabolcsi 1981, Horvath 1986, Kiss 1987). ${ }^{2}$ In this chapter, I want to give a basic overview of important concepts employed in theories of focus. The main goal is to provide a theoretical basis and a motivation for the method employed to look at focus marking in Kikuyu in the following chapters, which is that of question answer congruence.

\subsection{Terminology}

In recent decades, large amounts of literature have been devoted to the study of phenomena related to information structure. Unfortunately, the terminology in the field is often confusing, with different authors using different terms while meaning roughly the same, and yet other authors using the same terms but meaning something different. The following list of pairs of terms from Büring (1997: 29) illustrates the diversity in terminology in the field:

$\begin{array}{ll}\begin{array}{l}\text { Background } \\ \text { Topic }\end{array} & \text { Focus } \\ \text { (Psychological) Subject } & \text { Comment } \\ \text { (Psychological) Predicate } \\ \text { Theme } & \text { Rheme } \\ \text { Presupposition } & \text { Focus } \\ \text { Satzgegenstand } & \text { Satzaussage } \\ \text { Given } & \text { New } \\ \text { Old } & \text { New }\end{array}$

2 For a recent overview of the historical development of theories of focus, see Rebuschi and Tuller (1999). 
In this work, I will be using the first pair of terms, and primarily will be talking about focus. The following sections will try to provide an idea of what is meant by the dichotomy of focus and background.

\subsection{Focus and Accent}

It is a well-known phenomenon that sentences identical in word order are appropriate in different contexts due to a difference in accent placement. For example, (7b) is a good answer to the question in (7a), while (7c) is not. The same pattern holds in German in (8):
a. Who did Mary kiss?
b. Mary kissed JOHN. ${ }^{3}$
c. \# MARY kissed John.
a. Wen hat Maria geküsst?
b. Maria hat HANS geküsst.
c. \# MARIA hat Hans geküsst.

JOHN (HANS), in the (b)-examples, is the focus of the sentence. Generally, the part of the sentence that is not the focus is called the background. We can roughly characterize the notion focus here as the part of a sentence that provides the answer to the question that was asked in (a). Similarly, focus is often characterized as 'what is new or unexpected in a sentence' (Büring 1997: 29).

Jackendoff (1972) introduced the syntactic feature [F], which marks the focus of a sentence in the syntactic representation. This abstract feature is helpful to capture the fact that the relation between accent and focus is not one to one. The accent placement in the (b)-examples, for example, can indicate different foci. Therefore, these sentences are structurally ambiguous. They could also mark the entire VP as focus (9b), or even the entire sentence $(9 \mathrm{c})$. The according questions would be What did Mary do? for (b), and What happened? for (c):

$$
\begin{array}{ll}
\text { a. } & \text { Mary kissed }[\mathrm{JOHN}]_{\mathrm{F}} \\
\text { b. } & \text { Mary [kissed JOHN }]_{\mathrm{F}} \\
\text { c. } & {[\text { Mary kissed } \mathrm{JOHN}]_{\mathrm{F}}}
\end{array}
$$

Nonetheless, the accent placement and intonation is the same in all of these. To distinguish between the word that contains the accented syllable and the part of the sentence marked by the syntactic feature [F], we call the former the focus exponent, while the latter is simply referred to as focus. Hence, when I will be talking about focus in the following, I do not just mean the accented word, but rather the part of the sentence that constitutes the focus.

The ambiguity illustrated in (9) leads to the question of what rules govern focus projection, i.e. the question of how focus and focus exponent are related. This question can be asked in two different ways (Büring 1997: 44-45): We can ask how one can determine the different focusbackground divisions of a sentence, given a certain main accent. Or, alternatively, we can ask where to put the main accent, given a certain syntactic structure with the feature $[\mathrm{F}]$ on a part of the sentence.

It would go beyond the scope of this overview to discuss any details of the large amounts of research that have tried to answer this question. One of the major claims that has been put forward in trying to answer the second formulation of the question is that in head argument structures that are F-marked, the accent will usually go onto the argument (cf. Selkirk (1984) for English, and von Stechow and Uhmann (1986) for German).

3 The syllable bearing the nuclear pitch accent, i.e. the syllable that is perceived as most prominent in intonation, is written in captial letters, as is common in the literature. 
Another type of examples in which accent plays a role is often referred to as contrastive focus. Typically, this involves a refutation of some sort, correcting a part of a sentence that already was given in the context:
a. Hat Paul Maria geküsst?
b. Nein. HANS hat Maria geküsst.
a. Did Paul kiss Mary?
b. No. JOHN kissed Mary.

Some theories of focus take such occurrences to be different from the ones exemplified in (7) and (8) (see also the discussion below on Hungarian), while others try to account for both cases in a uniform manner. I will mainly discuss focus in question answer sequences, and therefore will mostly ignore this issue.

\subsection{Bound vs. Free Focus}

In addition to the type of examples we have seen so far, which is often labeled as free focus, there also are examples where the focus stands in a particular relation with an operator. Such occurrences are usually referred to as bound focus. Operators that are sensitive for focus include only, also ${ }^{4}$, even, must, not, and always. In cases of bound focus, there can be differences in truth conditions in addition to the differences in contextual adequacy that we saw for free focus. Compare the following examples:

$$
\begin{aligned}
& \text { a. John only kissed MARY. } \\
& \text { b. John only KISSed Mary. }
\end{aligned}
$$

The differences between these two become clear when we consider possible paraphrases. (12a) is true if the only person that John kissed is Mary, whereas (12b) is true if all that John did with Mary was to kiss her.

In this work, I will (almost) exclusively talk about free focus, and therefore will not go into the details of bound focus here. It should be noted that some theories consider free focus to be a special case of bound focus, where the binding operator in such cases would be an invisible illocutionary operator (cf. Jacobs 1984; von Stechow 1990; Krifka 1992).

\subsection{The Meaning of Focus}

All we have said so far about the meaning of focus is that it marks what is new or unexpected, or that it supplies the answer for the wh-word in a question. This notion of focus as new information is also reflected in the table of terms in (6) (e.g. New vs. Given), and it is one of the major approaches to the meaning of focus. The other approach relates focus to sets of alternatives, an idea that immediately becomes clear when considering the examples in (10), where the difference between (a) and (b) clearly lays in the different alternative situations that are excluded by only. So the alternatives in (a) would consist of other entities (or people, if we build in reasonable contextual restriction of the alternatives) that Mary could have kissed, and in (b) the alternatives range over relations between Mary and John. This idea of focus introducing sets of alternatives is the basis of an elaborate semantic theory of focus, usually referred to as Alternative Semantics (cf. Rooth 1985, 1992).

A common assumption that is based on the idea of the focus contributing something new is that the background (i.e. the part of the sentence that is not focus) is already presupposed in the context of the utterance. In the examples in (9) this would mean that in (9a) it was known to the discourse participants prior to the utterance that John kissed somebody, and in (9b) that John did something with Mary. This means that in question answer sequences, the background of the answer should be identical to (or be entailed by) the presupposition of the question. Another

4 See König (1991) for an extensive coverage of focus sensitive particles. 
semantic theory of focus, the Structured Meaning approach (cf. von Stechow 1981, 1990, Jacobs 1984, Krifka 1992, 2001) transfers the partition into focus and background directly into the semantic representation, thereby creating a more expressive framework for representing questions and answers (cf. von Stechow 1990 and Krifka 2001). Answers to a question must then fulfill the requirement that their background meaning is identical to the question meaning. The details of the different semantic proposals for the analysis of focus would go beyond this short overview. What is important is that semantic analyses of focus posit an extra level of meaning (an alternative or focus meaning in the case of Alternative Semantics and a structured meaning, split into focus and background, in case of the Structured Meaning approach) which allows for a fairly straightforward theoretical relation between questions and focus in answers to them.

A further important distinction that is made in relation to the meaning of focus is that between Contrastive Focus vs. Presentational Focus, or, alternatively between Identificational Focus vs. Information Focus. While some theories of focus do not (or at least not explicitly) distinguish between these different types of focus, Kiss (1998) argues that there is an important difference between these two types. In some languages, for example in Hungarian, this distinction is also reflected in different syntactic distributions. The difference in meaning primarily lies in the presence or absence of exhaustivity:

"An identificational focus represents a subset of the set of contextually or situationally given elements for which the predicate phrase can potentially hold; it is identified as the exhaustive subset of this set for which the predicate actually holds. [...] If a sentence part conveys new, nonpresupposed information marked by one or more pitch accents - without expressing exhaustive identification performed on a set of contextually or situationally given entities, it is not an identificational focus but a mere information focus" (Kiss 1998: 245-246; emphasis by F.S.)

This distinction is reflected in Hungarian syntax, as these different types of focus are realized in different syntactic positions (Kiss 1998: 249):
a. Mari egy kalapot nézett ki magának. ${ }^{5}$ Mary a hat.ACC picked out herself It was a hat that Mary picked for herself
b. Mari ki nézett magának EGY KALAPOT. Mary picked for herself A HAT.

According to Kiss, (13a) clearly implies a situation where Mary was choosing one from different pieces of clothing (and none of the others), while (13b) does not convey such alternatives, but merely presents new information. The conclusions that are drawn from the different word orders in these examples will be presented in the next section, where syntactic means for marking focus are discussed.

\subsection{Syntactic Focus Constructions}

Except for the Hungarian example (which we will come back to shortly) in the last section, focus has been determined in the examples we have considered so far through the placement of accent. There is, however, another grammatical tool for focusing, namely that of putting the focused element in a syntactically prominent position (this is often combined with putting an accent on the focused element). In languages like German and English, the most common way to do this is by ways of a cleft-construction:

(14) a. It is a BOOK that John gave to Mary.

b. Es ist ein $\mathrm{BUCH}$, das Hans Maria gegeben hat.

5 Kiss typographically distinguishes the two different types of focus by using bold letters for identificational focus and small capital letters for informational focus. 
There is an extensive amount of literature on the syntax and discourse function of clefts, and a number of different proposals have been put forward (cf. Akmajian 1970, Emonds 1976, Prince 1978, Collins 1991, Delin \& Oberlander 1995). Generally, the structure of clefts seems to be something like (15) (Prince 1978):

$$
\text { a. it Copula X [Relative [.........]] }
$$

In the main clause, we find a copula construction with an expletive it as a subject and some constituent $\mathrm{X}$ as a predicate, which is the head of the following relative clause, out of which $\mathrm{X}$ has been moved (hence the trace $t$ ). In terms of the focus-background terminology, $\mathrm{X}$ is the focus and the relative clause is the background.

A similar construction is that of pseudo-clefts, which also involve copula predication, but have a headless relative clause as a subject:

$$
\begin{aligned}
& \text { a. What John gave to Mary is a BOOK. } \\
& \text { b. Was Hans Maria gegeben hat ist ein BUCH. }
\end{aligned}
$$

While the clefting strategy is widely spread in the languages of the world, there also are a number of languages for which it has been claimed that they have a structural position for focus within the sentence. The most prominent case of such languages is Hungarian (see discussion below); others include Aghem (Watters 1979), Basque (Ortiz de Urbina 1995), Greek (Tsimpli 1994), Bulgarian (Rudin 1986), and Quechua. Languages that display such a structural focus (or topic) position are called discourse configurational (cf. Kiss (ed.) 1995). ${ }^{6}$ Typically, the focus position is either immediately before (e.g. Hungarian) or after the verb (e.g. Aghem). In the following, I will use Hungarian to illustrate the property of discourse configurationality.

As we already saw at the end of the previous section, identificational foci have to appear in a position immediately left of the verb (Puskás 2000: 56):

$$
\begin{aligned}
& \text { a. ATTILÁT szereti Emöke. } \\
& \text { Attila-ACC love-PRES-3SG Emöke-NOM } \\
& \text { Emöke loves ATTILA. } \\
& \text { b. A SÁTORJÁBAN feküdt a Hunok vezetöje. } \\
& \text { the tent-POSS-iness lie-PAST-3SG the Huns chief-his-NOM } \\
& \text { The chief of the Huns lays in HIS TENT. }
\end{aligned}
$$

While the assumed normal Hungarian word order is SVO, we find OVS in (17a), which exhibits focus on the object. That the focus is always occurring in a position directly preceding the verb can be seen from particle verbs, where the particle usually precedes the verb (18a), but follows it if there is an element in the focus position (18b) (Horvath 1995: 31):

$$
\begin{aligned}
& \text { a. Eldobtam az újságot } \\
& \text { away-threw-I the newspaper-ACC } \\
& \text { I threw the newspaper away } \\
& \text { b. AZ ÚJSÁGOT dobtam el. } \\
& \text { THE NEWSPAPER-ACC threw I away } \\
& \text { It's the newspaper that I threw away. }
\end{aligned}
$$

6 Kiss (1995) distinguishes between A-type and B-type discourse configurationality, the former referring to languages with a structural topic position, the latter to such with a structural focus position. The two types are compatible (and often co-occur), but independent of one another. 
There is a lively ongoing debate about the exact syntactic analysis of sentences containing a preposed focus ${ }^{7}$, but it is generally assumed that there is a syntactic feature $[+\mathrm{f}]$ that has to be checked by the focused constituent, and which (at least since Brody (1990)) is commonly assumed to be located in its own projection, FP (Focus Phrase). This FP is assumed to be located within IP, dominating VP (Brody (1990) and others), or, alternatively, in CP, dominating IP (Puskás 2000). The syntactic structure of Hungarian sentences containing a (identificational) focus hence is supposed to take one of the following two forms:

a. Brody (1990)

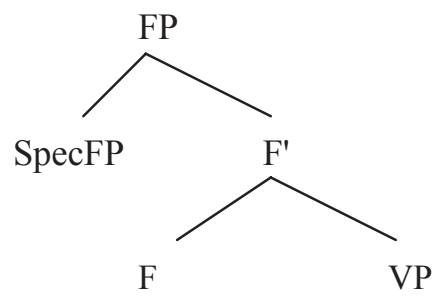

b. Puskás $(2000)^{8}$

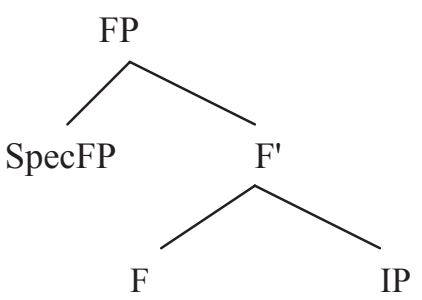

The focused constituent is then assumed to move into SpecFP.

There are some interesting parallels between the analysis of the Hungarian focus position and focus in other languages that do not have (obligatory) focus movement. First of all, it has been assumed that in English, focus movement takes place at the level of LF, mainly for reasons of scope and certain weak crossover effects (cf. Chomsky 1976, 1981). Furthermore, foci in Hungarian share a trait with English cleft-constructions in respect to meaning: The interpretation of both constructions involves exhaustivity. This, among other things, has led Kiss (1998) to analyze English cleft sentences in a manner parallel to the Hungarian focus sentences, namely as involving a focus phrase, that, in the case of English, takes a CP (containing the relative pronoun or the complementizer that) as its sister.

In the following chapters, we will face the question whether Kikuyu sentences with a preposed focused constituent are cleft sentences or rather instances of a syntactic focus phrase. The existent analyses of Hungarian provide an interesting background for the discussion of the Kikuyu data.

\subsection{Fieldwork on Focus - Question-Answer Congruence}

Theories of focus are, as the preceding sections have shown, rather complex and involve phonological, morphosyntactic, and semantic issues. It is helpful to keep apart the different types of questions that are important in connection with these phenomena. Generally, one can distinguish three different groups of questions. ${ }^{9}$ First of all, one can investigate how focus (or other information structure categories, e.g. topic) is realized, for example by means of certain syntactic constructions or pitch accent. Secondly, one can ask how focus is represented in the formal analysis of sentences (e.g. by a syntactic feature), and what rules govern processes like focus projection. Finally, one can investigate how focus is interpreted.

In this study, I mainly am looking looking at the realization and the representation of focus. The question is, of course, how to go about studying focus-related phenomena in another language, working with an informant. Judgments with respect to focus can be quite sublime, and linguists working on focus theories often work on their own native language and therefore are able to rely on their own judgments, which are trained (and possibly also biased) by intensive

7 See Puskás (2000), Kiss (1995), (2002), and Horvath (1995) for some recent discussions.

8 This is a simplified version, since Puskás (2000: 67) assumes a split IP, so that the sister of F would be AgrP, which in turn dominates TP and VP.

9 This tripartition of the central questions in the theory of informations structure is adapted from Daniel Büring's lecture notes for a class on information structure taught at the DGfS/LSA-summer school in Düsseldorf in July 2002. 
study of the relevant phenomena. The approach I have taken here is by presupposing, to some extent, some of the semantic insights of focus theories. In particular, I have applied the semantically motivated concept of question answer congruence to elicit judgments from the informant regarding the adequacy of different sentences as answers to questions. Taking for granted that the question context determines what is in focus in an appropriate answer, this will allow us to study how focus on a certain part of the sentence is realized. Since it turns out that focus is marked mainly by morphosyntactic means in Kikuyu, this also leads us to some considerations about how focus can be formally represented.

It turned out these this types of judgments concerning the adequacy of a sentence as an answer to a question seemed to be quite clear and consistent for my informant. Since the relation between question contexts and focus is also generally accepted in the field, it seemed like an adequate tool to determine focus in the following chapters.

\section{The Morphosyntax of Focus in Kikuyu}

While, historically, the study of focus has evolved from an interest in what determines the placement of pitch accent in languages like English and German, we can now, that we have a theoretical concept of focus, apply techniques like question answer congruence to look at what means different languages use to mark focus. As already mentioned at the end of chapter 2, this is the method that I will mainly use throughout this study to control for what is in focus in a sentence.

The way this technique has been applied is mainly in presenting the informant with a question and different sentence forms as an answer to it. He then was asked which sentences would be appropriate answers to the question.

This chapter is organized as follows: In the first section, the basic occurrences of the particle $n e$, which is crucial for many focus constructions as well as some basic data exemplifying different types of focus constructions will be presented. This will be limited to answers to questions with simple (as opposed to internally complex) foci to keep things simple. The data illustrates that both wh-words and foci can appear in-situ as well as in a preposed position. In the preposed case, they are preceded by the particle $n e$, which also appears preverbally and in copula constructions. One of the central questions of this and the following chapter will be how this particle should be analyzed. In the following two sections, several previous accounts of the particle ne will be presented, beginning with the early works of Armstrong (1940) and Barlow (1951), continuing with the first analysis in the generative framework by Myers (1971) and finally turning to Clements (1984) and the detailed study by Bergvall (1987). In the course of this discussion, new examples, which are crucial for the different authors' analyses, are introduced.

The discussion of Bergvall's and Clements' analyses leads to the question of whether the preposed $n e$-constructions are best to be analyzed as clefts or as focus phrases. At the end of this chapter, I give an overview of the problems that each of these approaches faces. This leads to chapter 4, where I try to argue, based on new data, that the cleft-analysis cannot be maintained.

\subsection{Basic Data}

Although not all data will be presented at this point, it is necessary to demonstrate the different basic types of relevant constructions in order to do justice to the amazing morphosyntactic variation we find in the data for seemingly identical meanings. First of all, some examples of the occurrence of the particle ne, which has been at the center of previous research on focus in Kikuyu, will be given. Next, I will give an overview of simple question-answer sequences and the different ways of how these can be expressed.

Note that the type of data presented in this section is mostly not new, but rather consists of examples which have the same structure as the standard data discussed in the literature. Some crucial pieces of new data are already mentioned, but will be discussed at a later point in chapter 
4, where they play an important role in the argument for my proposal of a new analysis of focus constructions in Kikuyu.

\subsubsection{The Puzzling Particle ne}

Virtually all discussions of focus or emphasis, as it has often been referred to in the literature on Kikuyu, concentrate on the particle ne. This particle occurs in three basic types of contexts, namely with fronted question words and focused constituents, at the beginning of the verbal complex in (certain) assertive sentences, and in copula constructions. The first type is exemplified in (20):

$$
\begin{aligned}
& \text { a. ne-kee Abdul a-ra-nyu-ir- } \varepsilon \text { ? } \\
& \text { FM-what A. SM-T-drink-ASP-FV }{ }^{10} \\
& \text { What did Abdul drink? } \\
& \text { b. } \\
& \text { ne ma-e Abdul a-ra-nyu-ir- } \varepsilon . \\
& \text { FM 6-water A. SM-T-drink-ASP-FV } \\
& \text { It is water that Abdul drank }
\end{aligned}
$$

The (a) and (b) types behave exactly the same with respect to focus and movement and therefore form a uniform category. ${ }^{12}$ The accuracy of the it-cleft translation in (20b) is one of the central questions in the discussion of different analyses in the course of this chapter. No claims are made at this point in this regard. I will choose cleft translations for the fronted focused constituents with preposed ne simply to keep the word order in the English paraphrase as similar as possible to the word order in Kikuyu. Otherwise, these might just as well be translated as English in-situ focus sentences, i.e. as Abdul drank WAter. ${ }^{13}$

The second type of constructions in which ne appears consists of sentences expressing an assertion with no emphasis on a single element:

$$
\begin{aligned}
& \text { a. Abdul ne-a-ra-nyu-ir- } \varepsilon \quad \text { ma-e }{ }^{14} \\
& \text { A. } \quad \text { FM-SM-T-drink-ASP-FV } \\
& \text { 6-water } \\
& \text { Abdul drank water. } \text { or } \\
& \text { Abdid drink water. }
\end{aligned}
$$

10 Although ne is commonly referred to as a focus particle in the literature, I will adopt the label focus marker ( $F M$ in the interlinear translation) in this study. This should avoid confusion with focussensitive particles such as English only, also, even, which also sometimes are referred to as focus particles.

11 Kikuyu has a rich tense and aspect system. Mugane (1997: 120) as well as Johnson (1980: 273) refer to the tense-aspect combination in (20) as near past completive. In the following, tense and aspect are not analyzed in detail, unless relevant in the context of discussion. Translations are therefore not necessarily accurate in this regard. Following Johnson, I take the relevant prefixes to mark tense and the suffixes to mark aspect. For detailed discussion of the highly complex tense and aspect system of Kikuyu, see Johnson (1978), (1980).

12 There are, of course, differences between wh-question words and referential NPs. We will come back to differences in the analysis of the two types of constructions. It should be noted already that the apparent focus-markig of questions as displayed in (20b) is an interesting phenomenon by itself.

13 While I will argue in chapter 4 that the preposed ne-constructions are not clefts, it might be that the cleft translation is more adequate for semantic reasons. See section 5.2. in chapter 5 for a discussion of this possibility. I will not use the cleft constructions in the translation for questions, as these are not as common in English.

14 In writing, ne is usually written as being part of the verbal complex. I will adopt this practice, although one might just as well write it seperately. However, this does not make a great difference, and we will have to come back to the status of $n e$ in the discussion of analyses of focus constructions. 
It was noted already in the early writings on Kikuyu that this use often comes with a certain emphasis that is affecting the entire sentence. Barlow (1951: 117) writes that it gives "definiteness or emphasis to a statement" and compares it to the effect of $d o$-support in English (hence the did in the paraphrase). Armstrong (1940: 168) describes this use as appearing in an "affirmative answer [...] made with strong certainty, definite promise, determination". The exact nature of this emphasis will be an important issue in this study, and will be discussed in section 4.2.6 in chapter 4 (as well as in the discussion of Clements' and Bergvall's work in this chapter). Note that the same form shows up in Yes/No-questions as well:

$$
\text { b. Abdul ne-a-ra-nyu-ir- } \varepsilon \text { ma-e? }
$$

Did Abdul drink water?

An answer to the question in (21b) has to have the form of (21a); in particular, it has to include preverbal $n e$. The question and the answer are only distinguished by intonation.

Finally, ne also appears in copula constructions as in (22). As a matter of fact, some authors (e.g. Barlow 1951) have analyzed ne to be the copula itself. However, as the discussion of the works by Clements and by Bergvall in section 3.3.1. will show, this may not be the best analysis.

$$
\begin{aligned}
& \text { Karioki ne mo-rutani } \\
& \text { Karioki FM/COM 1-teacher } \\
& \text { Karioki is a / the teacher }{ }^{15}
\end{aligned}
$$

The sentences in (20)-(22) exemplify the three basic environments in which ne occurs. One crucial task in this chapter and the next is then to determine whether we can give a unified analysis for these different occurrences of $n e$, and what such an analysis should look like. One important fact to note is that the different types of occurrence of ne seem to mutually exclude one another, i.e. within one clause we will only find one $n e$.

\subsubsection{Simple Questions and Answers}

In the previous section we have seen different contexts in which the particle ne appears, one of them being that of questions and answers. Let us now turn to the general question of how question-answer sequences can be expressed in Kikuyu. The first interesting fact that stands out immediately when we consider sequences of questions and answers is that both in-situ and fronted wh-question words are possible, with no apparent difference in meaning or contextual appropriateness. Thus, the question in (20a) above (repeated here as (23a)) can also be asked in the form of (23b):

$$
\begin{aligned}
& \text { a. ne-kee Abdul a-ra-nyu-ir- } \varepsilon \text { ? } \\
& \text { FM-what A. SM-T-drink-ASP-FV } \\
& \text { What did Abdul drink? } \\
& \text { b. Abdul a-ra-nyu-ir- } \varepsilon \text { kee? } \\
& \text { A. SM-T-drink-ASP-FV what }
\end{aligned}
$$

Crucially, the meaning of (23b) is, according to my informant as well as to all other authors that discuss this issue (e.g. Barlow 1951, Clements 1984, Bergvall 1987), identical to the meaning of (23a). In particular, it is not associated with the meaning of an echo-question, as is the case with in-situ questions in German and English. The typical answer to (23b) would be the sentence in (24):

$$
\begin{array}{ll}
\text { Abdul a-ra-nyu-ir- } \varepsilon & \text { ma-e } \\
\text { A. SM-T-drink-ASP-FV } & \text { 6-water } \\
\text { Abdul drank WAter } &
\end{array}
$$

15 There are no articles expressing definiteness or indefiniteness in Kikuyu, therefore this sentence can mean both that Karioki is $a$ or the teacher. 
Note that here, as well as in the question in (23b), the particle $n e$ is not present. In fact, the presence of preverbal $n e$ in (24) would make the sentence inappropriate as an answer to the question in (23b).

To some extent, it seems like both types of answers (i.e. in-situ and preposed) are acceptable in the context of both types of questions. As the compatibility of these different question answer constructions is not our central concern at this point, I will mainly discuss structurally equivalent question-answer-pairs. ${ }^{16}$

The two possibilities of question and answer formation can be found in constructions involving almost all types of questioned constituents, as the following list of examples (where (a) and (b) display the preposed question and answer with ne (henceforth the 'ne-form'), and (c) and (d) the in-situ-form) may illustrate:

\section{Objects of ditransitive verbs}

$$
\begin{aligned}
& \text { a. } \quad \text { n-oo Abdul a-ðom-ay-er-a i- } \beta u k u ?^{17} \\
& \text { Who does Abdul (usually) read a book to? } \\
& \text { b. ne mw-ana Abdul a-ðom-ay-er-a i- } \beta u k u \text {. } \\
& \text { FM 1-child A. SM-read-HAB-APPL-FV 5-book } \\
& \text { It is a child that Abdul (usually) reads a book to. } \\
& \text { c. Abdul a-ðom-ay-er-a oo i-ßuku? } \\
& \text { A. SM-read-HAB-APPL-FV who 5-book }
\end{aligned}
$$

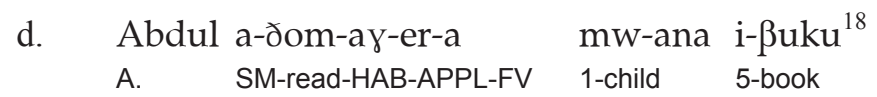

$$
\begin{aligned}
& \text { (26) a. ne-kee Abdul a-ðom-ay-er-a mw-ana? } \\
& \text { FM - what A. SM-read-HAB-APPL-FV 1-child } \\
& \text { What did Abdul read to the child? } \\
& \text { FM 5-book A. SM-read-HAB-APPL-FV 1-child }
\end{aligned}
$$

\section{Local Adverbial}

16 The issue of compatibility is picked up in in chapter 5 in section on semantic issues.

17 The particle ne merges with the question word oo, meaning who, to form noo. The morphological slot for tense is phonetically empty in this sentence, which, in combination with the aspectual marker ay, forms the current imperfect (Mugane 1997: 120) or long imperfect (Johnson 1980: 273). The applicative converts the (optionally) transitive verb doma into a ditransitive verb domera.

18 As in (23b) and (24) above, preverbal ne would turn the (c) and (d) examples in this list into ungrammatical questions and inappropriate answers, respectively.

19 There actually is yet another possibility for this question-answer-sequence, where the wh-question word and the answer to it are moved to the right. The possibility of right-moved question words is discussed in detail in Bergvall (1987a). The issue will be picked up again at a later point.

20 The verb kocndia, to sell, and verbs that end on -ia in general, take iric instead of ire as the aspectual marker (plus final vowel) (see Barlow 1951: 138). 
b. ne Nairobi Abdul end-er-iri- $\varepsilon$ ye-tonga nyomba

It's in Nairobi that Abdul sold the house to the rich man

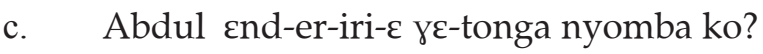

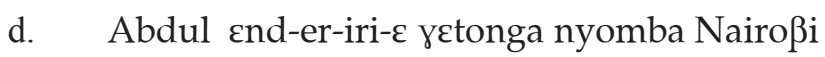

\section{Temporal Adverbial}
a. ne-re
Abdul عnd-er-iri- $\varepsilon$

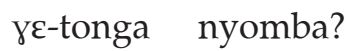
FM-when A. (SM)-sell-APPL-ASP-FV 7-rich man 9.house
When did Abdul sell the house to the rich man?
b. ne ira Abdul $\varepsilon$ nd-er-iri- $\varepsilon$ y-tonga nyomba
It was yesterday that Abdul sold the house to the rich man

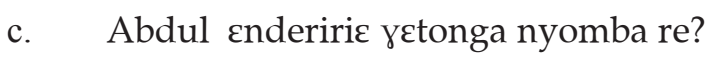
d. Abdul enderiric yetonga nyomba ira

This list is, of course, incomplete. It is simply supposed to illustrate the broad range of the phenomenon under discussion. Further examples will be given in chapter 4 .

Apart from the two types of constructions shown above, there is yet another possibility, which will turn out to be a variant of the (a/b)-type. This construction has not been documented so far in the literature, but my informant consistently produced it for all the listed examples. Shown here as a variant of (25), the construction looks as follows: ${ }^{21}$
(25) e.
$\begin{array}{llll}\text { Abdul n-oo a-ðom-ay-er-a i- } \beta u k u ? \\ \text { A. } & \text { FM-who } & \text { SM-read-HAB-APPL-FV } & \text { 5-book }\end{array}$
Who does Abdul (usually) read a book to?
f. Abdul ne mw-ana a-ðom-ay-er-a i- $\beta u k u$.
A. FM 1-child SM-read-HAB-APPL-FV 5-book
It is a child that Abdul (usually) reads a book to.

Since such examples have not been mentioned by any of the authors discussed in the following section, we will not come back to them before chapter 4 , where they will play a central role in my analysis.

While the co-existence of questions in the in-situ-form and in the $n e$-form is quite general, as we have seen in the previous examples, there are a few exceptions to this pattern. As the reader may have noted, we have not yet given an example of questions asking for a subject. This is because these constitute one of the exceptions - they only exist in the ne-form, as shown in (29):
a. n-oo o-ðom-ay-er-a mw-ana i- $\beta$ uku?
FM-who SM-read-HAB-APPL-FV 1-child 5-book
Who read the book to the child?
b. ne Abdul o-ðom-ay-er-a mw-ana i- $\beta$ uku
It is Abdul who read the book to the child
c. * oo a-ðom-ay-er-a mw-ana i-ßuku
d. \# Abdul a-ðom-ay-er-a mw-ana i- $\beta$ uku

21 More examples will be provided in chapter 4. 
(29d) is, of course, only unacceptable as an answer to (29c) or (29a). Therefore it is marked with '\#' (which will indicate that a sentence is inappropriate in the given context in all following examples).

One interesting point in (29) is that the subject prefix does not appear in its usual form $a$ but rather as an $o$ (which turns into $w$ by a phonological rule before vowels). This is the same form that is used as the concordance marker for the demonstrative -rea, which takes the form o-rea when occurring with a class one noun, e.g. as mw-ana o-rea, meaning this child. The same change in the subject prefix also occurs in relative clauses:

$$
\begin{array}{llll}
\text { Abdul o-ðom-ir- } \varepsilon & \text { i- } \beta \text { uku } & \text { ne-a-nyu-ir- } \varepsilon & \text { ma-e } \\
\text { A. SM-read-ASP-FV } & \text { 5-book } & \text { FM-SM-drink-ASP-FV } & 6 \text {-water } \\
\text { Abdul, who read a/ the book, drank water } &
\end{array}
$$

This, and other, similarities between focus constructions in the $n e$-form and relative clauses will be discussed in detail in the section on Clements work (3.3.2).

Another exception to the possibility of using both the in-situ and the ne-form in questionanswer sequences is that of manner-adverbials. They behave exactly in the opposite way of subjects in that they only allow for the in-situ form, whereas the $n e$-form is ungrammatical.
a. * ne atea
Abdul $\varepsilon$ nd-iri- $\varepsilon$
nyomba?
FM how/what A.
(SM)-sell-ASP-FV 9.house
How did Abdul sell the house?
b. * ne na-rua Abdul end-iri- $\varepsilon$ nyomba
FM quickly A. (SM)-sell-ASP-FV 9.house
Abdul sold the house QUICKly
c. Abdul عnd-iri- $\varepsilon$ nyomba atea?
d. Abdul عnd-iri- $\varepsilon$ nyomba na-rua

Another, similar case is that of (32), where the question asks for an instrument adverbial:
a. * ne na kee Abdul a-ra-hor-a fu(n)da? FM with what A. SM-T-beat-FV 9.donkey
With what did Abdul beat the donkey?
b. Abdul a-ra-hora fu(n)da na kee?
c. * ne na mo-te Abdul a-ra-hora fu(n)da FM with 3-stick A. SM-T-beat-FV 9.donkey
d. Abdul a-ra-hora fu(n)da na mote

Possibly, both of the constructions in (31) and (32) involve adverbial PP's, as true adverbs are extremely rare and (31) also involves the prepositional na. This might explain their parallel behavior.

These are the only exceptions that I have found up to this point of the otherwise fully general principle allowing for two types of constructions of questions and answers, the in-situ form and the $n e$-form.

This data shall suffice to establish a first overview of the dimension of variation in the construction of question-answer sequences in Kikuyu. In the course of the following discussion, more examples will be introduced and more subtle phenomena will be observed.

\subsubsection{Summary}

For the following discussion of the different proposals of analysis, we should keep in mind some central questions that a theoretical account of the particle ne, and, more generally, of focus in Kikuyu, has to provide answers to. 
- Is it possible to account for the occurrence of ne in the three different types of environments illustrated in 3.1.2 in a uniform way? If yes, what is the simplest way to do that?

- Why is it that only one ne occurs per clause? ? $^{22}$

- Why do subject-questions only allow for the $n e$-form?

- Why does the subject prefix on the verb change from $a$ to $o$ in subject questions and subject focus answers? $?^{23}$

- Why is the $n e$-form not possible in questions (and the respective answers) asking for a PPAdverbial (as in (31) and (32))?

The first four of these questions will be present throughout the discussion of Clements' and Bergvall's analyses as well as in my own proposal in chapter four. A very speculative answer is given to the last question in chapter 5 , section 5.2.

\subsection{Early Comments on ne}

Before turning to some more of my own data, and to an attempt of analysis, I want to give an overview of the existent discussion of the relevant phenomena in Kikuyu. As already mentioned, the authors discussed here are mainly concerned with the possible occurrences of the particle ne and its meaning. There are, however, also some remarks paying attention to the in-situ questions and answers. The contribution of the early writings by Armstrong, Barlow and Benson mainly consists of an informal description of the contribution of ne to the meaning of a sentence, and of the environments that require its presence or absence. The more recent writings by Myers, Clements, and Bergvall provide more detailed theoretical analyses and interesting examples that help to shed light onto the grammatical structures behind the observed phenomena.

\subsubsection{Barlow, Armstrong, and Benson}

Barlow (1951) recognizes all three usages of $n e$ described above. He describes the constituent focus with preposed ne as being used to express "ordinary contrasting emphasis" (Barlow 1951: 12), and gives a list of examples similar to the (b)-sentences in our list in 3.1.2. In another section, he notes that "in this way [by preposing a constituent preceded by ne F.S] prominence is given to the word following $n \tilde{\imath}$. The idiom is often employed with interrogative adverbs and pronouns, which then follow $n \tilde{\imath}$ instead of coming at the end of the sentence." (Barlow 1951: 48). The entry in Benson's dictionary for $n \tilde{\imath}$ (Benson 1964: 282) further notes the common combination of $n e$ with independent pronouns, e.g. in $n e-w e^{24}$, which also occurs in the data from my informant (see e.g. example (149) in section 4.2.10). Barlow (1951: 74) translates the similar example ne-guo as that is it.

Concerning its occurrence as a preverbal particle, Barlow writes:

$N \tilde{i}$, the copula, is commonly prefixed to affirmative verb-forms in the indicative and conditional moods. It gives preciseness or positiveness to the fact stated or the question asked, being equivalent to ,It is (a fact) that' or ,Is it (the case) that?'. Its function in past tenses is akin to that of the auxiliary, did' in English. [...] When a sentence consists of an affirmative finite verb only (e.g. nĩokire, he came), nĩ is indispensable. (Barlow 1951: 34)

22 Possible exceptions for this generalization are presented in section 4.1.2. and discussed in 4.2.10.

23 Another phenomenon appearing within the verb is a change in its tonal structure, as described in Clements (1984). This will be discussed in the section on Clements' analysis.

24 In addition, a use of ne that is best translated as by can be found in the entry, which appears, for example, in passive constructions: hürũo ne, which Benson translates as be beaten by. It is not clear how this use of $n e$ is related to the others, and I will not discuss this type of use.

25 Barlow (as well as Benson) uses the Kikuyu orthography, where ne is written as nĩ. I do not change this in text quotes, although I will deliberately convert Kikuyu examples from these authors into the IPAform generally used in this study to avoid confusion. 
Interestingly, Barlow also already notes that while the presence of preverbal ne has the effect of "uniform emphasis throughout" the sentence (Barlow 1951: 34), its absence causes another (postverbal) constituent to be in focus, and he gives examples similar to our in-situ focus examples above. ${ }^{26}$ Furthermore, Barlow provides a list of environments where ne never occurs:

- With a tense when used in the negative.

- With the consecutive tenses.

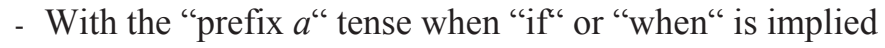

- With the $k \tilde{u}$ present tense when it is used as a perfect.

- In a clause which contains an interrogative enclictic, such as atĩa, kũ , kĩ, \&c.

- In a clause which contains ũria (=how, what)

- In a relative clause.

- With the $n g \tilde{\imath}$ (conditional) tenses when used in the protasis of a sentence (see p. 152).

- With the ki and ite and aga tenses when used in adverbial clauses, equivalent to English participles (see p.170).

(Barlow 1951: 117)

Armstrong (1940) further describes contexts where ne does occur with the verb:

[...] ne forms of the verb are used:

1. (a) In affirmative questions which may be answered by 'yes' or 'no', and

2. (b) In affirmative answers to questions of this type.

3. In many affirmative statements (not necessarily in answer to 'yes' or 'no' questions) made with strong certainty, definite promise, determination, defiance. Such statements include those which offer a strong contrast, flat contradictions.

4. In affirmative forms of the Subjunctive Mood which may be translated by 'Let...'. (Hortatory.)

(Armstrong 1940: 168-169)

Armstrong further notes that she found the $n e$-form of the verb to be rather rare in conversation and narration. As she remarks herself, this is evident in the texts she has included at the end of her book, although it is at least partially due to the fact that the texts predominantly use tenses that do not allow for the $n e$-form, e.g. the Remoter Past Consecutive.

Turning to the copula use of $n e$, Barlow as well as Benson (1964: 282) takes $n e$ to be the copula itself in these constructions. Barlow (1951: 48) remarks that "ne is the usual equivalent of the English copula (is, are, \&c.). It is only used in the 3rd person." There is, however, another element used in place of English to be in existential constructions that involve locality, namely the verb with the stem -re, as exemplified in (33) (Barlow's example):

\section{a. Kamau are haha}

Kamau is here

Interestingly, in questions "asking the situation of a place", ne is used (at least in these examples by Barlow (1951: 48)), as seen in (b) and (c),

$$
\text { b. ne ha? }
$$

which both mean Where is it? ${ }^{27}$ Even more interestingly, the verb -re ('be'), which also is used for copula constructions that are not third person or present tense (see data in 3.3.1.), can be used, on rare occasions, with preverbal $n e$, as the following example from Bergvall (1987: 103) illustrates:

26 His examples are different in that he describes the sentence-final constituent to be emphasized, not the one immediately following the verb. This is related to the issue of righ-moved questions, which will be briefly discussed in chapter 5 .

$27 h a$ and $k o$ are different forms of locative question words, with the former meaning where in a (spatially) limited sense, and the latter in a (spatially) wide sense (cf. Barlow 1951: 43). 


\section{MORPHOSYNTACTIC ASPECTS}

\section{a. Kamau ne aare moremi}

Kamau was a farmer

Such use is restricted to "strongly positive statements or emphatic questions", and rather rare, according to Barlow (1951: 47). Nevertheless, it is possible, and this may be a strong indication that $n e$ itself is not the copula, as argued by Clements (1980) and Bergvall (1987) (see discussion in the section covering these authors).

The important insights, then, which we gained from the authors discussed in this section, consist of the following:

- The use of ne is impossible in a number of tenses, including the consecutive tenses, as

listed above.

- $n e$ does not occur with verbs in the negated form.

- There is a copula-verb for existential predications, -re.

- ne can appear with this copula-verb.

- ne does not appear in relative clauses

\subsubsection{Myers}

Myers (1971) offers an interesting account of the distribution of $n e$ in the framework of generative semantics (McCawley 1968), proposing that ne is "derived from a higher verb of assertion" (Myers 1971: 135). She attributes the absence of $n e$ in subordinate clauses (she notes relative, temporal, and adverbial clauses as well as the protasis of conditionals) to its assertive nature, because only what is expressed in the main clause of a sentence can be asserted by a speaker. Material in subordinate clauses is presupposed, as she illustrates with an English example:

a. The man who killed John is here.

John's being killed is presupposed here, and only the presence of his murderer is asserted. She thus concludes that

When the truth of the predication is either presupposed or indeterminable, $n \tilde{\imath}$ does not appear. When the sentence involves the assertion by the speaker of the truth of what he says, $n \tilde{\imath}$ is used. (Myers 1971: 135)

Her analysis intends to cover preverbal $n e$ as well as sentence initial $n e$ with a constituent other than the verb following. Quoting Barlow's examples for the latter case, she maintains that "it is clear that an assertion is being made in the initial phrase of each of these sentences, and that the predication is, once more, presupposed to be true." (Myers 1971: 137)

She provides the following proposal for the analysis of the underlying structure of the preverbal occurrence of $n e$ :

a.

$$
\begin{aligned}
& \text { netoðiire moranga } \\
& \text { We went to Fort Hall }
\end{aligned}
$$

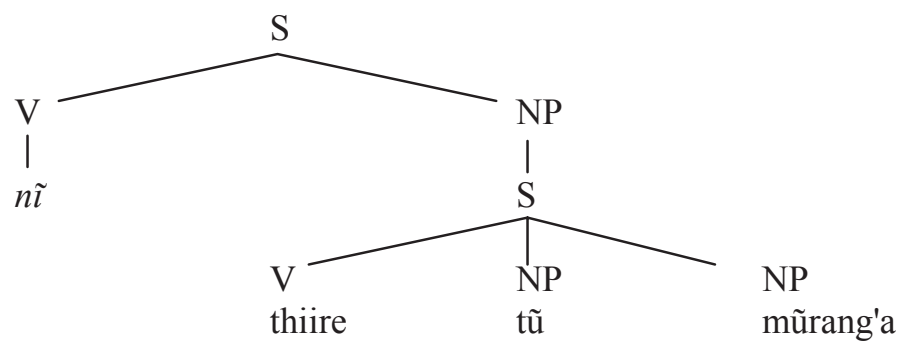

28 This is the tranlsation that Myers provides. 
It is unclear how this analysis could be generalized to the $n e$-form of focused constituents other than the verb, although Myers finds it plausible to assume that such a generalized analysis would be similar to the one in (36).

Although Myers' arguments are not very detailed, and her analysis remains quite vague, there appears to be some truth to the connection between the use of $n e$ and the question of what is asserted in a sentence. The nature of this connection is still unclear at this point, and Myers' analysis of $n e$ as a higher verb of assertion seems unconvincing. But stating this connection in more precise terms will be a central task ahead.

\subsection{Clements vs. Bergvall - Focus Marker or Cleft?}

In this section, I turn to the two most important competing theoretical accounts in the literature on $n e$, namely the analysis by Clements (1984) and the cleft-analysis by Bergvall (1987). Before turning to each of these, the next section will discuss the question whether ne should be analyzed as the copula or not. Both Clements and Bergvall agree on this issue, concluding that $n e$ is not the copula. Their arguments for this are presented in the next section.

\subsubsection{Against $n e$ as a Copula}

As already mentioned in section 3.2.1, there is another element, apart from ne, which is used in place of the English verb to be in locative constructions expressing the presence of the subject in the predicated location, as can be seen in Barlow's example repeated from above:

$$
\begin{aligned}
& \text { a. Kamau a-re haha } \\
& \text { Kamau SM-be here } \\
& \text { Kamau is here }
\end{aligned}
$$

The verb -re is defective in that it cannot take any aspectual or other suffixes. It can, however, take prefixes to express different tenses. It also takes the normal subject prefixes for the different noun classes. $N e$, on the other hand, does not take any prefixes (or suffixes). Its use is restricted to expressing present tense for third person subjects. In other cases, -re is used, as seen in (38):
a. Kamau ne mo-remi
Kamau is a farmer
b. Kamau a-a-re mo-remi
c. to-re a-remi
$\mathrm{SM}(1 \mathrm{PI})$-be $\quad$-farmer
We are farmers

Bergvall (1987: 76) points out that ne can also precede the verb in (b) and (c), but there can not be two $n e$ 's in (a):
a'. * Kamau ne ne mo-remi
b'. Kamau ne-a-a-re mo-remi
c'. ne-to-re a-remi

The verb -re can also mean have, in which case it is often, but not necessarily, combined with na (with). The following example from my informant neatly illustrates how the two forms encountered above (with $n e$ and $-r e$ ) interact and overlap:

$$
\begin{aligned}
& \text { a. Kamau ne mo-rutani } \\
& \mathrm{K} \text {. FM 1-teacher } \\
& \text { Kamau is a teacher }
\end{aligned}
$$




\section{MORPHOSYNTACTIC ASPECTS}

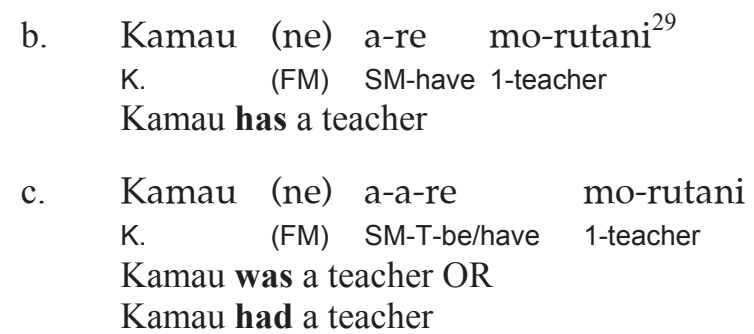

In (39), we see a contrast between (a) and (b), with the apparent absence of an overt verb triggering the copula meaning, and its presence standing for the possessive meaning (as in (b)). In the past tense form, the sentence is ambiguous.

Taken together, these examples suggest that ne is not the copula itself, but rather that in the case of $3^{\text {rd }}$ person present tense copula-constructions there is a phonologically null form of the copula verb following $n e$. The paradigms for the copula and the locative form would then be as follows

The two forms of to be:
\begin{tabular}{|l|l||l|c|}
\hline Copular $\boldsymbol{b} \boldsymbol{e}_{1}$ & \multicolumn{2}{|c|}{$-\boldsymbol{r} \boldsymbol{e}\left(\boldsymbol{b} \boldsymbol{e}_{2} ;\right.$ be in; have $)$} \\
\hline $1^{\text {st }} \mathrm{P} . \mathrm{Sg}$. & nd-e & $1^{\text {st }} \mathrm{P} . \mathrm{Sg}$. & nd-e \\
\hline $2^{\text {nd }} \mathrm{P} . \mathrm{Sg}$. & or-e & $2^{\text {nd }} \mathrm{P} . \mathrm{Sg}$. & o-re \\
\hline $3^{\text {rd }} \mathrm{P} . \mathrm{Sg}$. & (ne) $\varnothing$ & $3^{\text {rd }} \mathrm{P} . \mathrm{Sg}$. & a-re \\
\hline \hline $1^{\text {st }} \mathrm{P} . \mathrm{Pl}$. & to-re & $1^{\text {st }} \mathrm{P} . \mathrm{Pl}$. & to-re \\
\hline $2^{\text {nd }} \mathrm{P} . \mathrm{Pl}$. & mo-re & $2^{\text {nd }} \mathrm{P} . \mathrm{Pl}$. & mo-re \\
\hline $3^{\text {rd }} \mathrm{P} . \mathrm{Pl}$. & (ne) $\varnothing$ & $3^{\text {rd }} \mathrm{P} . \mathrm{Pl}$. & ma-re \\
\hline
\end{tabular}

In the case of the phonologically null forms in the third person, insertion of ne is obligatory to form a well-formed sentence (as exemplified in (24a)). In all other cases, ne can, but does not have to, occur (with its usual effect of emphasis).

The copular form for all non-human noun classes is also phonologically null (with obligatory occurrence of ne, as in the case of the third person form), while the verbal stem -re takes the regular noun class-prefixes. As Bergvall (1987: 76-77) notes, the exceptions of the first and second person in the copular form are reasonable, because if they would also come in the phonologically null form, there would be no way of telling the difference between I am a farmer, you are a farmer, and he is a farmer (etc. in the plural form). Alternatively, one could assume that there is only one verb of the form - re that is ambiguous, and that the ambiguity is distinguished in different forms in the third person.

Concerning the role that ne plays in these and other constructions, the accounts given by Bergvall and Clements differ substantially. They will be presented in the following two sections.

\subsubsection{Clements (1984)}

Clements is the first to propose an analysis of ne as a focus marker, which he describes as "an element occurring preposed to nouns and verbs, which indicates the scope of focus" (Clements 1984a: 39). He argues for an analysis involving a focus phrase within the CP (within $\mathrm{S}^{\prime}$, in his terminology), which contains ne and the focused element.

The argument in Clements (1984) is embedded in the context of the question of a special verb form that only occurs in specific syntactic environments, which all crucially involve, in Clements terms, an open clause. These environments are relative clauses, sentences with clause-initial constituents marked for focus, and wh-questions with preposed wh-question words. These three

29 Here, as well as in (c), ne is optional, having its usual effect of emphasis when it occurs. 
constructions show the same behavior concerning changes in the verbal morphology and syntactic constraints on extraction.

\subsubsection{Morphological Changes}

The following data illustrate the morphological changes that can be observed in these constructions when compared to normal main clauses (Clements 1984a: 39):
a. Kariokì á-'tém-îré mo-tẹ̌ $e^{130}$
K. SM-cut-T 3 -tree
Karioki cut a tree
b. nó.o o-tzm-iré mo-te?
FM-who PP-cut-T 3- tree
Who cut a tree?
c. né Káriokǐ ó-tém-'îré mo-te
FM K. PP-cut-T 3-tree
It's Karioki (that) cut a tree
1-person PP-DEM PP-cut-T 3-tree
the person (that) cut a tree
d. mo-ndo o-riă ó-tém-'îré mo-te

Clements describes the following changes in the verb form in the syntactic environments mentioned above, shown here in (b)-(d), in comparison to the regular main clause in (a):

- the post-verbal downstep ${ }^{32}$ is deleted.

- when the element that is asked for, focused, or relativized, is a class one subject, the subject prefix changes from /á/ to /o/.

- in addition, verbal negation changes from the infix /-tî-/ to /-tá-/

This last point is illustrated in (42) (Clements 1984a: 40):
$\begin{array}{lll}\text { a. ka-aná } & \text { yá-'tém-îré } & \text { mo-tě } \\ \text { 12-child } & \text { SM-cut-T } & \text { 3-tree }\end{array}$ the child cut a tree
b. ka-aná yá-tî-ná-tém-'á mo-te
12-child SM-NEG-T-cut-T 3-tree
The child didn't cut a tree
c. nó.o o-ta-ná-tॄm-á mo-te?
FM-who PP-NEG-T-cut-T 3-tree
Who didn't cut a tree?

Apart from other changes in the tonal structure and in the marking of tense $\mathrm{e}^{33}$, we can see here that the wh-question in (c) displays the $t a$-form of negation, whereas the negated main clause in (b) contains the $t i$-form.

$30 \%$ stands for downstep. Clements' examples deviate from the surface form in that the phonological processes affecting vowel sequences, as described in the introduction, have been reversed to promote morphological transparency.

31 I have taken over Clements' glosses in this section, except that I specify the noun class prefixes. Note that Clements does not distinguish between tense and aspect affixes.

32 This downstep is realized after the first complement of the verb in (41a) (see Clements and Ford (1981) for details on this phenomenon as well as on the notion of downstep). In addition, there often are other tonal changes in the verb. 


\section{MORPHOSYNTACTIC ASPECTS}

\subsubsection{Syntactic Constraints}

The syntactic constraints for extraction are illustrated in the following data. First of all, all the constructions under discussion allow for "long-distance", unbounded dependencies between an NP and its trace (Clements 1984a: 41, 43, 44):
a.
nó.o ó-yw-eciîri-a
Ngoye a-úy-îre áte FM-who PP-T-think-T N. SM-say-T that
$\begin{array}{ll}\text { Kama.ú } & \text { a-ón-'îré? } \\ \text { K. } & \text { SM-see-T }\end{array}$
Who do you think Ngũgĩ said that Kamau saw?
b. né Káma.ú n-gw-é'cîiri-a Ngoye a-úy-îre áte o-on-îré Kaanake FM K. SM-T-think-T N. SM-say-T that PP-see-T K. It's Kamau (that) I think Ngũgĩ said (that) saw Kanake
c. mo-ndo o-reǎ n-gw-éciîri-a Ngoye a-úy-îre áte Kama.ú a-ón-îr'é 1-person PP-DEM SM-T-think-T N. SM-say-T that K. SM-see-T the person (that) I think Ngũgĩ said (that) Kamau saw.

In all these cases, extraction out of an embedded clause is possible. Note that all embedded clauses in these examples are introduced by a bridge verb (cf. Bresnan 1968) like think or say. There are, however, island constraints restricting the possibility of extraction, as seen in (44) (Clements 1984a: 41, 43, 44): ${ }^{34}$
a. * nó.o Káma.ú a-ón-îre mó-ndo o-reă ó-rîng-'îré? FM-who K. SM-see-T 1-person PP-DEM PP-hit-T
Who did Kamau see the person (that) hit?
b. * né Kaanáké Kámá.'ú a-ón-'îre móndo o-reă ó-rîng-'îré FM K. K. SM-see-T 1-person PP-DEM PP-hit-T It's Kanake (that) Kamau saw the person (that) hit
c. * mo-ndo o-reă Kámá.'ú a-ón-'îre mó-ndo o-reă ó-ring-'îré 1-person PP-DEM K. SM-see-T 1-person PP-DEM PP-hit-T the person (that) Kamau saw the person (that) hit

Interestingly, the constructions in (44) can be improved by inserting a resumptive pronoun ${ }^{35}$ in the clause from which the element has been extracted (Clements (1984a: 42, 44), highlighting of object markers by FS):
a. ? nó.o Káma.ú a-ón-îre mó-ndo o-reǎ ó-mó-rîng-'îré? FM-who K. SM-see-T 1-person PP-DEM PP-OM-hit-T
b. né Kaanáké Kámá.'ú a-ón-'îre móndo o-reă ó-mó-rîng-'îré FM K. K. SM-see-T 1-person PP-DEM PP-OM-hit-T
c. mo-ndo o-reă Kámá.'ú a-ón-'îre mó-ndo o-reǎ ó-mó-ring-'îré 1-person PP-DEM K. SM-see-T 1-person PP-DEM PP-OM-hit-T

\footnotetext{
33 Affirmative and negative forms of verbs are quite different in most tenses, which has caused authors like Barlow and Armstrong to speak of affirmative and negative tenses. But these differences in form do not, of course, have anything to do with tense. Nevertheless, it is remarkable that the same tense is expressed quite differently in affirmative and negated verb-forms.

34 The examples here illustrate violations of Ross's Complex NP Constraint (Ross 1967). Clements (1984) also provides examples for Wh-island constraints and another constraint related to the nominal modifier /-a/, of'.

35 These are not formally distinct from the ,free' pronominal elements (Clements (1984a: 42), see also Bergvall $(1987,110-112))$.
} 
This results in fully acceptable sentences in case of (b) and (c), and in a question acceptable to some speakers in case of (a) (according to Clements). As Clements shows with further data, we actually find a complimentary distribution of gaps and resumptive pronouns in respect to islandversus non-island extraction sites, that is, only gaps occur in accessible (non-island) extractions sites, and only resumptive pronouns occur in island extraction sites.

So far, we have seen that the types of constructions under discussion display uniform behavior in several respects. The main goal of Clements' paper, however, is to explain why this is so, i.e., what property is shared by these constructions that causes them to behave uniformly. To do this, he attempts to show that they fulfill the same structural condition, which triggers the special verb form and the morphological changes. His goal is then to provide an analysis of these constructions that makes this structural similarity transparent.

\subsubsection{Analysis of preposed Focus constructions and wh-questions}

His analysis proposes the following phrase structure rules to account for the distribution of $n e$ in the different constructions (Clements 1984a: 45):

$$
\begin{array}{ll}
\text { a. } & \mathrm{S}^{\prime} \rightarrow \mathrm{COMP} \mathrm{S}^{36} \\
\text { b. } & \mathrm{COMP} \rightarrow \text { Comp (FOC) } \\
\text { c. } & \mathrm{FOC} \rightarrow \text { } \rightarrow \text { (NP) }
\end{array}
$$

This formalism generates all three basic constructions involving ne. The NP node is further subclassified by the feature $[ \pm \mathrm{WH}]$. If the optional nodes FOC and NP are both expanded, the result will be a preposed wh-question or focus construction, depending on the specification of the feature $[ \pm \mathrm{WH}]$. If FOC is expanded, but not NP, the focus marker $n e$ is moved downwards in the structure into preverbal position and cliticizes onto the verb, resulting in a sentence containing preverbal ne (as in our example (5a) above). This same mechanism applies in the case of the copula construction, only that there the verb is (in case of the third person present tense form) phonologically null. If neither FOC nor NP is expanded, the result will be a sentence with in-situ focus, as, e.g., in (8) and (26a) above. ${ }^{37}$

This analysis makes the correct prediction that there can only be one ne per clause, because maximally one node FOC is generated per clause. The ungrammaticality of the following sentences shows that this is correct (Clements 1984a: 46-47):

$$
\begin{aligned}
& \text { a. * nó.o né Káma.ú órîng-'îré ? } \\
& \text { b. * né Kaanáké né Káma.ú ó-rîng-'îré ? } \\
& \text { c. * nó.o nó.o o-गn-i'ré? }
\end{aligned}
$$

None of these sentences can be improved by inserting a resumptive pronoun for the Object NP, as was possible to minimize or avoid island constraints. Clements further notes that the ungrammaticality of these sentences "cannot be explained on semantic grounds" (Clements 1984a: 47), because all of the sentences in (47) are perfectly fine if one of the preposed elements remains in-situ.

While (47) shows that no two elements (whether focused constituents or wh-question words) can be preposed with $n e$, we can see in (48) that the combination of a preposed constituent with $n e$ and preverbal ne is impossible as well:

$$
\text { (48) a. * nó.o ne-a-o-on-i'ré Kaanáké ? }
$$

\footnotetext{
36 I will later deliberately switch to more recent terminology, with $\mathrm{S}^{\prime}$ being equivalent to $\mathrm{CP}$, and $\mathrm{S}$ to IP.

37 Clements does not say much about the in-situ focus constructions, altough he does note them, and at one point describes them as charachteristically being 'used when the focus of the sentence falls exclusively on a postverbal constituent which remains in-situ' (Clements 1984b: 313), a claim that we will discuss at a later point.
} 
Another interesting prediction is borne out in the following examples, namely that in cases of multiple embedded clauses, extraction is possible to the FOC node of any of the clauses dominating the extraction site (Clements (1984a: 47), question words highlighted by F.S.):

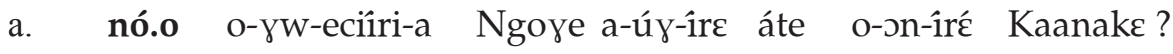

$$
\begin{aligned}
& \text { FM-who SM(2Sg.)-T-think-T N. SM-say-T that PP-see-T K. }
\end{aligned}
$$

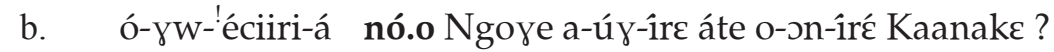

$$
\begin{aligned}
& \text { FM-who }
\end{aligned}
$$

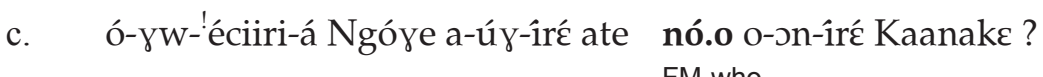

Here, the question word oo can be extracted to any of the available FOC nodes in the different clauses, where it combines with the focus marker $n e$. This type of extraction is blocked, however, if $n e$ is already present in one of these, as shown for the case of preverbal ne in (50) (Clements 1984a: 48) ${ }^{38}$ :
a. né-kó Ngóye á-úy-îre áte Kama.ú ne-a-ón-'î̀ré Kaanáké!? FM-where N. SM-say-T that K. FM-SM-see-T K.
b. * Ngoye a-úy-îré ate né-kó Káma.ú ne-a-ón-'î̀ré Kaanáké! ? FM-where
c. Ngoye a-úy-îré ate Kama.ú ne-a-ón-'î̀ré Kaanáké ! kó ?
where

All meaning: Where did Ngũgĩ say (that) Kamau saw Kanake?

(50b) is ungrammatical, because the first embedded clause contains two $n e$ 's.

\subsubsection{Analysis of Relative Clauses}

For the construction of relative clauses in Kikuyu, Clements proposes the following phrase structure rule (Clements 1984a: 48):

(51) $\quad \mathrm{NP} \rightarrow \mathrm{NP} \mathrm{S}$

Clements' reason for choosing S (= IP) rather than $\mathrm{S}^{\prime}(=\mathrm{CP})$ as the complement of the head NP of the relative clause is that no relative pronoun or complementizer can occur in Kikuyu relative clauses. Furthermore, $n e$ cannot occur in relative clauses either. ${ }^{39}$

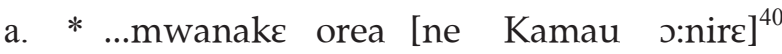 young-man DEM FM K. saw ...the young man that Kamau saw

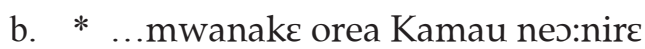 ...the young man that Kamau saw
c. * ...mwanake orea ne moremi young-man DEM FM farmer ...the young man who is a farmer

\footnotetext{
38 Any other construction with ne (focus constructions or preposed question words) displays the same pattern.

39 At least not in the matrix clause of the relative clause. Ne can occur in embedded clauses within relative clauses, as we will soon see.

40 This and the next example are taken from Bergvall (1987b: 108), who cites them from a paper presented by Clements in Groningen in 1980 (Clements 1980).
} 
All of these sentences are perfectly fine if $n e$ is omitted:

$$
\begin{aligned}
& \text { a/b. ...mwanake orea [Kamau J:nire] } \\
& \text { young-man DEM K. saw } \\
& \text {...the young man that Kamau saw } \\
& \text { c. ...mwanake orea moremi } \\
& \text { young-man DEM farmer } \\
& \text {...the young man who is a farmer }
\end{aligned}
$$

All of these facts are, as Clements argues, explained if we assume that relative clauses lack the COMP node, that is, that they only contain an S (IP) and not an S' (CP).

\subsubsection{Open Clauses}

Clements concludes that the property shared by the constructions discussed here is that they are instances of open clauses, which he defines as "any clause S whose root node dominates an indexed pronominal [+PRO] and does not dominate its (coindexed) antecedent" (Clements 1984a: 49). This description fits all three types of constructions considered above. The special verb form, with the morphological modifications mentioned above, occurs when it is contained in an open clause. Formally, the environment of an open clause can be specified as follows (Clements 1984a: 50):

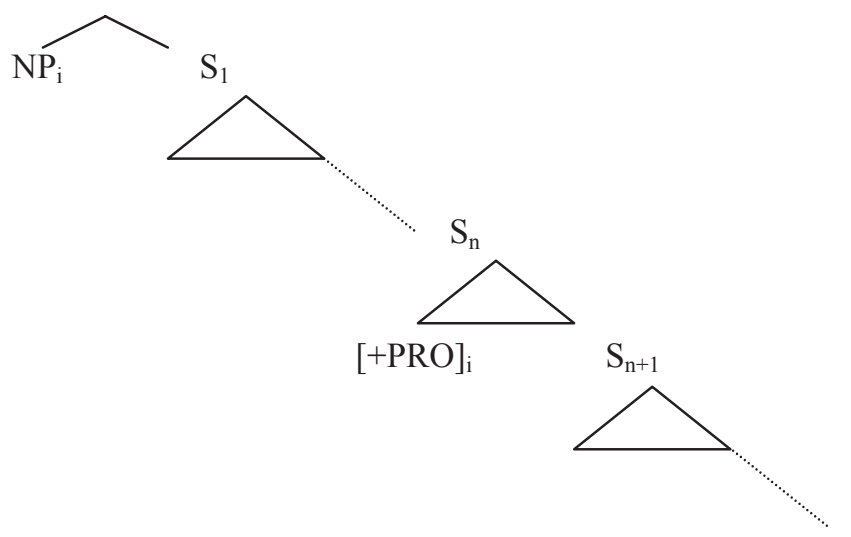

Note that this predicts that not only the clause out of which an element has been extracted will display the morphological changes on the verb (1), but also all clauses between the extracted element and the extraction site (2). In addition, all clauses above the extracted element (i.e., clauses dominating $\mathrm{NP}_{\mathrm{i}}$ ) (3) and below the extraction site (i.e., clauses dominated by $\mathrm{S}_{\mathrm{n}}$ ) (4) should contain the normal verb form.

Claim (1) was already discussed in the context of the morphological changes in the first place. Predictions (2) and (3) already prove to be true when we look at (49) above. The first verb, think, has its special tonal form (o-yz-eciiri-a) only in $(49 a)$, where it is preceded by the preposed question word noo. This, in combination with its normal tonal form (ó- $\gamma w w^{-}$'eciiri-á) in (49b) and (c) shows that claims (2) and (3) are correct. ${ }^{41}$ Claim (4) is shown to be true by the following example (Clements 1984a: 51):

$$
\text { a. }
$$

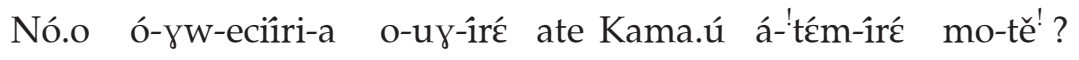

$$
\begin{aligned}
& \text { FM-who SM-T-think-T PP-say-T that K. SM-cut-T 3-tree } \\
& \text { Who do you think said (that) Kamau cut a tree? }
\end{aligned}
$$

41 Clements does not address the question of why the normal postverbal downstep is missing here. One possibility is that, according to Clements and Ford (1981: 317), downsteps are deleted in certain types of questions. This would, however, probably leave other occurrences of downstep in questions within the given examples unexplained (e.g. in (39) and (35)). 
The question word has here been extracted from the intermediate clause. Accordingly, the verb in the lowest clause appears in its normal tonal form (á-'tém-ír $\bar{\varepsilon}$ ) as opposed to the other tonal forms in (41b-d).

\subsubsection{Summary}

Clements' analysis provides an explanation for the uniform behavior of a class of syntactic constructions by showing that they all fulfill the same structural condition, namely that they all contain instances of open clauses. Within this account, Clements proposes to analyze focus constructions involving ne as containing a focus phrase FOC within $\mathrm{S}^{\prime}(=\mathrm{CP})$, which contains the focus marker ne as well as the focused element. He shows that these focus constructions allow for unbounded dependencies, but that they are subject to island constraints, along with the other constructions involving open clauses.

His analysis also provides answers to a number of central questions, namely

- why only one ne per clause is possible (because only one FP can be generated per clause),

- how the two different constructions involving focal ne, namely constructions involving preposed focused constituents and preverbal $n e$, are generated, and

- why ne does not occur in relative clauses (because relative clauses are simple S's/IP's that do not contain FP).

The explanatory power of Clements' account thus seems to be quite far reaching. There are, however, some problems (concerning the syntax of questions, for example), as we will see in the discussion of Bergvall (1987) and the following comparison of the two accounts. Nonetheless, we will come back to Clements' analysis, as it will be the basis of my own account in chapter 4 .

\subsubsection{Bergvall (1987)}

Just as Clements, Bergvall (1987) holds that $n e$ is not the copula itself, based on the reasons presented above in 3.3.1. But her analysis of the role of $n e$ is quite different from Clements. She claims that $n e$ is generated in the INFL node, and that it is not a particle expressing focus, but assertion. According to her proposal, the preposed focus construction with ne and a focused element are best to be analyzed as cleft sentences. Ne participates in these in the same way as it does in regular copula sentences. The focusing effect of these constructions is based on the biclausal cleft-structure, and not on the meaning of the particle $n e$.

\subsubsection{1 ne in INFL}

One of the problems that Bergvall sees with Clements' analysis is related to the latest syntactic theory of her time, Chomsky's government and binding theory (GB) in the version of Chomsky (1986). The problem is that, as is still generally assumed today, question words generally have to c-command their empty category. With his analysis of FOC being a sister to Comp, Clements cannot provide a structure where this is done. Clements' phrase structure rules are repeated here, and the problem is illustrated in the tree in (56) (Bergvall 1987b: 118):
a. $\mathrm{S}^{\prime} \rightarrow$ COMP S
b. $\mathrm{COMP} \rightarrow \mathrm{Comp}$ (FOC)
c. $\quad \mathrm{FOC} \rightarrow n e(\mathrm{NP})$

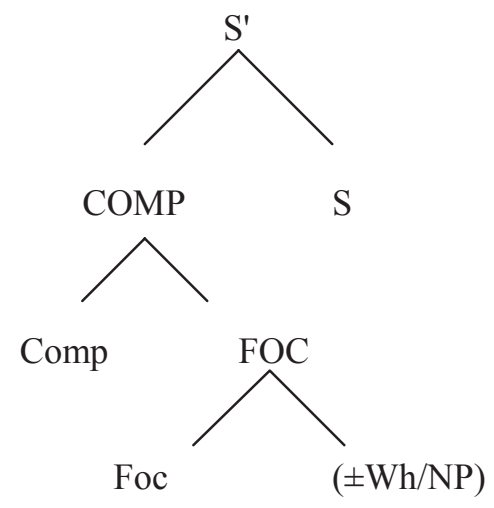


If the NP is [+Wh], there is no way that the according question word could c-command its empty category in $\mathrm{S}$, because there are two maximal projections in the way, COMP and S'.

On the other hand, if one assumes a more recent version of the X-bar scheme, there also is a problem. In the (now standard) tree-structure including CP and IP, it is generally assumed that question words in English move into the specifier of CP:

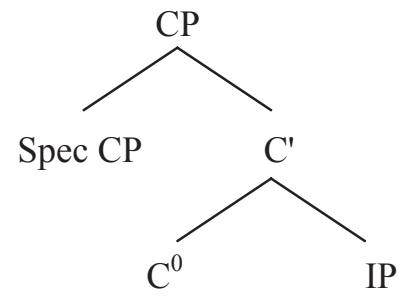

If the question word, e.g. oo, goes into Spec $\mathrm{CP}$, and the complementizer ate goes into $\mathrm{C}^{0}$, then this results in the wrong word order for our Kikuyu examples, as the complementizer always occurs before the question word when they occur together, as in (58) (from Clements (1984a: 47), repeated from (34c) above):

$$
\begin{aligned}
& \text { a. ó-yw-'éciiri-á Ngóye a-úy-îré ate nó.o o-วn-îré Kaanake ? } \\
& \text { Who do you think Ngũgĩ said saw Kanake? }
\end{aligned}
$$

Another problem with the Kikuyu data that comes with the structure in (57) is that it is completely unclear where $n e$ could be base generated.

The solution that Bergvall proposes for these problems is that $n e$ is generated in INFL. Based on this assumption, the cases of preverbal and copular ne are very easily generated (simplified from Bergvall 1987b: 120 $)^{42}$ :

$$
\begin{aligned}
& \text { a. Njecri ne-Ј:nire mwana } \\
& \text { Njeeri saw a child }
\end{aligned}
$$

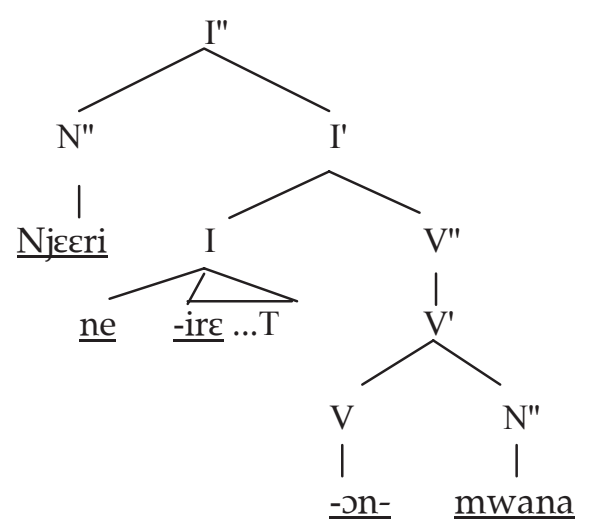

\section{b. Njecri ne mwana} Neeri is a child

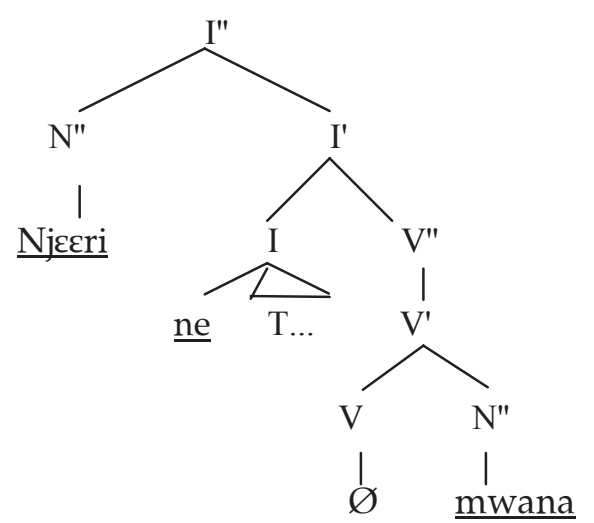

In the case of (a), ne will occur preverbally automatically, and will, according to Bergvall's analysis, be affixed to the verb by morphological rules. Note that this is different from Clements, who assumed that ne moves from CP into IP to cliticize onto to the verb. In the case of the copular construction in (b), basically the same thing happens as in (a), only that the copular verb is phonologically null (which was argued for, in accordance with Clements and Bergvall, above). Hence, the particle $n e$ is the only overt element occurring between the two NPs.

\subsubsection{Cleft-Analysis of Preposed ne-Focus}

How can Bergvall integrate the case of the preposed, focused constituent preceded by $n e$ ? Here her cleft-analysis comes into play. According to her, all of the preposed focus sentences involve a

42 VP-internal morphology is assumed to be affected by further rules to result in suface structure. 
cleft-construction, with the (usual) phonologically null copular verb, ne, and an empty, nonreferential pleonastic subject. The structure she proposes for these types of sentences is this (Bergvall 1987b: 123):

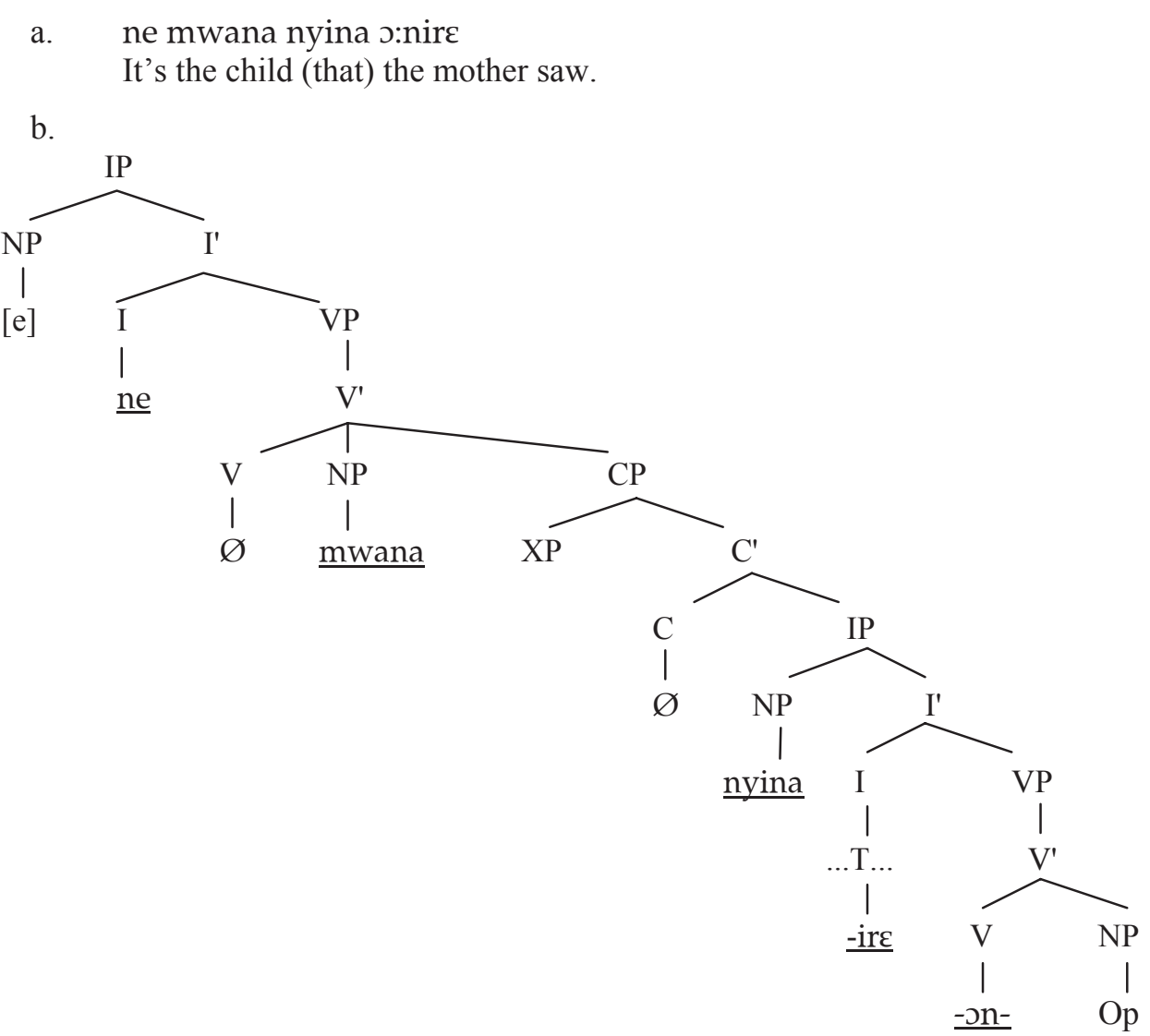

This structure is transformed by movements to result in the following structure at LF, with the relative operator moved to Spec $\mathrm{CP}$ of the embedded clause, and coindexation of nyina, the operator and the empty element in object position:

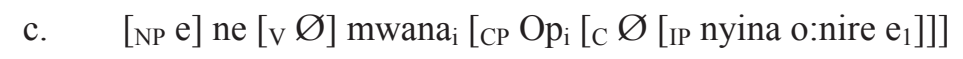

With this analysis, Bergvall can generate all three major occurrences of ne in a simple, uniform manner. And there are other constructions in Kikuyu that make such an account plausible.

\subsubsection{Pleonastic Subjects and Clefts in Dependent Clauses}

There are two phonologically empty slots in Bergvall's analysis, that of the subject and that of the copula verb. It has already been argued that a null-form of the copula verb appears in third person present tense copula constructions, so this is not a problem.

How about empty subjects in Kikuyu? Bergvall comes up with independent evidence, which shows that empty subjects are possible in Kikuyu. First of all, Kikuyu is a pro-drop language, and anaphoric pronominal subjects are commonly dropped: ${ }^{43}$

$$
\begin{aligned}
& \text { a. Kamau ne-a-ro-sn-a mo-ndu. Ne mo-dorume } \\
& \text { K. } \\
& \text { Kamau is seeing a person. It is a man. }
\end{aligned}
$$

43 Alternatively, one can analyze the subject marker on the verb as being ambiguous between a mere concordance marker and a fully pronominal element. 
Furthermore, there are sentences with a class 17 (locative, general place) prefix, which cannot take an overt subject (Bergvall 1987b: 126):

$$
\begin{aligned}
& \text { a. [e] ko-e-na mbura } \\
& \text { SM-be-with rain } \\
& \text { It's raining (lit. there-be-with, or there-has) }
\end{aligned}
$$

Even more interestingly, there are occurrences of the verbal stem -re in embedded clauses that seem to have an empty subject. The concordance subject prefix is always $a\left(3^{\text {rd }}\right.$ person singular $)$ in these cases, no matter what noun classes the nouns in the embedded clause (which might be candidates for the subject position) belong to. Bergvall again suggests that here we have an empty pleonastic subject. For illustration, Bergvall provides the following examples, originally taken from Barlow (1951: 267) (empty subject in (b) and (c) added by F.S.):

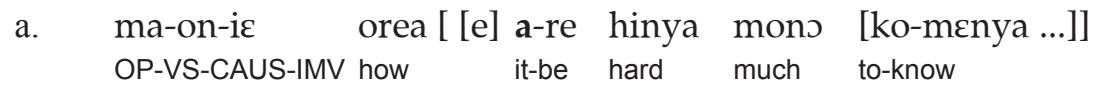

$$
\begin{aligned}
& \text { Show them how very difficult it is to know (lit. show them how it is very } \\
& \text { difficult to know) } \\
& \text { b. E-ko-aria ta [e] a-re ko-roara a-roar-ete } \\
& \text { SP-T-VS as-if it-be INF-VS SM-VS-T } \\
& \text { He speaks as if he were ill (lit. like it is being he is ill) } \\
& \text { c. e-yo-to-atha ta [e] a-re nyomba yake to-yo-aka } \\
& \text { SP-T-OM-VS as-if it-be house hers SM-T-VS }
\end{aligned}
$$

It seems very plausible that all of the sentences in (63) contain a cleft in the embedded clause. Even though are never changes its prefix, there is evidence that we still are dealing with the actual verb -re (and not a particle akin to $n e$ ). This evidence comes from the negated form, which is formed with the normal dependent clause negation marker $t a$ :

$$
\begin{aligned}
& \text { a. e-yo-to-atha ta [e] a-ta-re nyomba yake to-yo-aka } \\
& \text { SP-T-OM-VS as-if it-not-be house hers SM-T-VS }
\end{aligned}
$$

She commands us as if it weren't her house we are building.

So, given these examples, we may conclude with Bergvall that there are clefts in embedded clauses in Kikuyu.

\subsubsection{Biclausal ne-Constructions}

It only seems natural for Bergvall to extend this analysis to constructions with ne. But before she turns to ne-focus constructions, she gives examples of clearly biclausal constructions involving sentence initial ne (Bergvall 1987b: 128):

$$
\text { a. [e] ne } \begin{array}{llllll}
\varnothing & \text { hinya } & \text { mons } & \text { [komenya } & \text { wa } & \text { rwe:ka] } \\
\text { cop } & \text { difficult } & \text { very } & \text { to know } & \text { (of) } & \text { to do }
\end{array}
$$

It is very difficult to know what to do

$$
\begin{array}{llllll}
\text { b. } \quad[\text { e] ne } & \varnothing & \text { ma [ate } & \text { Njecri } & \text { nearonire } & \text { kaana] } \\
\text { COP } & \text { true that } & \mathrm{N} . & \text { saw } & \text { child }
\end{array}
$$

It is true that Njeeri saw a child

Both of these sentences quite clearly contain two clauses, the first of them being a copular construction with an empty subject. What is particularly interesting in (65b) is that there is another $n e$ occurring in the embedded clause. Clements would have to accept a biclausal analysis here as well, Bergvall argues, and hence accept the possibility of copula-constructions with an empty subject and an empty verb. 
And then, she continues, what reason should there be to not accept this analysis for preposed focus constructions? Her analysis of these thus looks in general like the tree-structure above in (60), shown here only with the empty elements marked (Bergvall 1987b: 128):

$$
\begin{aligned}
& \text { a. [e] ne } \varnothing \text { moremi [Kamau oonire] } \\
& \text { COP farmer } \mathrm{K} \text {. saw } \\
& \text { It was a farmer Kamau saw } \\
& \text { b. [e] ne } \begin{array}{lll}
\varnothing & \text { haha } & \text { [ngwatire] } \\
\text { cop } & \text { here } & \text { I-took-hold }
\end{array} \\
& \text { It is (or was) here I took hold }
\end{aligned}
$$

Her argument mainly appeals to the greater simplicity of her account. The structures for clauses containing ne and an empty subject and verb are needed anyway for other data. Her criticism against Clements then comes down to the question: Why should one assume another functional category and lots of more structure for a particular group of cases if there is a general analysis using the standard phrase structure inventory that can explain the same facts?

\subsubsection{Ne as an Assertion Marker}

Given that the effect of focus in the preposed constructions with ne results from the structure, namely the cleft-construction, for which there is general agreement that it has a focusing effect, Bergvall sees no need to posit a particular focal contribution of the particle ne. She can even explain why one might be tempted to see a direct relation between focus and ne, as ne standardly occurs in the cleft-constructions. Furthermore, she only sees a focusing effect in these constructions and claims "that $n e$ in its other two manifestations, 'copular' and 'preverbal predicator', does not give a focal reading" (Bergvall 1987b: 166). ${ }^{44}$ To support the first claim, she points out a difference of focus in the following two sentences, where only (b) is focused according to her (Bergvall 1987b: 132)

$$
\begin{array}{llll}
\text { a. } & \text { Kamau ne } & \text { moremi } \\
& \text { K. } & \text { FM } & \text { farmer } \\
\text { b. } & \text { ne } & \text { moremi } & \text { Kamau } \\
& \text { FM farmer } & \text { K. }
\end{array}
$$

In support of her second claim, she argues that $n e$ only can have scope over the entire $\mathrm{VP} .{ }^{46}$ It cannot focus a part of the verbal complex or a postverbal element. If ne was a particle marking focus, she argues, why can't it appear anywhere but in the three basic positions discussed at the beginning of this chapter? Her answer is, of course, that it cannot move anywhere else because it is generated in INFL and always stays in INFL. And the only way it can focus elements other than the VP is by participating in the cleft-construction.

But what role does ne play then? Bergvall asks us to recall Myers' analysis of $n e$ as a 'higher verb of assertion', and to reconsider the suggested translations for $n e$ given by Barlow as 'did' in its do-support function or as 'It is the case that'. She claims that this approach is essentially correct:

I claim here that the key to all three uses is to take ne as a particle within INFL connoting 'affirmation', in specific contrast to the use of $t i$ and $t a$ as 'negation'. The cover term for the use of both $n e$ and $t i$ is 'assertion', the affirmative and negative forms, respectively. (Bergvall 1987b: 133)

44 Of course, it is crucial how we (and Bergvall) define the notion of focus. Given that Bergvall is not very explicit about this, we will come back to this claim in the light of our undertstanding of focus.

45 Again, it is not clear how she determines what is in focus and what is not.

46 I will argue that this claim is incorrect in the next chapter. 
This, she continues, accounts for a number of facts, namely that ne only appears in asserted sentences (but see qualifications below!), that it does not appear with 'alternative weak focus' (in-situ focus) ${ }^{47}$, that it cannot occur with certain tenses, which Bergvall assumes to "weakly focus the temporal aspect" (Bergvall 1987b: 133), and finally, that it cannot appear in consecutive verb forms either, which she tentatively explains by saying that these assert the linkage of events rather than each individual sentence.

\subsubsection{No ne in Dependent Clauses}

One further question that Bergvall has to answer is, of course, the absence of $n e$ in relative clauses. In order to do this, she proposes an alternative to Clements notion of open clauses, namely the notion of dependent clauses.

She takes independent clauses to be basically the same as Emonds' (1976) root clauses, which are characteristically not subordinated by another verb. Their independence consists in being able "to stand alone as sentences" (Bergvall 1987b: 82). Dependent clauses are then subordinate to another verb and cannot occur alone. Typical independent clauses are simple declarative sentences, and typical dependent clauses are relative clauses. In addition, Bergvall includes the consecutive tenses and the protasis of conditionals in the category of dependent clauses.

There also are some clauses that are subordinate to another verb and yet display independent clause type behavior. These are typically embedded by an 'adsentential' bridge verb (Bresnan (1968), e.g. say, think etc.), which take sentential complements.

The reason that Bergvall gives for the absence of $n e$ in relative clauses, and in dependent clauses in general, is then a semantic one. The information in dependent clauses is not asserted, but rather presupposed, and therefore ne as an assertion marker cannot appear in them. ${ }^{48}$ Clements' argument against this that ne can appear in further embedded clauses is dismissed by Bergvall by pointing out that these examples all contain 'adsentential' verbs like say, which make the following embedded clause potentially independent and allow for the introduction of a new assertion.

One advantage of this account is, of course, that it not only explains the absence of ne in relative clauses, but also in consecutive tenses and the protasis of if-clauses, which all are dependent on another sentence. Clements' open clause theory does not account for these.

\subsubsection{Summary}

Bergvall's account assumes $n e$ to be generated in INFL, and takes it to be a particle of assertion rather than focus. The focal effect in constructions involving preposed constituents preceded by $n e$ is due to the cleft structure of these sentences, not to the particle. In these clefts, $n e$ plays its normal assertive role as a preverbal particle. The only thing special about these constructions (as well as copula constructions) is that the verb is phonologically null, which lets ne and the focused element appear adjacent to each other in surface structure. One major argument for this analysis is that such structures have to be assumed to exist in Kikuyu for independent reasons anyway.

One interesting consequence of Bergvall's account that she does not mention herself is that it would not posit wh-movement in Kikuyu. Generally it is taken to be a rather interesting fact about Kikuyu syntax that it allows for both in-situ and ex-situ questions. In Bergvall's analysis, the alleged ex-situ question words are really in-situ in the clefted part of the sentence. ${ }^{49}$

47 Bergvall frequently refers to in-situ focus as, weak focus', without specifiying in what way it is weaker than preposed focus with ne.

48 Note that this is different from claiming that there cannot be a focus in dependent clauses for semantic reasons. Although Bergvall does not address this question, her examples of cleft-structures in dependent clauses clearly show that it is possible to have a focus in a dependent clause.

49 Of course, one can still have different views about how the cleft is generated - with the question word base generated in the cleft or with movement from the embedded clause to the cleft. So, in any case, the type of movement will be different from regular wh-movement to the $\mathrm{C}$-domain. 


\subsubsection{Clefts or Focus Phrases?}

In the preceding two subsections, we have discussed two quite different accounts for the distribution of the particle ne in Kikuyu. Before we turn to the question whether we have any good reasons so far to prefer one of these over the other, let us look at a comparative overview of how the two accounts explain some of the crucial facts:

\begin{tabular}{|c|c|c|}
\hline $\begin{array}{l}\text { PROBLEM / } \\
\text { FACT TO BE } \\
\text { EXPLAINED } \\
\end{array}$ & CLEMENTS' ACCOUNT & BERGVALL'S ACCOUNT \\
\hline $\begin{array}{l}\text { ne in preposed } \\
\text { focus and } \\
\text { question word } \\
\text { constructions }\end{array}$ & $\begin{array}{l}\text { - Full expansion of the optional } \\
\text { Phrase structure rules COMP } \rightarrow \\
\text { Comp (FOC) and FOC } \rightarrow n e(\mathrm{NP}) \\
\text { - }[ \pm \mathrm{Wh}] \text { specifies whether the result } \\
\text { is a focus or question construction }\end{array}$ & $\begin{array}{l}\text { Biclausal structure; cleft- } \\
\text { sentence with empty subject and } \\
\text { null verb-form } \\
\text { - } \text { ne in preverbal position }\end{array}$ \\
\hline $\begin{array}{l}n e \text { in copula } \\
\text { constructions }\end{array}$ & $\begin{array}{l}\text { - ne has moved down into preverbal } \\
\text { position } \\
\text { - } \text { phonologically null copula verb }\end{array}$ & $\begin{array}{l}\text { - } n e \text { is in its basic position in INFL } \\
\text { - } \text { phonologically null copula verb }\end{array}$ \\
\hline preverbal ne & $\begin{array}{l}\text { - ne has moved down into preverbal } \\
\text { position }\end{array}$ & - $n e$ is in its basic position in INFL \\
\hline one $n e$ per clause & - $n e$ is only generated once per clause & $\begin{array}{l}\text { presumably, it is semantically } \\
\text { nonsensical to mark the assertive } \\
\text { force more than once }\end{array}$ \\
\hline $\begin{array}{l}\text { no } n e \text { in relative } \\
\text { clauses }\end{array}$ & $\begin{array}{l}\text { - The highest node of relative clauses } \\
\text { is } \mathrm{S} \text { (IP) } \\
\text { - The reason for this assumption is } \\
\text { the absence of complementizers or } \\
\text { relative pronouns } \\
\text { - Since FOC is generated in } \mathrm{S}^{\prime}(\mathrm{CP}) \text {, } \\
\text { ne cannot possibly occur in such } \\
\text { clauses }\end{array}$ & $\begin{array}{l}\text { - semantic reason: information in } \\
\text { relative clauses (and other } \\
\text { dependent clauses) is } \\
\text { presupposed, not asserted } \\
\text { - hence, the assertion marker ne } \\
\text { cannot occur }\end{array}$ \\
\hline $\begin{array}{l}\text { ne in subordinate } \\
\text { clauses } \\
\text { introduced by, } \\
\text { e.g., ate }\end{array}$ & $\begin{array}{l}\text { - The highest node of these clauses is } \\
\mathrm{S}^{\prime}(\mathrm{CP}) \\
\text { - hence, they can contain a FOC node } \\
\text { with ne }\end{array}$ & $\begin{array}{l}\text { These are subordinate to bridge } \\
\text { verbs, or verbs of assertion, } \\
\text { which allow for an embedded } \\
\text { assertion to be expressed }\end{array}$ \\
\hline
\end{tabular}

While both accounts seem to have (more or less) reasonable answers to these central issues listed in the table, they also both have their weaknesses and problems.

\subsubsection{Problems of Clements' Account}

The major point that Bergvall is making against Clements is that his account is much more complicated than hers, and this for reasons that are unnecessary. The type of structure she is supposing (that of copula constructions with empty subjects and a phonologically null verb form) exists in Kikuyu anyway, so why not extend it to the $n e$-focus sentences.

Furthermore, Bergvall rightly points out that Clements' open clause account is only partially adequate. While the observed morphological effects are always present in the clause from which an element is extracted, the other inbetween open clauses in examples such as in (43) only display the downstep effect. Furthermore, Clements account would have to be refined in order to distinguish between topicalization and focus-constructions. Topicalization constructions contain, according to Clements' account, an open clause, yet they do not display any of the phenomena

50 Bergvall does not talk abou this issue, but this seems like a likely argument from her viewpoint. 
associated with this type. Clements seems to not be aware of this problem, even though he himself provides examples for such constructions (Clements 1984a: 43):
a. mbere ya mo-te oó-reǎ Kámá.'ú a-ón-'îré Kaanáké! front of 3-tree PP-DEM K. SM-see-T K. In front of that tree Kamau saw Kanake
b. né mbére ya mo-te oó-reă Kámá.'ú a-ón-'îré Kaanake FM front of 3-tree PP-DEM K. SM-see-T K. It's in front of that tree that Kamau saw Kanake

Note the presence of the downstep after Kanake in (a), which contains a topicalized element, and its absence in (b), in which the same element is put into preverbal focus. Also, verbal negation in (a) would be formed with $t i$, and in (b) with $t a$. Nevertheless, one might assume the preposed phrase to be base-generated somewhere lower in the clause in both sentences and hence assume movement. This would result in both sentences fulfilling the condition on open clauses, yet only (b) displays the relevant effects. A possible solution for this could be to assume that the topic is base generated in the topic position.

Taking into consideration more recent syntactic theory, Clements' account also has the disadvantage of not being able to provide an account in which the generally agreed upon requirement can be met that wh-question words have to c-command their traces when moved.

Also, Clements does not have an obvious explanation for the absence of $n e$ in certain tenses, as listed by Barlow. It is not clear whether the argument for relative clauses, that they only consist of IP's, would go through for all of these as well. Bergvall, on the other hand, has a semantic motivation for this phenomenon, applying her notion of dependent clauses, whose information is not asserted.

Finally, Clements has to suppose downward movement of ne in the case of preverbal ne and its special case in copula constructions. Bergvall, on the other hand, never has to assume any movement for $n e$, and can maintain that it stays in its base position in INFL in all cases.

\subsubsection{Problems of Bergvall's Account}

Bergvall does not have an explanation as elegant as Clements' for the fact that only one ne occurs per clause. She does not discuss the issue, but all she could claim is that it is not reasonable to mark the assertive force of a sentence more than once.

Even more seriously, Bergvall's account depends, to quite an extent, on the assumption that $n e$ only occurs in assertions. But obviously, as we have seen all along, ne also appears in questions. In regard to the occurrence of ne with preposed question words (i.e., in Bergvall's terms, question words in clefts), she says that "these $n e$-initial questions [...] assert that there is some $\mathrm{x}$ which fulfills the question asked by the rest of the clause" (Bergvall 1987b: 170). Though it might be assumed that constituent questions presuppose that there is an $\mathrm{x}$ that fulfills the requirements of the question (or at least, expressed more weakly, that it is possible that there is such an $\mathrm{x}$ ), it seems unreasonable to claim that such questions assert this. As a matter of fact, if this notion of assertion is understood in any way related to being a speech act, it is unclear how the speech act of asking a question can at the same time be an assertion (or contain an assertion). Furthermore, there are not only wh-questions containing ne, but also questions involving preverbal or focal ne, as can be seen in the following two examples from my informant:

$$
\begin{array}{lll}
\text { a. Abdul ne-a-ra-nyu-ir- }-\varepsilon & \text { ma-e? } \\
\text { A. FM-SM-T-drink-ASP-FV } & 6 \text {-water } \\
\text { Did Abdul drink water? } &
\end{array}
$$$$
\begin{array}{lll}
\text { b. ne ma-e Abdul a-ra-nyu-ir- } \varepsilon \text { ? } \\
\text { FM 6-water A. } & \text { SM-T-drink-ASP-FV }
\end{array}
$$

Is it water that Abdul drank? 
These differ from their assertive counterparts only in intonation.

Now, while it is clear that yes/no questions are straightforwardly related to assertions, they themselves surely are not assertions. If Bergvall was to extend her argument for constituent questions above to cases like (69b), it would certainly not make any sense: She would have to say that the person uttering the question in (69b) is asserting that it is water that Abdul drank. But that, of course, is not the point of asking that question, which is aiming to find out whether it is true that it was water that Abdul drank. It seems that some substantial modification is necessary to make Bergvall's account adequate in this respect.

Finally, even though Bergvall can account for a number of facts in a simpler manner than Clements, she does not really have any forceful reasons for us to accept her cleft-analysis, i.e. she can only show that such constructions are possible in Kikuyu, but not that all constructions involving focal $n e$ have to be analyzed as clefts.

\subsubsection{Conclusion}

Given the comparison of these two accounts and considering the problems they each have, there seems to be no clear decisive reason to accept either one or the other. Both accounts have their intriguing aspects, but, as we have seen, they also both face some serious problems. The problems that Clements' account has to face are mostly of a rather technical nature, and they might be overcome by adjusting the formal mechanisms that are supposed to generate the right structures. Bergvall's account, on the other hand, is formally more simple and seems to make good predictions. It does face, however, the principle problem of the occurrence of $n e$ in questions discussed in the previous section, and it is not clear what type of modification would solve this problem. In any case, it would have to be a substantial, not just a technical, change in her account.

So which account is more promising as a basis for further theorizing? In the next chapter, I will first provide some data that makes it impossible to keep up the cleft-analysis. In the remainder of the chapter, then, I will try to develop a theoretical account for focus constructions in Kikuyu that includes the assumption of a focus phrase in Kikuyu syntax but avoids the problems of Clements' account mentioned above.

\section{New Evidence and a New FP-Analysis}

The previous chapter has left us with an open question: How could we decide which analysis for the preposed ne-constructions would be more promising, Bergvall's cleft-analysis or Clements' focus phrase analysis? In this chapter, I will try to argue against the cleft-analysis, and propose a new version of the focus phrase analysis. In the first section, I will present new data from my informant, which will serve as a basis for an argument against the cleft-analysis. The discussion of this data will lead to a new account for the preposed $n e$-sentences in the second section. After sketching this new analysis, I present more data with different parts of the sentence in focus. This goes beyond what has been known in the literature up to this point and includes focus on the verb, the VP, and the entire sentence.

\subsection{Arguments Against Analyzing Focal ne-Constructions as Clefts}

What kinds of arguments could we hope to find to decide the question whether focus constructions involving $n e$ are clefts or not? A reasonable approach would seem to be that we compare the alleged cleft-constructions with other, clearly bi-clausal constructions and test whether they show the same behavior. This is what I will do in this section, and the conclusion will be that the behavior of focus constructions differs from bi-clausal constructions in several respects, and therefore that the former are not bi-clausal, and hence not clefts.

The first and most important argument comes from the possibility of topicalization in connection with focus constructions and clearly bi-clausal constructions. This will be presented in the next subsection. A further argument involves an alternative type of focus constructions as 
well focus constructions involving locative predication, and this will be presented in 4.1.2. Finally, the fact that questions with a preposed question word preceded by $n e$ can participate in multiple interrogation can also be taken as evidence that these are not cleft-constructions.

\subsubsection{Topicalization and Focus Constructions}

Both Bergvall and Clements are aware of topic constructions in Kikuyu, and Bergvall (1987) actually dedicated a whole section to their discussion. ${ }^{51}$ However, neither one of them is looking at possible combinations of topic and focus constructions. Before we turn to this issue, let us look at simple topicalization constructions. Turning to complex sentences, we will see that the possibility of topicalization is subject to a clear restriction. This restriction, together with the possible combination of ne-focus and topicalization, will shed light on the structure of the focus constructions.

\subsubsection{Simple Topicalizations and/or Left Dislocations}

The typical examples of topicalizations in Kikuyu, as they are also noted by Bergvall and Clements, involve a left dislocation of an element, without ne preceding it (example taken from Clements 1984: 43):

$$
\begin{aligned}
& \text { a. mbere ya mo-te oó-reǎ Kámá.'ú a-J́n-'îré Kaanáké! } \\
& \text { front of 3-tree PP-DEM K. SM-see-T K. } \\
& \text { In front of that tree Kamau saw Kanake }
\end{aligned}
$$

Normally, the prepositional phrase mbere ya mo-te oó-reă would appear at the end of the sentence. This type of fronting is possible with about any postverbal constituent. As Bergvall notes, there is a difference between extracting human and non-human objects of the verb. The former require (more or less rigidly) that a resumptive pronoun is inserted in the verbal complex (which is realized as an object prefix), while this is optional in the latter case, as can be seen in (71) (Bergvall (1987b: 63), glosses modified by F.S.) $)^{52}$ :

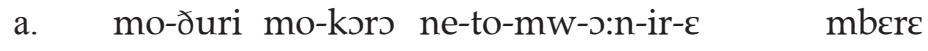

$$
\begin{aligned}
& \text { 1-man 1-old FM-SM(1PI)-OM-see-ASP-FV first } \\
& \text { The old man, we saw him first }
\end{aligned}
$$

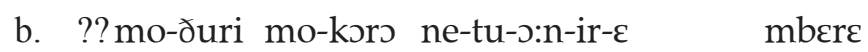

$$
\begin{aligned}
& \text { 1-man 1-old FM-SM(1PI)-see-ASP-FV first } \\
& \text { The old man, we saw first } \\
& \text { c. ka-ori ka-niini ne-to-ka-on-ir- } \varepsilon \text { mbere } \\
& \text { 12-goat 12-little FM-SM(1PI)-OP-(12)-see-ASP-FV first } \\
& \text { The little goat, we saw it first } \\
& \text { d. ka-sri ka-niini ne-tu-on-ir- } \varepsilon \text { mbere } \\
& \text { 12-goat 12-little FM-SM(1PI)-see-ASP-FV first } \\
& \text { The little goat, we saw first }
\end{aligned}
$$

Bergvall argues that the distinction between Topicalization and Left Dislocation can be collapsed in Kikuyu. Left Dislocation, according to Bergvall, is distinct from Topicalization in that it requires a resumptive pronoun in the clause from which dislocated element has been extracted. She argues that in cases like (71d) there is a null pronominal, which is not implausible as nonhuman objects can regularly be realized as phonologically null pronouns (Bergvall 1987b: 50).

\footnotetext{
51 Note that the notion of topic is used in quite different ways in the literature. Here it simply is taken as a syntactic process, partly due to lack of discourse evidence for topichood in my data.

52 My informant judges both (b) and (d) as ungrammatical. Hence, Bergvall's distinction of human and non-human objects does not seem to be relevant to him.
} 
But, on the other hand, one could argue that human objects are the only forms that require pronominal doubling when moved to the front of the clause. Temporal and locative adverbials, for example, which can be pronominalized with free standing pronouns, do not allow for pronominal doubling in these types of constructions, as Bergvall herself notes (Bergvall (1987b: 54, 56), her glosses):

a. nemaðiire res

They left then

b. ro:fi:ne, nemaðiire

This morning, they left

c. * ro: $i$ i:ne, nemaðiire res

This morning, they left then

(73) a. Wamboi neayitirs kus

Wambũi thatched there

b. (?) Nyeri, Wamboi neayitire $\varepsilon^{53}$

(In) Nyeri, Wambũi thatched

c. * Nyeri, Wamboi neayitire kuo

(In) Nyeri, Wambũi thatched there

The free pronouns can never be incorporated. This is only possible for object pronouns.

Fortunately, we do not have to ultimately decide at this point what the nature of the Topic or Left Dislocation structures is. First of all, that is not our central concern in this study, and secondly, we can form our argument on the basis of regular restrictions on this type of movement that are not dependent on an exact analysis. In the following section, I will use non-arguments in the examples, leaving it open whether these are topics or left dislocated elements. Shortly, we will see that there also is evidence for topicalization of subjects.

\subsubsection{Restriction for Topicalization}

The first restriction we can observe is that relative clauses do not seem to allow for any type of topicalization at all, neither within the clause nor outside of it:

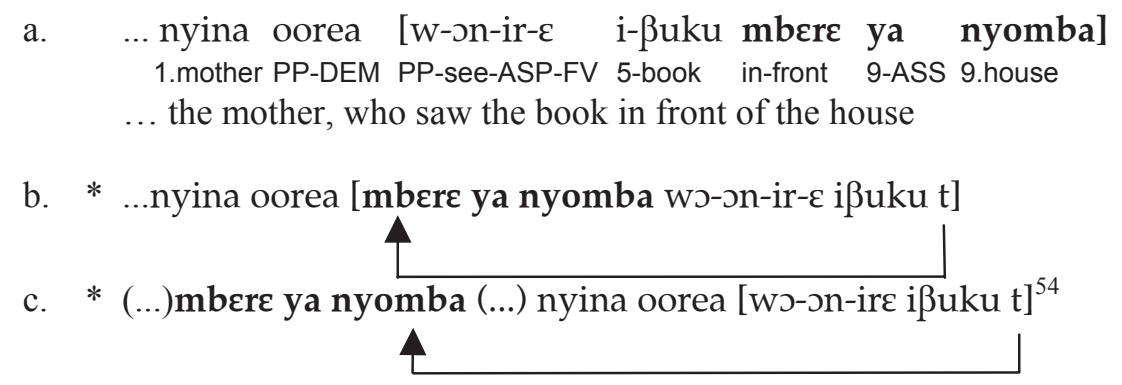

In other cases of complex sentences, however, topic movement is also possible in embedded clauses that are introduced by a complementizer like ate. However, the movement has to take place within the clause introduced by ate: ${ }^{55}$

53 Bergvall's informant(s) judge(s) this sentence as not being perfectly acceptable, my informant finds it okay, although there seems to be a slight, gradual distinction between ( $72 \mathrm{~b})$ and (73b). Fronted locatives seem to be better when a complex prepositional phrase, such as, in front of the tree' in (70a), is used.

54 The brackets indicate that this structure is impossible in the case of moving into sentence initial position as well as in the case of having it immediately precedethe head of the relative clause. 
a. Abdul ne-uy-ir-e [ate nyina ne-s:n-ire ißuku mbere ya nyomba] A. FM-say-T-FV that ?.mother FM-see-T-FV 5-book in-front 9-ASS 9.house Abdul said that (his) mother saw a/the book in front of the house.

b. Abdul ne-uy-ire [ate mbere ya nyomba nyina ne-s:nire ißuku t] Abdul said that in front of the house (his) mother saw a/the book.

c. \# mbere ya nyomba Abdul ne-uy-ire [ate nyina ne-s:nire ißuku t]<smiles>[3H]</smiles>

In front of the house, Abdul said that (his) mother saw a/the book.

Just as in the English paraphrase, (75c) can only be understood to mean that the event of Abdul saying something took place in front of the house, not that the event in the embedded clause took place there.

In sentences parallel to Bergvall's example in (65b) above, which also contains an embedded clause introduced by ate, we find the same pattern:

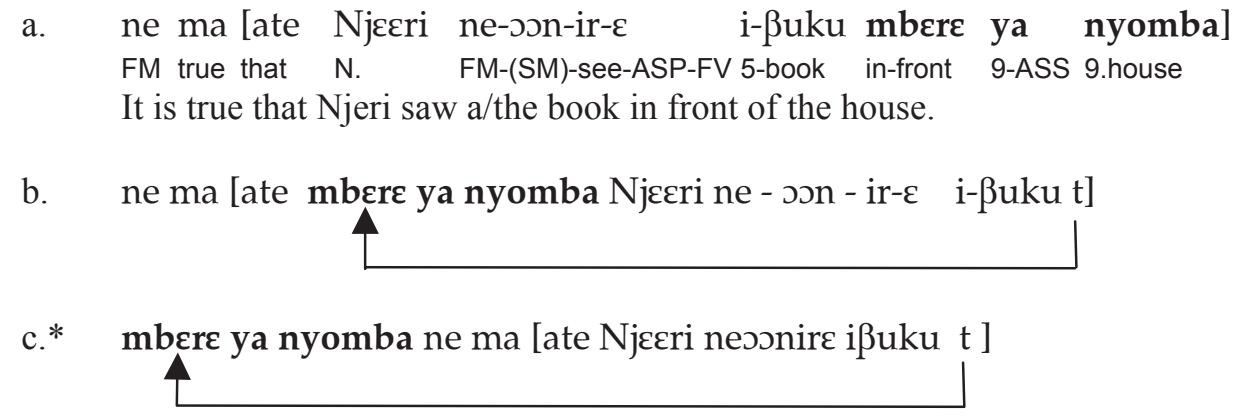

Finally, if we look at another structure that clearly seems to be biclausal, the embedded clefts formed with are, we also find that topicalization is not possible outside of the clause of the topicalized element, i.e. it can not appear in front of the cleft. (77a) is a variation of Bergvall's example in (63b):

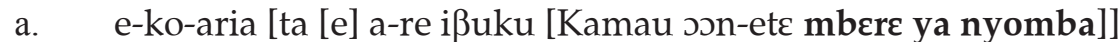 He speaks as if it is a book Kamau had seen in front of the house
b. * e-ko-aria ta mbere ya nyomba [e] a-re ißuku [Kamau oon-ete $\mathrm{t}$ ]

Whatever the exact analysis of (77b) would look like, it seems clear that the situation here is parallel to the case of the ate-clauses, namely that ungrammaticality shows up when the topicalized element is moved out of the clause. ${ }^{56}$ In more or less informal terms, we can state the restriction observed in this section as follows

\section{Restriction on Topicalization / Left Dislocation}

Topicalization and/or Left Dislocation can only occur within the clause of the topicalized / left dislocated element.

\footnotetext{
55 Note that this is different from the case of unbounded focus-movement, as we have seen it in Clements' examples above, e.g. in (43a).

56 In (77), there also cannot be any movement within the furthest embedded clause, because it is a relative clause. As we have seen in (74), no topic movement is possible in relative clauses.
} 


\subsubsection{Topicalization and ne-Focus}

Obviously, the restriction observed in the previous section can serve as a clear test for the nature of focus constructions involving ne. If these are clefts, and hence biclausal, as Bergvall claims, then it should be impossible to topicalize an element from the embedded clause by putting it in front of the clause initial ne. If it is possible, on the other hand, to put such topicalized elements in front of ne, this shows that $n e$-constructions are not biclausal, and hence not clefts.

As we already have seen in the beginning of chapter 3, there are focus constructions that have a sentence-initial subject followed by a focused constituent preceded by ne. Only after this comes the rest of the verbal complex. I claim that these structures are also examples of some sort of topicalization. They are possible not only with subjects, but also with other elements preceding the $n e$-focus construction.

(78a) repeats the example in (25f) above (with an additional locative), which answers the question Who read the book to the child in front of the house? In (78b) a variation of this sentence is shown with another element in a topicalized position.

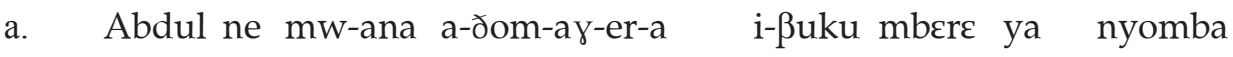

$$
\begin{aligned}
& \text { A. FM 1-child SM-read-HAB-APPL-FV 5-book in-front 9-ASS 9.house } \\
& \text { It is a child that Abdul (usually) reads a book to in front of the house. }
\end{aligned}
$$

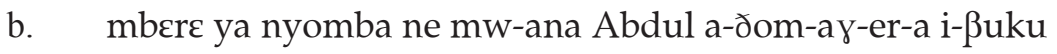

$$
\begin{aligned}
& \text { c. mbere ya nyomba Abdul ne mw-ana a-ðom-ay-er-a i-ßuku }
\end{aligned}
$$

As can be seen in (c), it also is possible for more than one constituent to appear before the preposed ne-focus. This type of topicalization of the subject (or some postverbal element) is possible in all focus constructions involving a fronted constituent preceded by $n e$, be it an element in focus or a question words. The following list illustrates this possibility for the other examples from section 3.1 in chapter 3:

$$
\text { a. }
$$$$
\begin{aligned}
& \text { Abdul ne-kee a-ðom-ay-er-a } \quad \text { mw-ana? } \\
& \text { A. FM-what SM-read-HAB-APPL-FV } \\
& \text { What does Abduld read to the child?. }
\end{aligned}
$$

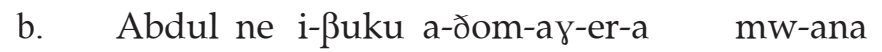
A. FM 5-book SM-read-HAB-APPL-FV 1-child It is a book that Abdul reads to the child.

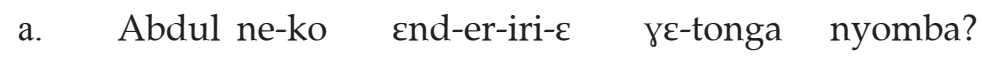
A. FM-where (SM)-sell-ASP-FV 7-rich person 9.house Where did Abdul sell the house to the rich person?

b. Abdul ne Nairobi $\varepsilon$ nd-er-iri- $\varepsilon$ ye-tonga nyomba It's in Nairobi that Abdul sold the house to the rich person

a. Abdul ne-re $\quad$ nd-er-iri- $\varepsilon \quad \gamma \varepsilon$-tonga nyomba? A. FM-when (SM)-sell-APPL-ASP-FV 7-rich person 9.house When did Abdul sell the house to the rich person?

b. Abdul ne ira $\varepsilon$ nd-er-iri- $\varepsilon$ $\varepsilon$-tonga nyomba It was yesterday that Abdul sold the house to the rich person

When we turn to the biclausal constructions discussed in the previous section, however, it is not possible to move the subject outside of its clause: 
a.

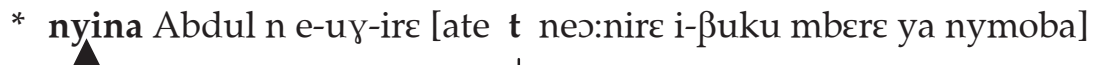

Abdul said that the/his mother saw a book in front of the house

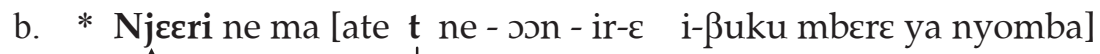<smiles>[3H][3H]</smiles>

It is true that Njeeri saw a book in front of the house

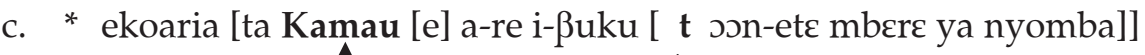<smiles>C=C[Te]</smiles>

He speaks as if it is a book Kamau had seen in front of the house

Bergvall's analysis assumes that $n e$-focus sentences and sentences like (82b) and (c) have the same structure, namely the one given in (60) above. If this was true, there would be no clear explanation why $n e$-focus sentences do allow for topicalization of the subject or other elements into a postion preceding the alleged cleft, and sentences like (82b) or (c) do not. Therefore, there seems to be good reason to assume that these two types of structures are different.

Interestingly, embedded clauses introduced by ate display the same variation in $n e$-focus constructions and topicalizations as main clauses:
a.
Abdul ne-uyire

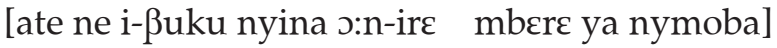
A. FM-(SM)-say-ASP-FV that FM 5-book mother (SM)-see-ASP-FV front ASS 9.house Abdul said that it was a book that the/his mother saw in front of the house.
b. Abdul ne-uyire [ate nyina ne ißuku o:n-ire mbere ya nymoba]
c. Abdul ne-uyire [ate mbere ya nymoba ne ißuku nyina s:n-ire]

(83a) shows the 'normal' focus construction in the embedded clause, with initial ne. In (b), the subject nyina is moved to a position preceding the focus, and in (c) the locative phrase in front of the house is moved into the initial position of the embedded clause, preceding ne.

\subsubsection{Conclusion}

Given the phenomena presented in the last subsection it seems reasonable to conclude that $n e$ focus constructions are not biclausal, and hence not clefts. Furthermore, the different behavior of relative clauses and embedded clauses introduced by ate can be used to support Clements' claim that relative clauses have IP as their highest node, while ate-clauses are CP's. This is plausible if we assume that the type of movement we have presented in this section, be it topicalization or left dislocation, is movement to the $\mathrm{C}$-domain. ${ }^{57}$ If a clause does not contain a $\mathrm{CP}$, topicalization is impossible, just as $n e$-focus is impossible in the same clauses (for the same reason). These considerations will be picked up when we turn to a new analysis.

For now it suffices to note that the different behavior of $n e$-focus constructions and biclausal constructions can be easily explained if we assume the former to be mono-clausal.

\subsubsection{Locative Focus and an Alternative Focus-Construction}

A further argument against a biclausal analysis of focus constructions involving $n e$ comes from phenomena related to locative focus and to an alternative focus construction.

As we have seen above, the verb -re is used in constructions in which the predicate expresses the location of the subject. This is again exemplified in (84):

57 If topicalization and left dislocation turn out to be distinct, the former could plausibly be assumed to be movement into Spec-CP, while the latter might be adjunction to $\mathrm{CP}$. 


$$
\begin{aligned}
& \text { a. Kamau a-re Nairoßi. } \\
& \text { K. } \text { Samau is in Nairobi }
\end{aligned}
$$

This same form is also used in the case of a phonologically null anaphoric subject, as the second sentence in the following example shows:

$$
\begin{aligned}
& \text { a. Kamau ne-a-hor-ir- } \varepsilon \text { dimo omoði. a-re Nairoßi } \\
& \text { K. FM-SM-call-ASP-FV phone today. SM-be-in N. } \\
& \text { Kamau called me today. He's in Nairobi. }
\end{aligned}
$$

Based on this example, we might expect that in cases where a location is the preposed focus, the verb form are would appear as well (as in (86b)), if we assume that the fronted part of the sentences consists of a cleft. But this is not the case. In all cases of focus on an expression for a location, $n e$ is used when the construction involves preposing the fronted constituent. Hence, only, (86c) is an appropriate answer to the question in (86a):

$$
\begin{aligned}
& \text { a. neko Kamau are? } \\
& \text { b. * are Nairoßi Kamau } \\
& \text { c. ne Nairoßi Kamau are }
\end{aligned}
$$

This evidence may not be sufficient by itself to decide the question whether (c) is a cleft or not. But it can serve as another argument against the cleft-analysis if we consider how a focus phraseanalysis can explain this fact. The reason for the ungrammaticality of (b) becomes clear when we analyze the structure in (c) as a focus phrase introducing ne and Nairobi as being moved from its base position (which is postverbal) into the position for the focused element. Naturally, the verb are is then in the wrong place in (b), because only the focus marker ne can appear in this position.

Another, similar, argument comes from an alternative focus construction that we have not mentioned yet. In addition to a preposing of the focused element it involves the insertion of a pronominal expression:

$$
\begin{aligned}
& \text { a. Noo Kamau oonire? } \\
& \text { Who did Kamau see? } \\
& \text { b. Abdul ne we Kamau o-on-ir- } \varepsilon \\
& \text { A. FM 3Sg.PRON K. (SM)-T-see-ASP-FV } \\
& \text { It is Abdul (that) Kamau saw } \\
& \text { c. Kamau Abdul ne we oonire }{ }^{58}
\end{aligned}
$$

As can be seen in (b), the focused element actually precedes ne in this construction, and the pronoun showing concord agreement with the focused element immediately follows ne. Considering Bergvall's analysis, we might assume that here we really have encountered a type of cleft-construction (which could be paraphrased as Abdul is the one (that) Kamau saw), but the data in (87c) indicates that this is not the case, at least if the argument in the previous section is correct. An analysis for this construction will be discussed in 4.2.10. But for now, let us look at the interesting case where this construction involves a first person singular pronoun in focus. The following example shows the according form and an appropriate question context.

$$
\begin{array}{ll}
\text { a. Noo W- } \quad \text {-end-iri- } \varepsilon \text { nyomba? } \\
\text { FM-who PP-sell-ASP-FV } & 9 . \text { house } \\
\text { Who sold the house? } &
\end{array}
$$

58 It should be noted that my informant did not like this sentence as much as topic-focus combinations of the type discussed up to this point. 
b. nie ne nie nd- $\varepsilon$ nd-iri- $\varepsilon$ nyomba

1Sg.PRON FM 1 Sg.PRON SM-sell-ASP-FV 9.house

It is me who sold the house. or:

I am the one who sold the house

If the construction in (88b) would involve a true copula construction, we would expect that the regular first person present tense form for the copula appears, as exemplified in (89):

$$
\begin{array}{lll}
\text { a. } & \text { nde } & \text { moremi } \\
& \text { 1Sg.COP } & \text { 1-farmer } \\
\text { I am a farmer }
\end{array}
$$

But instead, the construction in (88b) uses the particle ne. Hence, not even this type of construction, which very much looks like it involves some form of clefted copula construction, seems to contain a copula.

Just how these constructions are to be analyzed is unclear at this point. But if we consider the fact that ne appears here, and also in similar cases involving a first person plural or a second person (singular or plural) pronoun, which all come with forms for the copula verb distinct from ne, or rather, distinct from the zero verb form found for the third person, there does not seem to be a way to analyze this as involving a cleft.

Taking into account these two cases - the one of locative focus and the one of the alternative focus construction in (88b) - it seems like we can turn around Bergvall's argument, claiming that there are cases where a cleft-analysis is not possible for $n e$-focus constructions, and extending the alternative account of $n e$ as a focus marker to other constructions involving a fronted constituent preceded by $n e$. This will result in a more adequate account as the possibility of topicalization can be explained.

\subsubsection{Multiple Wh-Questions}

Yet another reason against analyzing the ne-constructions with a preposed constituent as clefts can be seen in the fact that such constructions can participate in multiple wh-questions: ${ }^{59}$

$$
\begin{aligned}
& \text { a. Noo W- } \quad \text { nd-iri- } \varepsilon \text { kee? } \\
& \text { FM-who PP-sell-ASP-FV what } \\
& \text { Who sold what? }
\end{aligned}
$$

There do not seem to be any restrictions on multiple wh-constructions. If the subject is one of the wh-elements, then it has to be the element that is preposed with ne. This is not surprising, since subject wh-elements always have to be preposed. It seems like there are no superiority effects, i.e., if there are multiple postverbal wh-elements (and the subject is not wh), then any (or none) of these elements can be preposed. It also seems like these multiple wh-questions come with both a pair-list and a single pair reading. However, these issues need to be investigated more thoroughly than it was possible for me to do.

What is important for our argument at this point is that it is (at least) extremely uncommon to have multiple wh-constructions that involve a cleft-fronting strategy for one of the wh-elements. This is, for example, not possible in German or English:

$$
\begin{aligned}
& \text { a. * Who is it that sold what? } \\
& \text { b. * Wer ist es, der was verkauft hat? }
\end{aligned}
$$

If the generalization that clefts cannot participate in multiple questions is correct, then the possibility of fronted wh-constructions in Kikuyu to participate in multiple wh-constructions speaks against the cleft-analysis.

59 Thanks to Anna Szabolcsi (p.c.) for pointing this out to me. 


\subsection{A New Account of Focus Constructions in Kikuyu}

The arguments in the preceding section showed that focus constructions with a preposed constituent preceded by ne cannot be analyzed as clefts. Therefore, we should come back to Clements' idea of introducing a focus phrase into Kikuyu phrase structure. Doing this, we also should address the problems we have found with Clements' account.

In the following subsection I will propose a general phrase structure for Kikuyu sentences that involves a focus phrase, but avoids the problems of Clements' account. In the subsequent sections, I will consider how different elements can be put in focus, presenting new data for a number of constructions. The goal throughout this is, of course, to try to explain the data within the theoretical approach outlined in the next subsection. However, I will also present some data for which I can give no explanation, but which should be interesting for further research. Towards the end of this section, I will also consider the question of contrastive focus, and the alternative focus construction mentioned in the last section.

\subsubsection{Syntactic Focus Marking in Kikuyu}

Taking a step back and considering the data we have discussed so far, it should be noted that both Bergvall's and Clements' accounts take focus to be determined by syntactic (or morphosyntactic) factors. And indeed, the variation in possible expressions for question-answer sequences mainly occurred in the order of the elements in a sentence. This is different from cases like English or German, for example, where there also can be some syntactic variation related to focus, but where the main factor is intonation, namely the placement of the pitch accent. But as we have mentioned in chapter 2, there are many other languages for which it has been argued that there is a syntactic position reserved for focus, so called discourse configurational languages (cf. Kiss (ed.) 1995). We discussed the example of Hungarian to illustrate this property. In (19) we saw the two variations on the assumption of a focus phrase in Hungarian syntax, either immediately dominating VP or IP.

The central idea that we can adopt from such approaches dealing with syntactic, or structural, focus is the position of the focus phrase.$^{60}$ One problem of Clements' account was that the element moved into the focus position did not c-command its trace, a requirement that most syntactic theories would posit in one way or another. This problem evolved because the focus phrase was embedded in the $\mathrm{CP}$ (or $\mathrm{S}^{\prime}$ ) in Clements' proposal. Adopting the common assumption (illustrated in (19) above) that the focus phrase is situated between the CP and the IP, or alternatively, that it either immediately dominates the IP or the VP, we can avoid this problem. Thus, the general phrase structure for Kikuyu should be something like the following:

a.

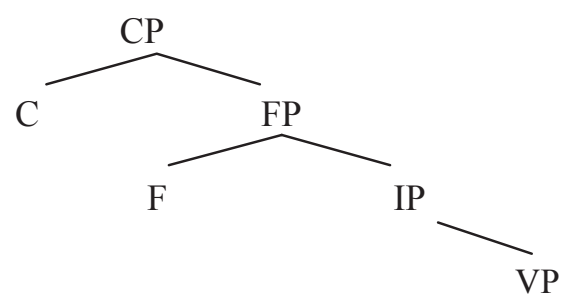

This also accounts for the right word order in the case of embedded clauses, with the complementizer preceding the focus phrase (this was one of the problems Bergvall saw with the assumption of a focus phrase in $\mathrm{CP}$ ), while still leaving room for the subject to appear after the focus, presumably in SpecIP. Hence, for the analysis of preposed focus constructions with $n e$, we could, in a first attempt, propose the following structure:

${ }^{60}$ Horvath (1995) actually already argued for Kikuyu (which in many respects is similar to Hungarian in terms of the expression of focus) that it has a similar phrase structure involving a focus phrase. 


a. (ate) ne $[\text { moremi }]_{F}$ Kamau
(that) FM 1 -farmer วonir $^{61}$
(that) it was a farmer Kamau saw.

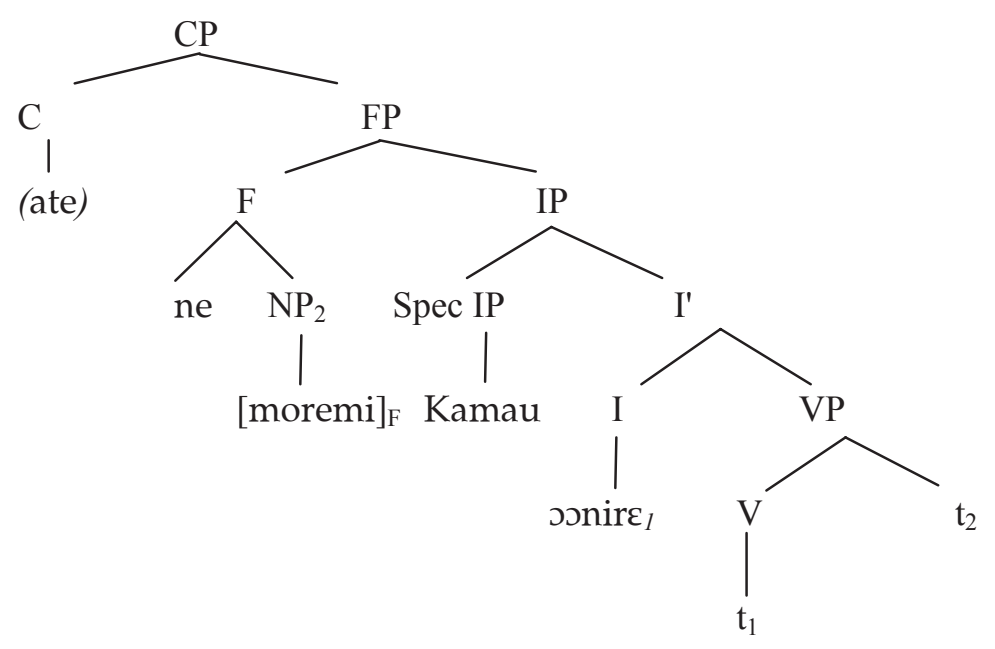

It should be noted that this analysis would need further refinement to be fitted into more elaborate and detailed syntactic frameworks. Crucially, the internal structure of the focus phrase most likely has to be modified. In the Hungarian syntax literature on focus, it is normally assumed that the position for the focused element is the specifier of the focus phrase, SpecFP. The question then is what exactly $n e$ is in such a theory. As Horvath (1995: 41) points out, one cannot assume that $n e$ is the head of the focus phrase and that the focused element moves to SpecFP, because that would get the word order wrong, with ne appearing after the focused element. Alternatively, Horvath suggests to analyze $n e$ as the feature $[+\mathrm{F}]$, which appears in SpecFP, preceding the focused constituent. This might be a better alternative, at least if it can be fitted into a framework where this really adds to the explanatory adequacy of the account, and does not just 'get the word order right'. ${ }^{62}$ As I have not used a syntactic framework in this study that works with feature-checking mechanisms, I will simply leave the internal structure as an open question, assuming that there still is some merit in arguing for a focus phrase analysis of Kikuyu that needs refinement.

In addition to the ex-situ focus construction, we also have found in-situ focus. This type of insitu focus is generally on a postverbal element. In simple sentences containing transitive verbs, the object will be in focus. If we would want to analyze these cases in a parallel way, we could assume a similar structure, just without object movement and with a covert focus operator in place of the overt focus marker $n e$ that assigns focus to the postverbal position. However, the simpler alternative might be to assume that FP is only an optional projection (as in Clements' phrase structure rules above) and that it is not present whenever ne is not present. focus is then assigned to a postverbal element whenever $n e$ is not present. ${ }^{63}$ The phrase structure of a sentence without ne would then be simpler, not containing an FP:

$$
\text { a. (ate) Kamau sonire }[\text { moremi }]_{\mathrm{F}}
$$

61 Henceforth, I will mark the focus of a sentence (as determined by the context) with brackets and a subscript $F$, following the assumption that there is a syntactic feature [F] that marks focus (Jackendoff 1972). In the rare cases, where the (focus-determining) context of the sentence is not given explicitly, it can be constructed by asking for the focused constituent.

62 There might be a problem, however, with the alternative focus construction introduced in 4.1.2. (which is discussed again in 4.2.10).

63 This phenomenon, by the way, poses another serious problem to the cleft-analysis: If ne (be it preverbal or with a preposed constituent) is assumed to be an assertion marker, as claimed by Bergvall, then it is unclear why the absence of ne should trigger focus on a postverbal element. 


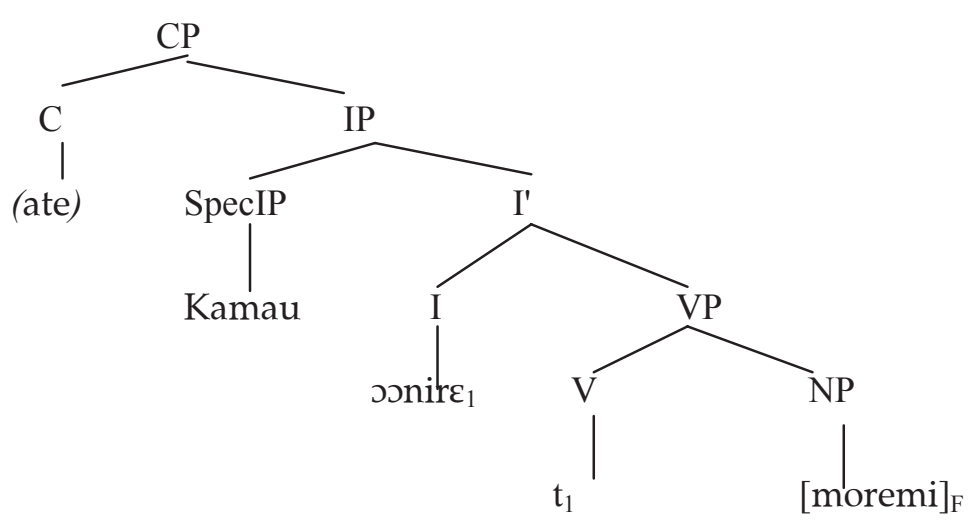

It should be noted at this point that it is unclear how the focus is determined when there is more than one postverbal element. It may be that such structures are simply ambiguous, because there is no clear evidence that there are tonal differences between these cases.

Looking just at the formal mechanism involved here, we have to ask ourselves how we could generate the preverbal occurrence of $n e$. Before we try to answer this question, we should recall the data on topicalization and left dislocation from above. It is not a goal of this study to determine the exact internal structure of the topicalized or left dislocated element, though that would be an interesting topic for further research. ${ }^{64}$ But at least one thing is clear with respect to them: They have to end up in some position between the complementizer position and the focus phrase. The evidence for this comes from embedded clauses introduced by ate, which allow for a subject (or some element that is normally in some postverbal position) to precede the $n e$-focus phrase. To account for this, then, I will assume a topic phrase between the $\mathrm{CP}$ and the FP, into which topicalized elements can go. ${ }^{65}$ As already mentioned, we may have to distinguish between left dislocated elements and topicalized elements, but the details concerning the topic phrase will be ignored here. A clause (non-embedded or embedded by ate) with a topicalized and a preposed focused element then would have the following structure:

$$
\text { a. }
$$

(...ate) Kamau ne $[\text { moremi }]_{F}$ oonire

$$
\text { (...that) K. FM 1-farmer }
$$

(that) it was a farmer Kamau saw

(SM)-T-see-ASP-FV

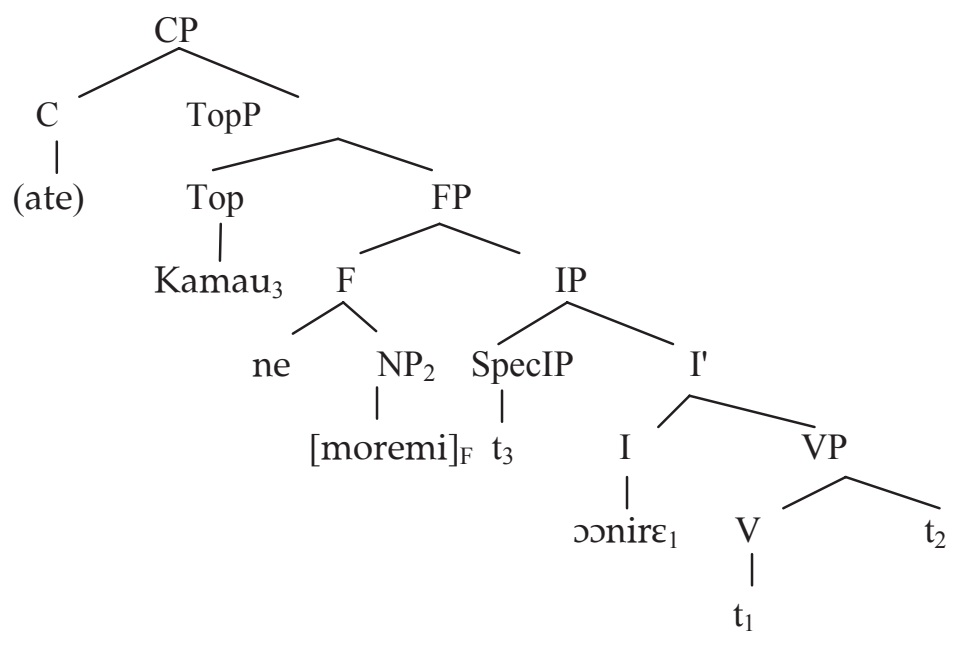

64 Possibly the distinction between internal and external topic, as it has been proposed for Mayan by Aissen (1992), could be applied here.

65 Similar claims have been made for Hungarian (most recently in Puskás (2000), chapter 3). If we would find further discourse evidence for the topichood of these fronted constituents, this would mean that Kikuyu was discourse configurational in respect to topic as well (see chapter 2). 
If we assume that there is some kind of position for the subject to move into, as in (95), then this also might be the solution for the generation of preverbal focus. If the subject is moved into the topic position and everything else stays in place, then we get the correct linear order for constructions involving preverbal ne. It might actually be reasonable to assume some other movement, e.g. of the verbal complex or of a speech act or truth operator into the focus position. But these should not affect the linear order of the surface structure. We will come back to these questions in the section on sentence and verum focus.

In principle, we also can account for the case of $n e$ in copula constructions. The right word order would be obtained, for example, if we assume that ne there appears in preverbal position, with the actual verb being phonologically null. There are some problems, however, in connection with copula constructions, which I will discuss in section 4.2.7. Nonetheless, the account proposed here can account for the constructions at least to the same extent as Bergvall's analysis.

For now it should suffice to show that we can easily provide the right word order for the case of preverbal focus and $n e$ in copula constructions as well. Note that it is not necessary to assume any movement of $n e$, as was done by Clements. Since we have independent evidence for movement of the subject into some kind of topic position, it seems reasonable to also posit this movement in the case of preverbal ne. The motivation for this movement is that the subject would be in the way between $n e$ and the verb. If it would stay in its position and ne would be inserted in the sentence, then we would get a subject-focus sentence. Therefore the subject has to move in order to get a sentence with the meaning of preverbal ne. ${ }^{66}$ The structure would then be as follows (leaving open the question of movement of the verb or something else):

$$
\begin{array}{llll}
\text { a. } & \text { Kamau } & \text { ne-J-Jn-ir- } \varepsilon & \text { mo-remi } \\
\text { K. } & \text { FM-(SM)-T-see-ASP-FV } & \text { 1-farmer }
\end{array}
$$

Kamau saw moremi

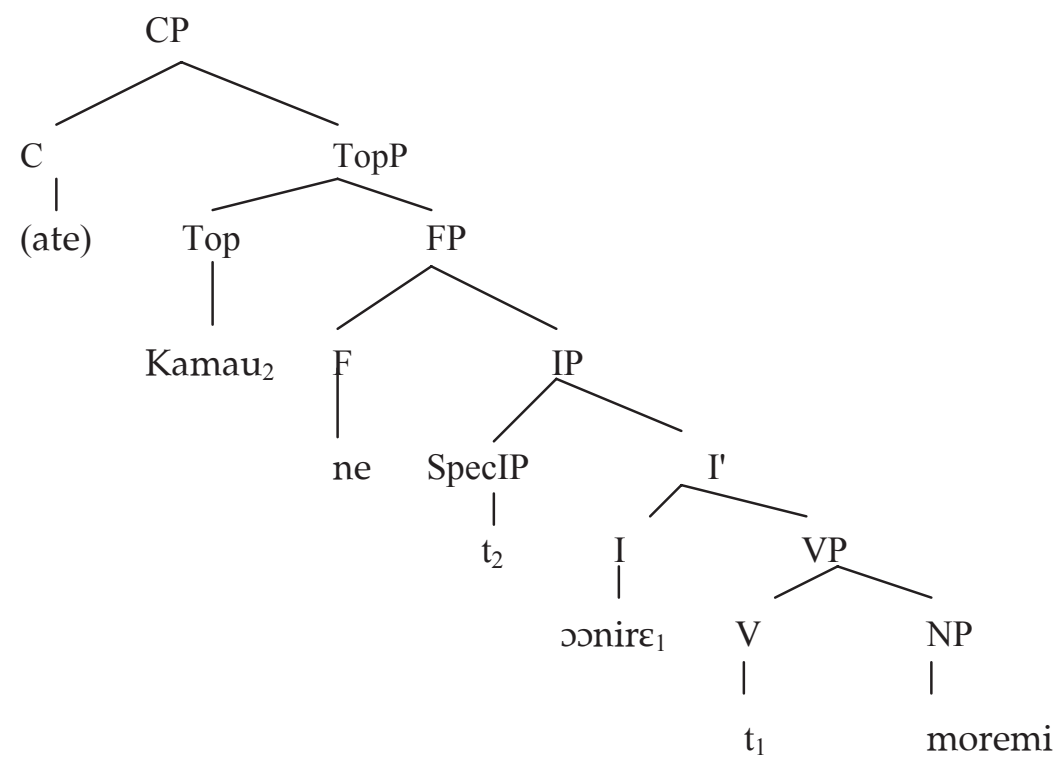

The full range of variation in connection with the projections introduced here can then be described in general terms in the following scheme:

66 What type of focus is involved in the case of preverbal ne will be discussed in section 4.2.6. 
(97)

a.

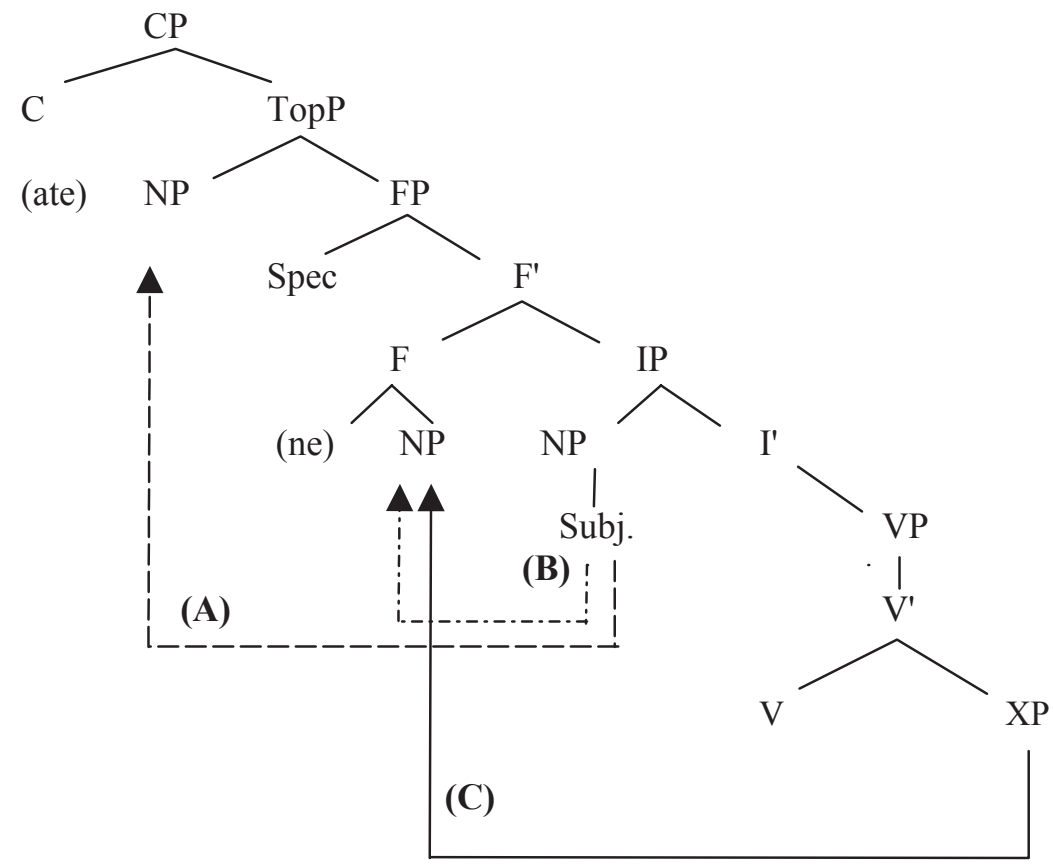

Movements A and B as well as B and C exclude one another, as one element can only undergo one of the movements and only one element can move to the same position. To get preverbal ne, movement A will be sufficient for the right word order. For preposed focus on the object, we can assume movement $\mathrm{C}$. To have the subject precede the preposed focus, we simply add movement A. Copula constructions can be accomodated in this model in two ways: Either ne occurs preverbally (which requires movement $\mathrm{A}$ ), and $n e$, due to the phonologically null form of the copula verb, appears next to the predicate, or both movements $\mathrm{A}$ and $\mathrm{C}$ take place, which also will result in the right word order (see section 4.2.7. below for some problems with these predictions).

Taking this structure as the basis of the variation in questions and answers, I will present new data in the next section and will consider how this analysis works out with different types of questioned and focused elements.

\subsubsection{Object Focus}

\subsubsection{Transitive Verbs}

We already have seen cases of object focus in sentences with ditransitive verbs. One interesting thing is, of course, that the question word shows the same variation in its position as the focused element. So the according questions that the object-focus sentences in (93) to (95) answer are as follows ${ }^{67}$ :

$$
\begin{aligned}
& \begin{array}{lll}
\text { a. } & \mathrm{N}[\mathrm{ooo}]_{\mathrm{F}} & \text { Kamau Jonire? } \\
& \text { FM-who K. } & \text { (SM)-T-see-ASP-FV }
\end{array} \\
& \text { b. Kamau oonire }[0 o]_{\mathrm{F}} \text { ? } \\
& \text { K. (SM)-T-see-ASP-FV who } \\
& \text { c. Kamau } \mathrm{n}[\mathrm{oo}]_{\mathrm{F}} \text { गonire? } \\
& \text { K. FM-who (SM)-T-see-ASP-FV } \\
& \text { all meaning: Who did Kamau see? }
\end{aligned}
$$

67 Mostly, it seems like questions and answers of the same structure are at least preferred. I will discuss this issue briefly in section 5.3. in chapter 5 . 
Another point worth mentioning is that our choice of moving the entire NP (or DP, depending on your terminology) in the trees in (93) and (95) is motivated by the fact that complex objects will move into the focus position as a whole, as can be seen in the following example, which also is an answer to the question in (98a):

$$
\begin{array}{llll}
\text { a. } & \text { [ne mo-remi mo-koro oorea }]_{F} & \text { Kamau } & \text { oonire } \\
\text { FM 1-farmer 1-old PP-DEM K. } & \text { (SM)-T-see-ASP-FV } \\
\text { It was this old farmer (that) Kamau saw. } &
\end{array}
$$

Moving only part of the complex NP would not render a grammatical sentence.

The same patterns that we have seen for the example used so far can also be found for other types of objects, e.g. for directional arguments:

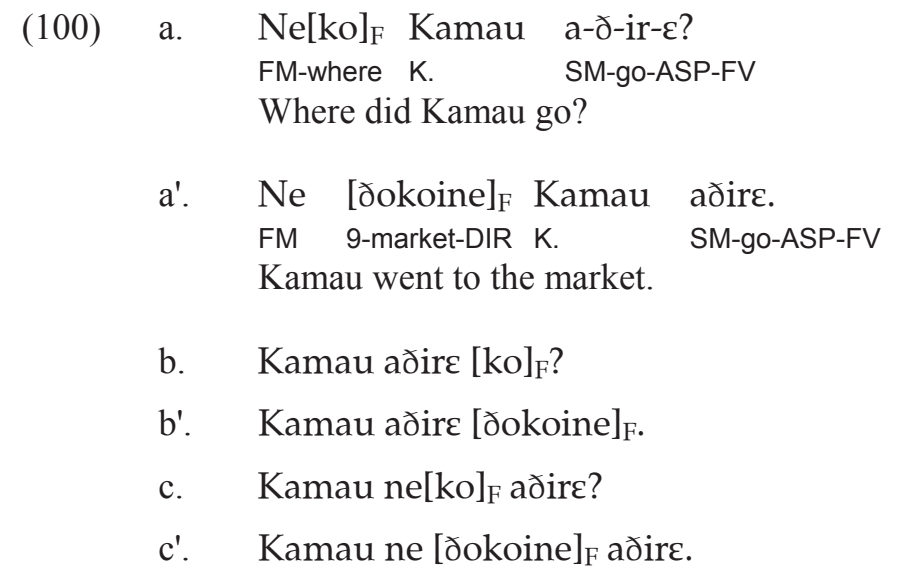

\subsubsection{Ditransitive Verbs}

Naturally, the number of possible constructions is even bigger for ditransitive verbs. Apart from the pattern for the object adjacent to the verb, which is the same as in transitive verb constructions, there also are all three possible patterns for the second object:
a. $\quad \mathrm{Ne}-[\mathrm{kee}]_{\mathrm{F}}$ Abdul a-ðom-ay-ir-a mw-ana?
FM-what A. SM-read-HAB-APPL-EV 1-child
What did Abdul read to the child?
a'. $\quad \mathrm{Ne}$ [ibuku] $]_{\mathrm{F}}$ Abdul a-ðom-ay-ir-a mw-ana?
FM 5-book A. SM-read-HAB-APPL-EV 1-child
It was a book (that) Abdul read to the child.
b. Abdul aðomayira mwana $[k e e]_{F}$ ?
b'. Abdul aðomayira mwana [ibuku $]_{\mathrm{F}}$.
c. Abdul ne[kee $]_{\mathrm{F}}$ aðomayira mwana?
c'. Abdul ne [ibuku $]_{\mathrm{F}}$ aðomayira mwana.

Here, of course, the question comes up of how the postverbal focus is determined in (b'), given that the answer to the question asking for mwana (child), can have the same word order. ${ }^{68}$ One possibility might be that there is a tonal (or intonational) distinction between the two answers to different questions. However, up to this point, there is no evidence that there is a difference in tone between the two relevant cases, although there might be other intonational differences. Otherwise, sentences like (b') may simply be ambiguous.

68 Note that this ambiguity is not only one where focus projection can take place to different extents (as we will see in the section on VP-focus), but one where different narrow foci are possible. 
There is yet another possibility for the question and answer focusing the human (and in general, the first) object. In addition to the three expected patterns, a fourth pattern exists where the human object, or the question word asking for it, appear to the right of the second object. This will result in unambiguous focus on the human object:

$$
\begin{aligned}
& \text { a. Abdul aðomayira ibuku }[\mathrm{oo}]_{\mathrm{F}} \text { ? } \\
& \text { b. Abdul aðomayira ibuku [mwana }]_{\mathrm{F}} \text {. }
\end{aligned}
$$

As my informant noted, $(102 b)$ is a somewhat rare answer, given that in normal every day discourse the arguments given in the question would be pronominalized, so that (b') would be the most natural answer to $(\mathrm{a})^{69}$ :

$$
\begin{array}{lll}
\text { (102) b'. } & \begin{array}{l}
\text { a-re-ðomayira } \\
\text { SM-OM(cl.5)-read-HAB-APPL-FV }
\end{array} & \text { 1-child } \\
& \text { He read it to the child. }
\end{array}
$$

But nonetheless, (102b) is a possible, grammatical sentence, if, and only if, mwana is in focus. The question then is, of course, where the right-moved object moves to. ${ }^{70}$ And if we consider $\left(101 b^{\prime}\right)$, a sentence containing a ditransitive verb with basic word order of its objects, how can we account for the fact that this sentence allows for either object to be in focus ${ }^{71}$, while the latter only is acceptable when the right-moved object is in focus? Presently, I do not have an explanation for these phenomena of postverbal focus, and can only describe them here. ${ }^{72}$

\subsubsection{Subject Focus}

As we saw in the first section of this chapter, questions asking for the subject, as well as their answers, are exceptions to the general possibility of having two different types of constructions, one in-situ, and one preposed with $n e$. There is only one possible construction for subject questions, and that is the one involving $n e$ :

$$
\begin{aligned}
& \text { a. } n \text {-[oo }]_{\mathrm{F}} \text { o-ðom-ay-er-a mw-ana i- } \beta u k u \text { ? } \\
& \text { FM-who SM-read-HAB-APPL-FV 1-child 5-book } \\
& \text { Who read the book to the child? } \\
& \text { b. ne }[A b d u l]_{F} \text { o-ðom-ay-er-a mw-ana i- } \beta u k u \\
& \text { It is Abdul who read the book to the child } \\
& \text { c. * [oo }]_{\mathrm{F}} \text { a-ðom-ay-er-a mw-ana i- } \beta u k u \\
& \text { d. * [Abdul }]_{\mathrm{F}} \text { a-ðom-ay-er-a mw-ana i- } \beta \text { uku }
\end{aligned}
$$

Why is it that (c) and (d) are ungrammatical with the element in subject position in focus? One possible answer to this question could be based on the observation that in the case of object questions, all the possible positions for the question word and the focused element are such that they can receive focus. More precisely, it seems that the only preverbal position that can receive focus is the one in the focus phrase, while elements in postverbal position can all receive focus (when no ne appears in the sentence). If this is correct, we have a good explanation for the ungrammaticality of (c) and (d), at least if we assume that question words in Kikuyu have to be in a position where they can receive focus. The reason then, why the question in (c) is impossible is that the question word is not in a position where it can receive focus. Namely, it would be in the

69 It should also be noted that this pronominalization of the second object is only possible in this configuration, where the first object appears to its right and is in focus.

70 That is, if we assume at all that movement to the right has taken place. Lisa Cheng (p.c.) suggested to me that we might rather be dealing with some type of object shift.

71 The question word oo would appear in the same in-situ position as the human object.

72 see also Bergvall (1987a) on the issue of right moved questions 
supposed subject position in SpecIP, whereas in (a) we would assume movement into the focus phrase. The same is the case with the focused subject in (d). As soon as it moves to the focus position, it is necessary for ne to precede it. Hence, (d) is not a possible Kikuyu sentence when the subject is supposed to be in focus.

From a cross-linguistic perspective, it is no surprise that focus on a subject has to be marked explicitly, as subject focus is generally rarer. Subjects have a strong tendency to refer to entities that are already introduced in the discourse. Hence they are likely to be part of the background, and often are the topic. This cross-linguistic tendency also makes it plausible that the normal subject position cannot be assigned focus in Kikuyu.

\subsubsection{VP-Focus}

\subsubsection{Intransitive Verbs}

One way of putting a VP into focus involves constructions with control verbs like want. In the case of intransitive verbs, we find the same pattern for the lower VP that we have found for objects of the verb, though with a slight variation. When the verb is preposed with ne, an overt copy may remain in the in-situ position:

a.

$$
\begin{aligned}
& \text { ne atea Abdul a-r-end-a rw-ek-a? } \\
& \text { FM what A. SM-T-want-FV SM(INF)-do-FV }
\end{aligned}
$$

What does Abdul want to do?

b. ne $[\text { ko-nyu-a }]_{F}$ Abdul a-r-end-a

FM SM(INF)-drink-FV A. SM-T-want-FV

Abdul wants to DRINK.

c. ne $[\text { ko-nyua }]_{\mathrm{F}}$ Abdul arenda konyua

a. Abdul arenda rweka atea?

b. Abdul arenda [konyua $]_{F}$

In (104b), we see the same form as in the case of preposed objects (or other elements) in focus. The interesting thing in (104c) is that the verb konyua appears twice. This suggests that the movement we have talked about so far in fact is a copy and deletion process. ${ }^{73}$ For some reason, the deletion does not have to take effect in the case of (104c). In (105) we can see that the postverbal focus construction works just as well in the case of VP-focus, i.e. in-situ focus marking of a VP that appears under a control verb takes place in the same way as object focus marking in the case of transitive verbs.

Why should it be that cases like (104c) allow for the verb konyua to appear in-situ and in the focus position at the same time? The direction of the answer might become more clear when we take a look at simple intransitive sentences without a control verb: ${ }^{.7}$

$$
\begin{aligned}
& \text { a. ne atea Abdul ek-ir- } \varepsilon \text { ? } \\
& \text { FM what A. (SM)-do-ASP-FV } \\
& \text { What did Abdul do? } \\
& \text { b. ne [ko-nyua }]_{F} \text { Abdul a-nyu-ir- } \varepsilon \\
& \text { FM SM(INF)-drink A. (SM)-drink-ASP-FV } \\
& \text { Abdul DRANK. }
\end{aligned}
$$

In this case, it is obligatory for the verb to appear in its base position. The reason here seems fairly obvious: Since the verb appears in the focus position in its infinitive form, and since the

73 This was indeed already suggested by Clements (1984).

74 See Bergvall (1987: 136) for a similar example. She also notes that similar constructions can be found in other African languages, e.g. in Yoruba and Temne, and gives Bynoe-Andriolo (1975) as a reference. 
verbal complex normally contains information at least about subject, tense and aspect, it would seem just about impossible to completely delete the verb in its base position (cf. Bergvall 1987: 136-137). Note that while this is to some extent similar to do-support in English, it is not possible to use the verb ek-ir- $\varepsilon$, (the inflected form of the verb $d o$ ), as it appears in the question, in place of the inflected form of drink. The construction in (104c) seems analogous in one way, but is, of course, different in respect to the morphological information on the verb. Since it appears in the infinitive in its base position in (104c), it does not have to appear there when put into preposed focus. Nonetheless, this double occurrence of the verb is optional in that case.

There is another interesting piece of data related to this, with an infinitive in postverbal position. According to Bergvall (1987: 139) and Barlow (1951: 127), this conveys a particular kind of emphasis, as indicated in the following example (adopted from Barlow (1951: 127)):

$$
\begin{array}{lll}
\text { a. } & \text { to-haat-et- } \varepsilon & \text { ko-haat-a } \\
& \text { SM(1PI)-sweep-ASP-FV } & \text { SM(INF)-sweep-FV } \\
& \text { We have swept thoroughly. }
\end{array}
$$

Barlow describes the infinitive here as being "used adverbially before any tense of the same stem to express slight emphasis" (Barlow 1951: 127). My informant judged this construction to be at least very rare in use, although he would be able to understand it. Interestingly, however, this would not be an adequate answer to the question What did you do?, i.e., this construction does not express VP-focus in the appropriate question context. It therefore seems like it is not a construction analogous to the examples containing a preposed verb.

\subsubsection{Transitive Verbs}

Turning to VPs containing a transitive verb, there is an interesting change in focus marking compared to intransitive verbs. Now it is not the verbal complex that is formally marked for focus (i.e., moved into a focal position), but rather the object of the verb. Hence, we seem to be dealing with a case of focus projection, where focus marking of the object can express focus on the entire VP:
a. Abdul ek-ir- $\varepsilon$ atea?
What did Abdul do?
b. Abdul [a-nyu-ir- $\varepsilon$ ma-e]F.
A. SM-drink-ASP-FV 6-water
Abdul drank water.
(109) a. ne atea Abdul ek-ir- $\varepsilon$ ?
b. ne $[\text { mae }]_{\mathrm{F}}$ Abdul [a-nyu-ir- $\left.\varepsilon\right]_{\mathrm{F}}$
c. Abdul ne $[\text { mae anyuire }]_{\mathrm{F}}$

Note that F-marking here was done on the basis of the question context. Structurally, following the analysis proposed here, only the object is in a position where it can receive focus. Only after that has been done can the focus be projected onto the entire VP. ${ }^{75}$ That this is possible in (109b) is particularly interesting, given that the phrase in focus, i.e. the VP, is realized discontinuously in its surface form. ${ }^{76}$

75 It is an important task for future research to determine the rules for focus projection in these types of examples.

76 As Manfred Krifka pointed out to me, this could be similar to certain cleft-constructions in French that can also indicate focus on a constituent larger than the one moved to the cleft, as the following example from Lambrecht (1994) shows:

a. What happened? 
In the case of a pronominal object, focus on the VP has to be expressed by preposing the verbal infinitive, just as was the case for transitive verbs:

$$
\begin{aligned}
& \text { a. ne atea Abdul ekire? } \\
& \text { b. ne kohora amohorire } \\
& \text { FM SM(INF)-beat SM-OM-beat-ASP } \\
& \text { He beat him. } \\
& \text { c. * ne komohora ahorire } \\
& \mathrm{OP} \\
& \text { d. ? ne komohora amohorire } \\
& \text { OM OP }
\end{aligned}
$$

It is interesting that the pronominal object marker cannot be marked on the copy of the verb in the preposed position. One can observe a similar phenomenon in languages that mark focus by pitch accents. In these, it is usually not possible to have a pitch accent on a pronoun, which generally is attributed to the fact that pronouns refer to a discourse referent that has already been introduced in the discourse, which makes the pronoun GIVEN in the sense of Schwarzschild (1999). Nonetheless, the sentence in (c) gets slightly better if the object marker occurs both on the preposed and the in-situ copy of the verb (d).

While it was impossible to prepose the entire VP in the simple transitive sentence above, this is possible in some restricted cases, for example in the following question context:

(111) a. What happened to Abdul? Why is he wet?

$$
\begin{array}{llll}
\text { b. ne }[\text { konyua mae }]_{F} & \text { Abdul anyuire } \\
& \text { FM SM(INF)-drink 6-water } & \text { A. } & \text { SM-drink-ASP }
\end{array}
$$

Abdul drank WAter.

The difference between this example and the previous is not quite clear, but it is interesting that there is the possibility of preposing the entire VP. Note that the object NP water is not repeated in the in-situ position. This speaks in favor of the idea that the only reason that the copy of the verb in the in-situ position only serves to bear tense and agreement information.

The pattern for a VP embedded by a control verb is the same as in simple transitive sentences. We again find the possibility of focus projection from the preposed object onto the VP that is in focus due to the question context.:

a.

$$
\text { ne atea Abdul a-r-e(n)da yw-eka? }
$$

What does Abdul want to do?

b. Abdul ne[mae $]_{F}$ a-r-e(n)da [konyua $]_{F}$.

Abdul wants to drink water.

c. \# ne[konyua mae $]_{\mathrm{F}}$ are(n)da konyua

d. \# ne[konyua $]_{\mathrm{F}}$ are(n)da konyua $\left[\mathrm{mae}_{\mathrm{F}}{ }^{77}\right.$

(113) a. Abdul arenda yweka atea?

b. Abdul are(n)da [konyua mae $]_{F}$

\section{b. J'ai ma VOITURE qui est en panne}

'I have my car which is in trouble', meaning My car broke down.

Here, however, the focus is on the whole sentence, not on the VP.

77 As we will see in the next section, this sentence is felicitous if only the verb is in focus. 
As was the case above, (c) can be felicitous if the question is slightly different, for instance Why is Abdul so restless? Then, however, the focus would not just be on the VP drink water, but on the bigger VP wants to drink water.

\subsubsection{Ditransitive Verbs}

Again, ditransitive verbs allow for more variation in the expression of VP-focus, just as it was the case with object focus. Interestingly, the apparent focus projection that we saw take place in the case of transitive verbs can be based on either object being put in focus in the case of ditransitive verbs, i.e., focus on the VP can be expressed by putting either object in the preposed focus position:

$$
\begin{aligned}
& \text { a. ne atea Abdul eka-ya? } \\
& \text { FM how/what A. (SM)-do-HAB } \\
& \text { What does Abdul do? } \\
& \text { b. ne mw-ana Abdul a-ðom-ay-er-a i-ßuku. } \\
& \text { FM 1-child A. SM-read-HAB-APPL-FV 9-book } \\
& \text { c. ne i-ßuku Abdul a-ðom-ay-er-a mw-ana } \\
& \text { (115) a. Abdul eka-ya atea? } \\
& \text { b. Abdul a-ðom-ay-er-a mw-ana i- } \beta \text { uku }
\end{aligned}
$$

In (114), the answer in (b) seems to be slightly preferred over the answer in (c), although both seem to be acceptable. Comparing the preposed and in-situ versions of this sentence, my informant remarked that he would prefer (115b) as an answer to the question in (114a), which seems to indicate that projection is easier from the in-situ focus construction. ${ }^{78}$

Another interesting point to note is that the type of right-moved focused objects that we saw in the section on object focus is not an option for VP-focus. Hence, (115c) is not a felicitous answer to the question in (115a):

$$
\text { c. \# Abdul a-ðom-ay-er-a i-ßuku mw-ana }
$$

This type of structure is only possible in the case of narrow focus on the right moved element. Hence, in the case of ditransitive verbs, focus projection for postverbal focus is restricted to cases where the objects appear in their normal order.

\subsubsection{Verb Focus}

\subsubsection{Intransitive Verbs}

For intransitive verbs, it is quite hard to construct question contexts that invoke narrow focus on the verb. Alternatively, one can provide a context that involves contrastive focus. Formally, narrow focus on the verb is marked in the same way as focus on a VP containing an intransitive verb:
a. Abdul ne-a-ðek-ir- $\varepsilon$ ?
b. Afa. Abdul ne-ko-rer-a a-rer-ir- $\varepsilon$. no. A. FM-SM(INF)-cry-FV SM-cry-ASP-FV No. Abdul cried.

\footnotetext{
78 It is to some extent possible to answer a question in the in-situ form with an answer in the preposed form, also in the case of transitive verbs, but that is normally not the preferred form (see also section 5.1.4. in chapter 5).
} 
This fits the picture that the lexical content of the verb is focused by having been moved into the focus position, while the in-situ verb form cannot be deleted because it carries important morphological information.

\subsubsection{Transitive Verbs}

In the case of transitive verbs, it is easier to provide wh-question contexts that assure narrow focus on the verb in the answer. Such questions can be formed using the scheme What did A to with $B$ ? Applying this, we get the same result as for intransitive verbs, namely an infinitive form of the verb in the focus position and an inflected form in the in-situ position:
a.
Kamau ek-ir- $\varepsilon$
K. (SM)-do-ASP-FV with 9.house what?
b.

$\begin{array}{llll}\text { ne atea Kamau ek-ir- } \varepsilon & \text { na nyomba? } \\ \mathrm{FM} \text { what } \mathrm{K} . & \text { (SM)-do-ASP-FV with 9.house }\end{array}$
both meaning: What did Abdul do with the house?
c. Kamau ne-kw- $\varepsilon$ ndia $\varepsilon$ nd-iri- $\varepsilon$ nyomba
K. FM-SM(INF)-sell (SM)-sell-ASP-FV 9.house
d. Kamau ne-kw-endia a-me-end-iri- $\varepsilon$
K. FM-SM(INF)-sell SM-OM-sell-ASP-FV
Abdul sold the house/ it.

Note that this is different from marking the entire VP for focus, which is done by putting the object into a focus position. This is illustrated by the difference between the following two examples:
a. ne atea Abdul ek-ir- $\varepsilon$ ?
What did Abdul do?
b. ne [mae $]_{F}$ Abdul [a-nyu-ir- $\left.\varepsilon\right]_{F}$ Abdul drank WAter
(119) a. ne atea Abdul ekirs na mae?
What did Abdul do with the water?
b. ne $[\text { konyua }]_{F}$ Abdul anyuire mae.
He DRANK the water.

As in the case of intransitive verbs, this fits neatly into the picture that the lexical content of the verb is focused in the latter case by moving a copy of the verb into the preposed focus position.

\subsubsection{Sentence Focus and Verum Focus - The Case of Preverbal ne}

So far, we have looked at cases involving the occurrence of ne with preposed constituents. How should we analyze the case of preverbal $n e$ ? To approach this question, lets remind ourselves of the types of contexts in which we have found preverbal ne. One such context was that of Yes/Noquestions. Preverbal ne appeared here in the question as well as in the answer. There also are Yes/No questions that do not contain preverbal ne, but if ne appears with another fronted element or does not appear at all, we get the familiar focus interpretation of the fronted element (121) or a postverbal element (122):

$$
\begin{aligned}
& \text { a. Abdul ne-a-ra-nyu-ir- } \varepsilon \text { ma-e? } \\
& \text { A. FM-SM-T-drink-ASP-FV 6-water } \\
& \text { Did Abdul drink water? }
\end{aligned}
$$


b. ee. Abdul ne-a-ra-nyu-ir- $\varepsilon$ mae.

Yes. Abdul did drink/ drank water.

(121) a. ne $\left[\mathrm{mae}_{\mathrm{F}}\right.$ Abdul aranyuire?

Did Abdul drink WATer?

b. ee. ne $[\mathrm{mae}]_{\mathrm{F}}$ Abdul aranyuire.

Yes. Abdul drank WATer.

c. a a a. ne $\left[\int a i\right]_{F}$ Abdul aranyuire

No. Abdul drank TEA.

(122) a. Abdul aranyuire $\left[\mathrm{mae}_{\mathrm{F}}\right.$ ?

Did Abdul drink WATer?

d. ee. Abdul aranyuire $[\text { mae }]_{F}$

Yes. Abdul drank WATer.

e. afa. Abdul aranyuire [ $\left[\mathrm{ai}_{\mathrm{F}}\right.$

No. Abdul drank TEA.

Another place where preverbal ne appears is in general statements, which may come with certainty or determination (see the descriptions by Barlow and Armstrong discussed in chapter 3 above). This is the reason that translations will often include a form of $d o$-support. Another interesting case is provided by Armstrong (1940: 297), who presents the following dialogue:
A: waira ha?
Where did you put it?
B: ndaira ikoombe
I put it in the granary.

[A then suggests B has made a mistake, whereupon he answers emphatically:]

B: nendaiya ikoombe

I DID put it in the granary

She continues her description:

Here $n e$ has strong stress; there may also be a lengthening of the $\mathbf{n}$ and an extended range of intonation to show contradiction. If this were an answer to 'Did you put it in the granary?', $[\ldots]$ there would be no extra stress, lengthening of $\mathbf{n}$, or extended tonerange.

(Armstrong 1940: 297)

One interesting thing about this example by Armstrong is that intonational stress seems to play a meaningful role. But in the present discussion, the important point is that here the role of ne seems to be quite straightforwardly related to the truth of the sentence. Namely, it seems like we are dealing with a case of verum focus (cf. Gussenhoven (1983) and Höhle (1992)), i.e., what is in focus here is the truth of the proposition expressed by the sentence.

The situation isn't really so different with Yes/No-questions. If they do not involve narrow focus (as in (121) and (122)), what else could be focused in them than the truth-value? When we ask a Yes/No-question, we want to find out whether the expressed proposition is true or false. Therefore, the affirmation of the truth of the proposition in question is what is important in the 
answer to a Yes/No-question. ${ }^{79}$ If the answer is positive, it involves $n e$, and what is focused is the truth of the sentence. The difference of intonation between a simple answer to a Yes/No-question and the last statement in (123) seems to be based on the fact that in the one case, the addressee does not know whether the proposition in question is true or not, while in the other, the truth of the proposition is controversial between speaker and hearer.

Finally, the regular use of preverbal ne in contexts where there is no question preceding the utterance also may be related to such highlighting of the truth of the sentence, especially if we consider the descriptions of this use as involving 'certainty' or 'determination'. After all, Bergvall concluded that $n e$ was best to be analyzed as 'a particle connoting affirmation' on the basis of the effect of preverbal ne as it has been described by Barlow, Armstrong, and Myers. This effect is in need of explanation if, as was argued above, ne is not directly responsible for the assertive or affirmative meaning. But, again, how could ne be an affirmative assertion marker if it also appears in questions?

Maybe the direction of a possible explanation becomes more clear if we consider another example. There is yet another interesting case that was already documented by Barlow as well as by Armstrong, which is the one of the subjunctive used with ne, which renders a hortative reading:

$$
\begin{aligned}
& \text { a. ne-agwate } \\
& \text { Let him take hold (Barlow 1951: 30) } \\
& \text { b. ne-mateyere } \\
& \text { Let them run (Armstrong 1940: 170) }
\end{aligned}
$$

This should make it evident that $n e$ is not necessarily marking an assertion. Also, it should be clear that it is not the verb that is in focus in any of the examples. One feasible option might be to assume that some sort of illocutionary operator is in focus in these cases of preverbal ne. Höhle (1992) suggests a similar analysis for verum focus phenomena in German. ${ }^{80}$ Such an operator, which need not be bound to any particular position, could be moved into the focus position in the case of preverbal ne. Since this operator is phonologically null, the subject has to be moved into the topic position to avoid a surface form that is identical to that of a subject focus sentence.

Another possibility could be to follow Höhle's (1992) alternative proposal to analyze cases of verum focus by saying that the weakest element, the one that is least likely to receive a pitch accent, is formally marked for focus in order to express verum focus. Adapting that idea to the Kikuyu data, one could assume that the focus position actually remains completely empty, which would be the case parallel to placing the accent on the weakest element in Höhle's account.

Independent from what exact analysis we choose for these cases, the advantage would be that we can explain the 'affirmative' effect of preverbal ne without excluding the possibility of preverbal $n e$ in questions and the subjunctive hortative construction. This is a clear advantage over Bergvall's analysis of $n e$ as a marker of assertion.

If we look at another case, however, it may be reasonable to assume that preverbal ne does not always express verum focus. Armstrong (1940: 171) gives a whole list of question and answer contexts, one of which involves a question asking why something had been done:

$$
\begin{array}{lll}
\text { a. } & \text { o-rrh-ir- } \varepsilon \quad \text { mo-kaanda neke }{ }^{81} \\
\text { SM-bring-ASP-FV } & \text { 5-rope } & \text { why } \\
\text { Why did you bring a rope (today)? }
\end{array}
$$

79 An additional factor in the answer is that all parts of the sentence are already given (in the sense of, e.g., Schwarzschild (1999)), which means that no particular word or constituent should be in focus.

80 It should be noted, however, that Höhle (1992) ultimately concludes that this analysis is not correct, based on facts about verum focus in German embedded clauses. Nonetheless, his idea seems appealing in the light of the Kikuyu data discussed here.

81 It is unclear how neke, why, is related to ne. It probably has the same origin, but has become part of the word, since it can occur postverbally. 
b. toondo ne-Yo-tu-a $\quad$ mereeJ.
because FM-SM(INF)-pick-FV potato-leafs
Because I'm going to pick potato leaves.

In this case, it is not the truth of the proposition expressed in (b) that is emphasized. Rather, the sentence as a whole is an answer to the question: it is for picking potato leaves that the speaker brought the rope. This might make it reasonable to assume wide focus in (125b), rather than verum focus, i.e. focus on the whole sentence. ${ }^{83}$ Other examples for this are given in (126) and (127):

a. o-r-cndi-a i-ßuku neke?

Why did you sell the book?

b. toondo $\beta \mathrm{a} \beta \mathrm{a}$ ne-a-r-end-a mbe $а$

because my.father FM-SM-T-want-FV money

Because my father wanted/needed money.

a. ne-kee ke-oru?

FM-what CLM-bad

What is bad? (meaning: What is wrong? What happened?)

b. Abdul ne- nd-iri- $\varepsilon$ nyomba
A.

Abdul sold the house.

The last example is very similar to the classic examples of questions inducing sentence focus (e.g. What happened?), and it therefore seems reasonable to conclude that preverbal ne can also express sentence focus.

Furthermore, it seems like sentences with preverbal ne also appear in normal speech in contexts where there is neither a Yes/No-question to be answered nor a controversy about the truth of the statement. This also seems plausible if we assume that preverbal ne can be used to express wide focus on the entire sentence.

The reason for the form of preverbal ne being chosen to express sentence focus becomes clear if we consider the range of possible alternative expressions and their meaning. One alternative to preverbal $n e$ is to have a sentence with no ne at all. In that case, as we have seen above, a postverbal element is focused. Another alternative is to have ne followed by a constituent other than the verb. Then that constituent (or part of it) is focused. So what should one do if one does not want to focus either a postverbal or a preposed element? The most reasonable strategy, and apparently the one chosen by Kikuyu grammar, seems to be the use of preverbal ne.

Given these considerations, the next question is how this analysis could be included in the focus phrase analysis of Kikuyu phrase structure proposed above. I can only sketch the direction of a possible answer at this point. One option might be to move the verb into the focus position. But that has already been proposed for the case of VP-focus above, where it was obligatory to leave a copy of the verb carrying all the inflectional information in its base position. The difference here might be that, in the present case, the inflectional features have to move with the verb to the focus position. However, it still would be unclear why the subject has to move into the topic position if the verb moves.

82 The translation is Armstrong's, the interlinear translation mine. The rope is needed to pick the potato leaves, therefore (b) is an adequate answer to (a).

83 Armstrong's translation might suggest that not everything in the answer is in focus, since the referent of the pronoun $I$ in (b) is already mentioned by you in (a). But as the interlinear translation shows, there is no pronominal reference in (b). A more adequate translation might be for picking potato leaves. 
Another idea might be to move the entire IP into the focus position. That way everything in the IP could receive focus. ${ }^{84}$ This might be the most straightforward approach. But it surely brings lots of technical questions with it. The subject, for example, has to receive focus through its trace then. If it is not moved into topic position, we don't get a preverbal ne-construction in the first place. So it has to be moved. But when it is moved, it is not in the IP anymore. This probably could be solved by undoing topic movement when the sentence is interpreted in LF.

Unfortunately, I cannot discuss these questions here at more length. ${ }^{85}$ What is important is that it seems reasonable to analyze preverbal ne constructions as ambiguous. They can either express focus on the truth-value of an utterance or sentence focus. ${ }^{86}$

The analysis of preverbal ne as expressing sentence focus allows for a further interesting prediction. One of the interesting points in the quote by Barlow above (chapter 3,) was that "when a sentence consists of an affirmative finite verb only (e.g. nĩokire, he came), ni is indispensable." (Barlow 1951: 34) This has been confirmed by the data from my informant, and becomes plausible if we assume that every sentence has to contain a focus. ${ }^{87}$ Since sentences without ne will cause a postverbal constituent to be in focus, and since this is impossible if there is no postverbal constituent, the only way for such simple intransitive sentences to have a focus is through preverbal ne. This phenomenon is hard to explain from the viewpoint of Bergvall's assertion marker analysis, since it is unclear why sentences consisting only of an intransitive verb should always receive a special marking for assertion. It follows, on the other hand, quite naturally from the focus phrase analysis.

\subsubsection{Focus and Copula Constructions - A Possible Reanalysis}

In the preceding sections, I have tried to provide a new analysis for two of the constructions where $n e$ appears, namely constructions with preverbal ne and constructions with ne preceding a preposed element. The third type of context where ne appears, the one of copula constructions, still is in need of analysis. Basically, there are two possible ways of dealing with these cases. First, we could argue that ne plays a different role here than it does in the other cases. This would either mean to take $n e$ as a genuine part of the copula-verb paradigm, which, as was argued above with Clements and Bergvall, seems unreasonable, or to simply say that ne does not have a focal effect in copula constructions, as Bergvall does (see the discussion of her argument above in section 3.3.3).

Secondly, we can try to fit the phenomena related to ne in copula constructions into the general picture of the analysis provided above. I will follow this latter approach, based on the fact that I did find effects of $n e$ in copula constructions when put in question and answer contexts that are similar to the already familiar cases. However, it seems like the range for variation is more restricted in the case of copula constructions. I do not have any conclusive explanation for these different patterns, and maybe another analysis would be more successful. However, the alternative options that I can see do not seem any more promising, but rather less. So the following analysis should be understood as a first approach to a unified analysis of $n e$, but there certainly needs to be more work done to determine its adequacy. If all else fails, one could

84 See Puskás (2000: 95-96) for a similar proposal for Hungarian.

85 The illocutionary operator analysis is, of course, in need of much more discussion as well. It is unclear, for example, why preverbal ne can occur with the subjunctive to have a hortative meaning, but not in other speech acts, e.g. orders expressed by imperatives.

86 Note that the analysis of preverbal ne marking sentence focus is different from the analysis proposed in Güldemann (to appear). Güldemann argues that preverbal ne marks predication focus, in case of which the predicate is part of the focus, but the complement or adjunct is not. He explicitly does not talk about sentence focus. Güldemann also takes instances of preposed ne-focus to be clefts (see also Güldemann 1996: 160-165).

87 See, for example, Kiss (1998: 246). 
always go back to the idea that $n e$ in copula constructions is a historical leftover of some sort that does not behave in exactly the same way as the focus marker.

To determine the possibilities of focus marking, we once again apply the tool of questionanswer sequences. To ask for the subject or the predicate NP of a copula construction, there are the following options: ${ }^{88}$
a. $\mathrm{n}$-[oo $]_{\mathrm{F}}$ mo-remi?
FM-who 1-farmer
Who is a farmer? $\begin{array}{ll}\text { b. ne }[\mathrm{Kamau}]_{\mathrm{F}} & \text { mo-remi. } \\ \text { FM K. } & 1 \text {-farmer }\end{array}$
KAMAU is a farmer.
a. Kamau $n[o o]_{F} ?^{89}$
b. Kamau ne $[\text { moremi }]_{F}$.
a. ? $\mathrm{n}[\mathrm{oo}]_{\mathrm{F}} \mathrm{Kamau}$ ?
b. ? ne $[\text { moremi }]_{\mathrm{F}}$ Kamau.

(128) shows the subject question, for which there only is one option. This is no surprise, given that we already found subject questions to be an exception in respect to possible word order variations. (129) and (130) show the options for asking for the predicate NP. For some reason, the form in (130) is at least strongly dispreferred.

Note that these results are rather different from Bergvall's. As was mentioned in section 3.3.3., Bergvall tried to support her account by claiming that only (130b) exhibited focus, and that (129a) did not show any focal effect at all. As she did not give any contextual information for these sentences it is hard to see what she based this claim on.

If we take the data presented here to be correct and adequate, there is a problem for Bergvall's analysis. If (129) is possible to express focus on moremi, her cleft-analysis cannot account for this. If she analyzes the $n e$ construction as a cleft, she cannot explain why the subject ends up in front of the cleft. The other alternative for her account is to claim that $n e$ is preceding a null form of the verb. But that would be at odds with the fact that in-situ question words do not allow for preverbal ne. Finally, the oddness of (130) also is unclear from Bergvall's viewpoint, as this should be just another cleft-construction.

Let us have a look, then, at how the analysis pursued here would fare with this data. As a reminder, I repeat the scheme from above (adapted to copula constructions) to illustrate the possibilities of movement in the Kikuyu sentence:

88 The choice of a proper name as the subject of the sentence should ensure that we can clearly distinguish subject and predicate NP.

89 That Kamau is the subject of this construction is also supported by the following piece of data involving mo-niini, meaning small:

(i) moniini noo?

This can only be interpreted as somebody having the name moniini; the question cannot mean Who is small? 
a.<smiles>C[C+][PbH]</smiles>

(ate)

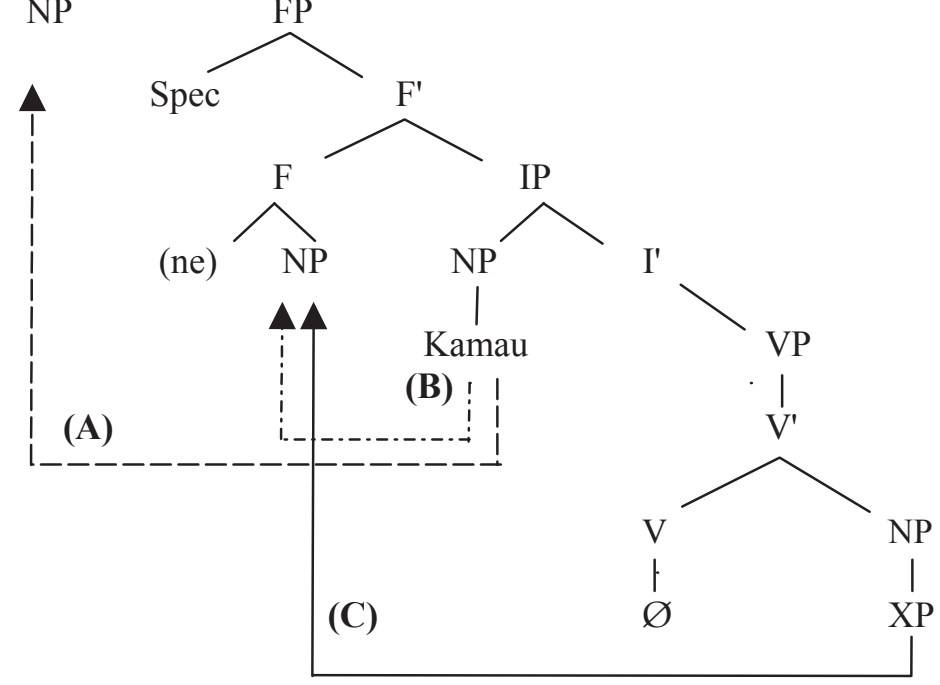

The case of subject focus is easily explained by assuming movement (B), which puts the subject in the focus position. A more complete description of (128b) that shows the position of the null form of the copula verb would then look as follows:

$$
\text { a. ne }[\mathrm{Kamau}]_{\mathrm{F}} \varnothing \text { moremi. }
$$

Focus on the predicate NP in the form of (129) can be achieved by combining movement (A) and (C). That way, the subject Kamau ends up in the topic position and the predicate NP moremi in the focus position. The surface form, including the null form of the copula, then looks as follows:

\section{(133) a. Kamau ne $[\text { moremi }]_{\mathrm{F}} \varnothing$}

In this analysis, we might even find an explanation for the oddness of (130). In this case, only movement (C) takes place. It might be odd because the proper noun Kamau in subject position has a strong tendency to go into the topic position.

Note that there is another possible analysis for copula sentences without focus on either the subject or the predicate NP. In these cases, only movement (A) takes place, leaving ne in preverbal position, only that the verb is phonologically null, so that ne appears adjacent to the predicate NP in surface structure. The correct description, however, would look as follows:

\section{(134) a. Kamau ne $\varnothing$ moremi}

Unfortunately, there is a problem with this analysis when we apply it to copula constructions in the past tense. As the reader will remember, the verb stem -re is used as the copula verb in tenses other than the present and for constructions with first and second person subjects. For past tense examples, not all constructions with focus on the predicate NP that my analysis predicts are possible:

$$
\begin{aligned}
& \text { a. } \mathrm{n}[\mathrm{oo}]_{\mathrm{F}} \text { W-a-re mo-remi? } \\
& \mathrm{FM} \text {-who SM-T-be 1-farmer } \\
& \text { Who was a farmer? }
\end{aligned}
$$

b. ne $[\mathrm{Kamau}]_{\mathrm{F}} \mathrm{W}$-a-re moremi 


$$
\begin{aligned}
& \text { a.*/?? n[oo }]_{\mathrm{F}} \text { Kamau aare? } \\
& \text { b.*/??ne [moremi }]_{\mathrm{F}} \text { Kamau aare. } \\
& \text { a.*/?? Kamau n[oo }]_{\mathrm{F}} \text { aare? } \\
& \text { b.*/??Kamau ne [moremi }]_{\mathrm{F}} \text { aare. }
\end{aligned}
$$

It is not quite clear whether (136) and (137) are strictly ungrammatical or just very odd. In the case of (136) one could assume, just as above, that the proper noun subject has a strong tendency to go into the topic position. But that does not make sense if we look at (137), which is just as bad. In any case, the strongly preferred, if not the only possible, form to express the meaning of (136) and (137) is that of leaving the predicate NP in its noun phrase, with no ne present before the verb, thereby focusing the element following the verb.

$$
\begin{array}{ll}
\text { a. } & \text { Kamau aare }[\mathrm{oo}]_{\mathrm{F}} \text { ? } \\
\text { b. } & \text { Kamau aare }[\text { moremi }]_{\mathrm{F}} .
\end{array}
$$

I do not have an explanation for this pattern. Note, however, that the equivalent of (134) is possible in the past tense form (in the appropriate context, of course):

\section{(139) a. Kamau ne aare moremi}

Also, the full pattern of variation exists for the verb stem -re when used as a locative copula expressing the location of the subject:

$$
\begin{aligned}
& \text { a. neko Kamau aare? } \\
& \text { FM-where K. SM-T-be(in) } \\
& \text { Where is Kamau? } \\
& \text { b. ne Nairobi Kamau aare. } \\
& \begin{array}{llll}
\text { FM N. } & \text { K. } & \text { SM-T-be(in) }
\end{array} \\
& \text { Kamau is in NAIROBI. } \\
& \text { (141) a. Kamau neko aare? } \\
& \text { b. Kamau ne Nairobi aare. }
\end{aligned}
$$

Perhaps the reason for the different patterns of $n e$ in copula constructions is that there really are two ne's, that go back to the same origin, but which have developed differently to some extent.

In any case, I have to admit that the analysis that I proposed overgenerates in the case of copular $n e$, i.e. more constructions are predicted than actually are possible. However, one could argue that it would be reasonable to have certain restrictions in a particular type of occurrences. It seems easier to restrict an account that overgenerates than to have an account that cannot predict all the possible occurrences, as seems to be the case with Bergvall's in the light of the examples discussed in this section.

One should keep in mind at this point as well that historical considerations might be helpful. If $n e$ originally goes back to a copular particle ${ }^{90}$, then the analysis proposed here would involve quite a substantial reanalysis of the meaning of that particle. But if the argument against ne being part of the copula verb-paradigm is valid, then some reanalysis seems inevitable, if one wants to provide a unified account of $n e$ in all its environments.

90 This seems plausible, as $n e$ is present in a number of Bantu languages of zone $\mathrm{J}$ and $\mathrm{E}$ (see Güldemann (1996) and (to appear)). 


\subsubsection{Focus on other Elements}

In sections 4.2.2. and 4.2.3. we have looked at focus on arguments of the verb. But, as the examples in the section presenting the basic data in chapter 3 showed, it is also possible to focus non-argument elements by the same means. For example, one can focus locative and temporal adjuncts by the same means as arguments:
a.
ne-ko
Abdul $\varepsilon$ nd-er-iri- $\varepsilon$
үe-tonga nyomba?
FM-where A.
(SM)-sell-APPL-ASP-FV 7-rich person 9.house
Where did Abdul sell the house to the rich person?
b. ne Nairoßi Abdul enderiric yetonga nyomba
It's in Nairobi that Abdul sold the house to the rich person
c. Abdul $\varepsilon$ nderiric $\gamma \varepsilon$-tonga nyomba ko?

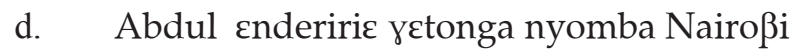
a. ne-re Abdul end-er-iri- $\varepsilon$
FM-when A. (SM)-sell-APPL-ASP-FV 7-rich person 9.house
When did Abdul sell the house to the rich person?

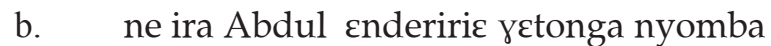
It was yesterday that Abdul sold the house to the rich person

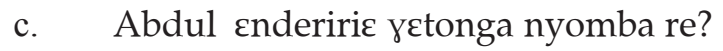

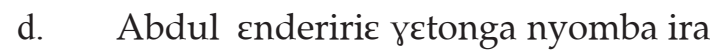

In addition, the forms with the subject preceding the focus are possible as well. I assume that all these forms fit into the same syntactic pattern presented for argument focus above. For the in-situ forms, we face the same problem as with ditransitive verbs: How is it determined which postverbal element is focused? Again, it does not seem like there are any tonaly differences, and it might be that these forms just are ambiguous.

As already mentioned, the only exceptions I have found to the otherwise fully general pattern are the two adverbial constructions mentioned in 3.2.2. One reason for these exceptions might be in connection with the interpretation of preposed $n e$-focus as being exhaustive (see the next chapter for a discussion of this).

Another interesting case is that of complex NPs with focus on a part of that NP. In the preposed version, the entire NP has to move into the focus position:
a.

$$
\begin{array}{llll}
\text { Abdul aðomayira } & \text { mwana } & \text { ißuku } & \text { [rereku }]_{\mathrm{F}} \text { ? } \\
\text { A. SM-read-HAB-APPL-FV } & \text { 1-child } & \text { 5-book } & \text { 5-which } \\
\text { Which book did Abdul read to the child? } &
\end{array}
$$
b. Abdul aðımayira mwana i $\beta u k u$ [rekuru $]_{\mathrm{F}}$
A. SM-read-HAB-APPL-FV 1-child 5-book 5-old
Abdul read the OLD book to the child:

(145) a. Ne ißuku [rereku] $]_{F}$ Abdul aðımayira mwana?

b. Ne ißuku [rekuru] $]_{\mathrm{F}}$ Abdul aðomayira mwana

(146) a. Abdul ne i $\beta u k u[r e r e k u]_{F}$ aðomayira mwana?

c. Abdul ne ißuku [rekuru $]_{\mathrm{F}}$ aðəmayira mwana 
Presumably, such cases involve some mechanism akin to pied piping. A detailed theoretical analysis of such cases would go beyond this study. ${ }^{91}$

Altogether we can state that almost all sentential constituents can be focused either in-situ or by movement into the focus position.

\subsubsection{Contrastive Focus}

The context that has determined what is in focus in the previous sections was that of question answer-sequences. Another common tool for inducing focus is that of correction sequences, where an assertion by one speaker is corrected in part by another. I did not study this type of context in as much detail as question answer-sequences, but did test a few basic constructions. The results from these few examples indicate that contrastive focus and question answer-focus are marked by the same means (as is the case, e.g., in English and German):

a. Sam ne- $\varepsilon$ nd-iri- $\varepsilon$ re-tonga nyomba?

S. FM-sell-ASP-FV 7-rich-person 9.house

Did Sam sell the house to the rich person?

b. Afa. Ne $[\text { Abdul }]_{F}$ W- $-\varepsilon n d-i r i-\varepsilon$ retonga nyomba No. FM A. SM-sell-ASP-FV 7-rich person 9.house

No. It was ABDUL that sold the house to the rich person.

(148) a. Abdul neendiric yetonga nyomba?

b. Afa. Abdul (*ne-)हnd-iri- $\varepsilon$ [mo-tumia $]_{F}$ nyomba No. A. (FM-)sell-ASP-FV 1-woman 9.house

No. Abdul sold the house to the WOMAN

b.' $\quad$ Afa. ne [motumia $]_{F}$ Abdul हndiric nyomba.

No. It was the WOMAN that Abdul sold the house to.

As (148b) and ( $\left.b^{\prime}\right)$ show, both strategies for focus marking (i.e., the in-situ and the preposed construction) of the human object are possible to express contrastive focus.

\subsubsection{An Alternative Focus Construction}

In section 4.1.2. I presented yet another possible focus construction. It was of the following form:

a. $\quad \mathrm{N}\left[\mathrm{ooo}_{\mathrm{F}}\right.$ Kamau oonire?

Who did Kamau see?

b. Abdul ne [we $]_{F}$ Kamau o-sn-ir- $\varepsilon$
A. FM 3Sg.PRON K.
(SM)-T-see-ASP-FV

It is Abdul (that) Kamau saw

(150) a. N[oo $]_{F}$ W- $\varepsilon$ nd-iri- $\varepsilon$ nyomba?

FM-who PP-sell-ASP-FV 9.house

Who sold the house?

b. nie ne $[\text { nie }]_{F}$ nd-end-iri- $\varepsilon$ nyomba

1Sg.PRON FM 1Sg.PRON SM-sell-ASP-FV 9.house

It was me who sold the house. or:

I was the one who sold the house

91 Note that this is, again, similar to Hungarian. Kiss (1998: 260) provides a number of examples where the same complex NP is in the focus position, but where different placement of accent will determine what alternatives are introduced. 
(150b) served as an argument against the cleft-analysis of $n e$-focus sentences, because if this sentence would be an independent clause of its own, it should contain the first person copula form instead of ne. But how could this construction fit into the analysis proposed here? One way to fit it into the syntactic account would be to assume a second movement of the focused constituent. But into which position does it move? It seems unlikely that it moves into topic position, because then the same element would be topic and focus. Furthermore, the subject in (149b) can also move to the front of the sentence. Maybe a possibility would be the specifier of the focus phrase. This would allow for the correct word order. The internal structure of the FP would then be as follows:

a.

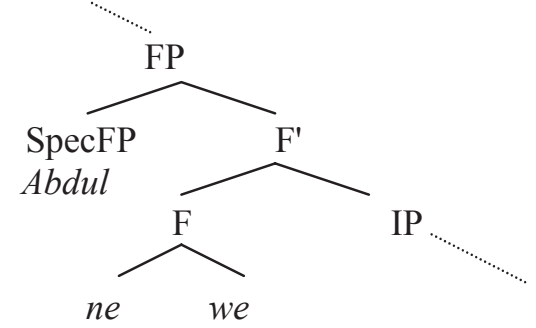

It is unclear what exactly the motivation for this second movement would be. Potentially it could be the expression of a strongly exhaustive interpretation that triggers this movement. The issue of exhaustivity will be picked up again briefly in the section on the semantics of focus in chapter 5 .

\subsection{Summary}

In this chapter, I have argued that preposed $n e$-focus constructions in Kikuyu cannot be analyzed as cleft sentences. The main argument came from examples involving the combination of preposed focus and topicalization. Further supporting arguments came from preposed focus on locatives and from multiple wh-questions. Based on these arguments and the data on sentences that contained both a focus and a topicalized element, I proposed a syntactic analysis that crucially involves a focus phrase and a topic phrase. This analysis was inspired by Clements' proposal on the one hand and recent work on discourse configurationality on the other hand. The extra positions in the phrase allow us to account for the variation in word order that we found in the data. Most of Clements' answers to central questions as presented in the overview at the end of chapter 3 can be held up for this modified analysis. The phrase structure for focus phrases is not recursive, which explains that only one ne can occur per clause. In relative clauses, the highest node is IP, which is why ne, which is generated in the domain of $\mathrm{CP}$, cannot occur in them. Subordinate clauses introduced by ate do allow for $n e$ to occur, because they have $\mathrm{CP}$ as their highest node. If the analysis of copula constructions can be refined to explain the restrictions on word order variation observed in the data, then the approach pursued here can provide a unified account of all three types of occurrences of ne (preverbal, with a preposed constituent, and in copula constructions).

The exact syntactic nature of the particle ne and the internal structuer of the FP are not quite clear at this point, although it seems reasonable that $n e$ is generated in the FP. Crucially, the topic and focus phrase are optional. This allows to account for the descriptive generalization that if no $n e$ appears in a sentence, a postverbal element is focused. If ne had nothing to do with focus (as in Bergvall's analysis), this interaction would be unclear. When the optional FP is expanded, ne appears either preverbally or preceding a fronted constituent. In both cases, it marks focus. In the case of preverbal $n e$, it can either indicate focus on the truth-value or wide focus on the entire sentence. Syntactically, this is achieved by moving the subject to the topic position, while the focus position is filled with a truth-value (or illocutionary) operator or the content of the IP, depending what is focused.

In the last sections of the chapter, I provided new data that illustrated how different parts of the sentence can be focused. In particular, I showed that VP-focus involves focus projection in the case of transitive verbs. Formally, the object is marked for focus, but this focus can project to 
the entire VP. An interesting case was that of focus on the verb (as well as on intransitive VP's), where the infinitive form of the verb appeared in the fronted position, while a copy of the verb remained in-situ, apparently to ensure that inflectional information gets expressed.

As the method to control for focus that has been used here was that of question answer congruence, a further conclusion that can be drawn from the data discussed here is that questions words only appear in positions where they can receive focus. For example, question words cannot appear in-situ when the sentence contains preverbal ne (because preverbal ne excludes the possibility of narrow focus on a postverbal element). This also explains why subject question words cannot appear in-situ, as they could not receive focus there.

\section{Loose Ends}

In this chapter, some issues are addressed that cannot be treated in depth within this study, but which nonetheless should at least be mentioned. First of all, there are some open questions and further issues that the analysis proposed in chapter 4 will have to deal with at some point. These include the morphological effects of preposed focus constructions, the impossibility of $n e$ in certain tenses, negation, and alternative questions. For some of these, data is provided, and considerations on the relation of the relevant phenomena with the analysis proposed in chapter 4 are presented. Secondly, some issues concerning the meaning of the preposed and in-situ focus constructions discussed in this study are raised and discussed. Finally, potential issues related to tone are considered, although no clear results have been found in this regard.

\subsection{Further Issues for the New Analysis}

\subsubsection{Morphological Effects of $\boldsymbol{n} e$-Focus}

As we have seen in the discussions of Clements' proposal for the treatment of ne in chapter 3, there are certain morphological effects (mainly) on the verb that can be found in preposed $n e$ focus constructions (containing wh and non-wh elements) as well as in relative clauses. Namely, the subject prefix for class 1 , third person, changes form $/ \mathrm{a} /$ to $/ \mathrm{o} /$, and negation changes form $/ \mathrm{ti} /$ to $/ \mathrm{ta} /$. Furthermore, the tonal form of the verb also changes to what is often referred to as relative form. These phenomena are, of course, easily accounted for within the cleft-analysis of preposed $n e$ constructions, because the cleft-constructions actually contain a relative clause, and therefore it is only natural that we find the relative form. This is one of the reasons why the preposed nefocus construction has been analyzed as a cleft (cf. Güldemann 1996: 161).

However, as we have seen in the context of Clements' proposal, it is also possible to account for these morphological changes by assuming that they are triggered by open clauses, that is, clauses from which an element has been extracted. Something along the lines of Clements' open clause analysis is needed for my analysis in chapter 4 . Therefore, further research has to show to what extent this analysis can be integrated into contemporary syntactic frameworks, and whether it is cross-linguistically reasonable to assume such an analysis.

In general, it is no surprise that there is a high degree of similarity between focus constructions and relative clause constructions, as this is quite common cross-linguistically (cf. Schachter 1973). Also, it might be reasonable from a historical perspective to assume that the preposed $n e$-focus constructions have their origin in cleft-constructions, since $n e$ is present in (what looks like) cleft-constructions in a number of Bantu languages. ${ }^{92}$ If this is so, it would be

92 See Güldemann (to appear). In several languages, including Masaba (J31 in Guthrie's classification), Vunjo (E62b), and generally in zone E50 (which includes Kikuyu), ne also occurs as a preverbal particle. It is not quite clear, however, whether the function it serves in that position is always exactly the same. 
expected that relative clause features are still present in such constructions, especially if the grammaticalization has taken place recently. ${ }^{93}$

But given the data that I have presented, it seems like we are not dealing with clefts anymore in Kikuyu, and if these constructions ever were clefts, they seem to have been grammaticalized into the focus phrase. In this connection, it is interesting that Kiss (1998) argues that there is a focus phrase in English cleft sentences as well. Possibly, an argument could be made that this also was the case in Kikuyu, and that, over time, this focus phrase has become integrated into the extended phrase structure at the left periphery. This then made it possible to have topicalized elements appear in front of the ne. In particular, topicalization of the subject made it possible for ne to also appear preverbally. This would be a possible path that Kikuyu could have taken from $n e$-clefts to the general focus marker ne. However, these considerations are rather speculative, and in-depth historical and cross-linguistic research is necessary to pursue these issues further.

\subsubsection{The Absence of $n e$ in Certain Tenses}

An interesting fact about the distribution of ne was, as we have seen in the discussion of Barlow's work on Kikuyu above, that there are a number of tenses in which ne cannot occur. For some of these, like the negative and relative tenses (or rather forms of tenses), an explanation may be fairly straightforward (see next section for negation). For others, like the consecutive tenses, the "prefix- $a$ " tense used in the protasis of conditional clauses and others, it is less clear why ne cannot appear in them. All of these seem to occur in clauses that are not fully independent. Further research will have to show whether there is syntactic evidence that these do not contain a CP (as in the case of relative clauses), or whether other motivations for the impossibility of ne can be found. So far, no attempt of an explanation has been forward in this regard in the literature, except for Bergvall's idea mentioned above that consecutive tenses emphasize the connection to the previous sentence, and therefore cannot focus any particular element.

\subsubsection{Negation}

As Bergvall (1987: 86) shows, the marker of negation, $t i$, and ne are in complementary distribution. In independent clauses, ti occurs in the fronted constituent construction as well as in the verbal complex. In the latter, it appears in a different position than $n e$, namely after the object marker, as can be seen in the following examples (from Bergvall 1987: 86):

$$
\begin{aligned}
& \text { a. Kamau ti mo-remi } \\
& \text { K. NEG 1-farmer } \\
& \text { Kamau is not a farmer. } \\
& \text { b. Ti mw-ana w-oon-ir- } \varepsilon \text { mobiira } \\
& \text { NEG 1-child SM-see-ASP-FV ball } \\
& \text { It wasn't the child who saw the ball. } \\
& \text { c. To-ti-noon-a mwana (*netotinoona) } \\
& \text { SM-NEG-see-FV 1-child. }
\end{aligned}
$$

In subordinate clauses, as well as following $n e$-focus, verbal negation changes from /ti/ to /ta/ (see also example (42) above).

Given their complimentary distribution, the question arises whether ne and $t i$ are also generated in the same position. It does seem like $t i$ has a similar effect in question answer sequences. In particular, a postverbal element cannot be in focus when $t i$ appears on the verb.

93 Heine and Reh (1984: 168) describe the grammaticalization of the copula in Rendille, which has become a focus marker. Sentences containing it also still have certain relative clause features. 


\section{LOOSE ENDS}

However, more data is needed to systematically relate these phenomena to one another. The interaction between negation and focus therefore is an interesting field for future research.

\subsubsection{Alternative Questions}

One type of questions that we have not yet talked about is that of alternative questions. Although these may, at first sight, appear to be a type of Yes/No-question, they are more like a constituent question when we look at the possible answers (Krifka 2001):

$$
\begin{aligned}
& \text { a. Do you want TEA or COFFEE? } \\
& \text { b. I want TEA. }
\end{aligned}
$$

In the question in (a), both of the nouns connected by the disjunction are stressed. This distinguishes alternative questions from Yes/No-questions containing a disjoined object NP, which can be answered by yes or no:

(154) a. Do you want milk or sugar?

We find the same pattern in Kikuyu. To ask an alternative question, the two disjoined object NP's have to be marked for focus, i.e. they either have to appear in-situ (and without preverbal $n e)$ or in a preposed position with ne:

$$
\begin{aligned}
& \text { a. } \text { SM-T-end-a Jaai kana kahowa? } \\
& \text { b. ne Jaai kana ne kahowa o-kw-end-a? } \\
& \text { FM tea or FM coffee SM-T-want-FV } \\
& \text { both meaning: Do you want TEA or COFFEE? }
\end{aligned}
$$

The Yes/No-question in (154), on the other hand, is expressed in Kikuyu by the question in (156):

$$
\begin{aligned}
& \text { c. ne-J-kw-end-a Jukari kana iria? } \\
& \text { FM-SM-T-want-FV sugar or milk. } \\
& \text { Do you want sugar or milk? }
\end{aligned}
$$

Note that in this case, ne has to appear in the preverbal position, as is normally the case in Yes/No-questions.

One interesting point in (155b) is that ne occurs twice. So far, it has been one of the most stabile generalizations in the data that $n e$ can only occur one time per clause. What could the syntactic structure of (155b) look like? One approach that could preserve the idea that $n e$ is only generated one time per clause (because FP can at most be generated once per clause) might be to analyze the sentence as containing an elliptical structure, so that each ne appears within its own clause.

\subsection{Semantic Issues}

Comparing the meaning of the in-situ and the preposed focusing strategy, we have noted above that it is hard to detect a difference. Both seem to serve the general function of focus of introducing new information or alternatives, depending on how one wants to analyze focus in general (see chapter 2). However, there are a few hints that there might be a difference between in-situ and preposed focus. First of all, in question and answer sequences it generally seems to be required that the question and the answer follow the same pattern:

$$
\begin{aligned}
& \text { a. ne kee Abdul } \varepsilon(n) d-i r i-\varepsilon \text { retonga? } \\
& \text { FM what A. (SM)-sell-ASP-FV 7-rich man } \\
& \text { What did Abdul sell the rich man? } \\
& \text { b. } \sqrt{ } \text { ne nyomba } \\
& \text { FM 9.house }
\end{aligned}
$$




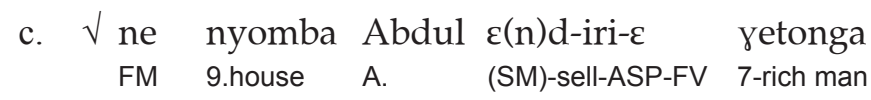

d. $\sqrt{ }$ Abdul ne nyomba $\varepsilon(n)$ diric retonga

e. * nyomba

f. * Abdul $\varepsilon(\mathrm{n})$ diric retonga nyomba
a. Abdul $\varepsilon$ (n)diric retonga kee? Abdul (3Sg)-sell-TMP 7-rich man what
b. * ne nyomba
c. ? ne nyomba Abdul $\varepsilon(\mathrm{n})$ diric retonga
d. ? Abdul ne nyomba $\varepsilon(\mathrm{n})$ diric yetonga
e $\sqrt{ }$ nyomba
f. $\quad \sqrt{ }$ Abdul $\varepsilon(n)$ diric retonga nyomba

The preposed question in (157a) hast to be answered in the preposed ne-form, in the short term answer as well as in a full sentence answer. In case of the in-situ question, the requirement seems to be slightly less strict, as the full sentence answer with preposed focus seem to be acceptable to some extent. Note, however, that the term answer is not possible with ne. Unless one assumes that this is simply some sort of surface parallelism requirement, the incompatibility of questions and answers of the different forms seems to indicate that there is a difference in meaning between them.

A further hint stems from Bergvall (1987: 139), who gives the following example of a preposed infinitive and notes that her informant "finds that the $n e$-initial form implies exclusivitiy: 'we swept, but did nothing else"':

$$
\begin{array}{ll}
\text { a. } & \text { ne ko-haat-a to-haat-Et- } \varepsilon \\
\text { FM INF-sweep-FV SM-sweep-ASP-FV } \\
\text { We did the sweeping (Bergvall's translation) }
\end{array}
$$

It is not clear whether the same holds for other elements in the preposed focus position as well. But it would fit nicely into the cross-linguistic picture if the preposed position indeed involved exhaustivity.

Remember that in the discussion on Hungarian in chapter 2 the general claim was presented that preposing of elements into the focus position in Hungarian marks identificational focus, which involves exhaustivity. To show that this is so, Hungarian linguists have proposed a couple of tests for exhaustivity. One of these tests involves judgments about logical consequence. In Hungarian, sentence (b) is not a logical consequence of sentence (a) (from Kiss 2002: 78) ${ }^{94}$ :

$$
\begin{aligned}
& \text { a. János PETERT ES ZOLTANT mutatta be Marinak. } \\
& \text { John Peter-ACC and Zoltan-ACC introduced VM Mary-to } \\
& \text { As for John, it was Peter and Zoltan that he introduced to Mary. } \\
& \text { b. János PÉTERT mutatta be Marinak. } \\
& \text { John Peter-ACC introduced VM Mary-to } \\
& \text { As for John, it was Peter that he introduced to Mary. }
\end{aligned}
$$

The argument is as follows: Because preposed focus identifies an exhaustive subset of referents, sentence (b) is not true when sentence (a) is true. Sentence (b) accordingly claims that only Peter was introduced to Mary, which would not be true if sentence (b) was true. The same test does not work for Hungarian in-situ focus, which, according to Kiss, only expresses informational focus.

94 Kiss attributes the test itself to Szabolcsi (1981). 


\section{LOOSE ENDS}

A further test ${ }^{95}$ involves the following dialogue:
a. János PÉTERT mutatta be Marinak.
John Peter-ACC introduced VM Mary-to
As for John, it was Peter that he introduced to Mary.
b. Nem, Zoltánt is bemutatta neki.
no Zoltan-ACC also introduced to.her
No, he also introduced Zoltan to her.

The response in (b) only makes sense if the focus on Pétert in (a) implies that nobody else was introduced to Mary. Otherwise, it would not make sense to begin the utterance in (b) by no. In case of the in-situ version of (a), it would indeed not make sense to reply by uttering (b). Therefore, preposed focus can be assumed to express exhaustivity, whereas in-situ focus does not.

A first attempt to apply these tests to Kikuyu seemed to indicate that the contrast between insitu and preposed foci was not as clear in Kikuyu. According to my informant, there is no clear difference in the relation of (162b) to (162a) compared to the relation between (163b) to (163a), i.e., in both cases it seems like (b) is true whenever (a) is true.
a. Kamau ne nyomba na funda endiric
b. Kamau ne funda endiric.
a. Kamau endirie nyomba na funda
b. Kamau cndiric funda.

However, it should be noted that the judgments involved here are quite subtle, and that these tests have been designed and used by linguists with extensive training in such judgments. Therefore, one should be careful to draw the conclusion to quickly that there is no difference at all in meaning between the two types of focus constructions in Kikuyu. The same is also valid for the second test, which did not deliver any clear results, either, although my informant could not make much sense of the reply analogous to (161b) for either type of focus construction.

These first tests then seem to indicate that exhaustivity is not necessarily involved in the preposed ne-constructions. Bergvall's example, on the other hand, seems to show that exhaustivity does play a role, at least to some extent. Further research needs to be carried out to clarify the issue. It should be noted in this context that there is an explicit way of expressing exhaustivity. This can be done by replacing ne by no, which roughly means only: ${ }^{96}$

$$
\begin{aligned}
& \text { a. Kamau no funda endirie. } \\
& \text { K. only 9.donkey (SM)-sell-ASP-FV } \\
& \text { Kamau only sold the DONkey. }
\end{aligned}
$$

It is unclear how no is related to ne. Benson's dictionary characterizes it as the "emphatic form of nĩ “" (Benson 1962: 283).

Another construction that apparently involves exhaustivity, according to my informant, is that of the alternative focus construction discussed in section 4.2.10., repeated here:

$$
\begin{aligned}
& \text { a. Abdul ne [we }]_{F} \text { Kamau o-sn-ir- } \varepsilon \\
& \begin{array}{lll}
\text { A. } & \text { FM 3Sg.PRON K. (SM)-T-see-ASP-FV }
\end{array} \\
& \text { It is Abdul (that) Kamau saw }
\end{aligned}
$$

This construction seems to come with a fairly strong exhaustive reading, so that it is understood as meaning that it was only Abdul that Kamau saw.

95 see Kiss (2002: 79), who attributes it to Donka Farkas.

96 It should be noted that there is a difference between expressing exhaustivity by only and by a cleft construction. In the first case, exhaustivity is asserted, while it is presupposed in the case of clefts. 
One final note concerning the potential exhaustivity involved in the preposed focus constructions is related to the case of prepositional phrases mentioned in chapter 3 . These cannot be preposed with $n e$. If preposed $n e$-constructions come with an exhaustive reading, this might explain the exception. In order to interpret something as an exhaustive subset, there needs to be a reasonable restriction on the alternatives. In the case of manner adverbials, this might be impossible, as activities can be described as being carried out in many ways. For example, while the example in (31) expressed that Abdul sold the house quickly, this action can surely be described by other modifiers as well (carefully etc.). It is hard to see how only one manner adverb could fit an action. Therefore, if preposed foci would imply exhaustivity, this could explain why one cannot use this construction with manner adverbials.

\subsection{Tonal Issues}

Up to this point, the issue of tone has been almost completely ignored. There are several reasons for this: The tonal system of Kikuyu is very intricate, and it requires quite a bit of training to even hear the tones in an utterance correctly. Furthermore, there seem to be dialectal variations in the tonal system, which make the application of the existent literature to newly collected data potentially problematic. ${ }^{97}$ Nonetheless, interaction between tone and the focus background structure have frequently been observed in the literature on Bantu, and it seems promising to at least consider this dimension as well. Hyman (1999), who gives a survey of the interaction of tone and focus in Bantu, thus concludes that "whether one is a syntactician or semanticist wishing to study focus $o r$ whether one is a phonologist wishing to study tone, one must consider all aspects of the grammatical system of a Bantu language" (Hyman 1999: 174). Although it proved to be extremely difficult to find such interaction, I want to present some considerations on this issue in the present section. Certainly, the amount of research efforts put into this has been insufficient, and the points of interest that I point out here are at best a helpful start for further research.

In the literature on Kikuyu, very little attention has been paid so far to the relation between tonal surface forms and the focus background partition of sentences. ${ }^{98}$ There are, however, numerous studies on this issue for a number of Bantu languages (see Hyman (1999) for an overview). Most notably, Kanerva (1990) and (1990a)) showed that focus affects the formation of phonological phrases in Chichewa, which in turn determines where tonal processes such as lenghtening and retraction take place. In Kikuyu, attention has mainly been paid to the tonal effects that come along with the presence or absence of ne on the verb. And at this point, it seems like this might be all there is in terms of interaction between tone and focus. One crucial difference to Chichewa seems to be that there are no phonological processes that take place at the end of some form of intermediate phonological phrases. These processes were crucial for Kanerva's study, as they allowed him to argue that the phrasing in sentences with identical word order changed due to different placement of focus.

In Kikuyu, on the other hand, focus is determined in large parts by word order. Therefore, it seems like the only interaction between focus and tone is related to the different verbal forms we find in different focus constructions. It seems, for example, that certain verbal forms protect a following argument or adjunct from a general flattening rule that turns sentence final high tones into low tones (Clements 1984a: 285). Hence we find the following variation on the object NP:

$$
\begin{array}{ll}
\text { a. } & \text { njonîré [Ngangá }]_{F} . \\
& \text { I saw Nganga } \\
\text { b. } & \text { ndinośna Nganga. } \\
& \text { I didn't see Nganga. }
\end{array}
$$

97 This is pointed out by Bergvall (1987) as one of her reasons to not study tone in detail.

98 To some extent, Clements (1984) and (1984a) are the exception to this, where tonal forms of the verb in connection with the appearance of $n e$ are discussed. Some aspects of this discussion will be presented shortly. 


\section{LOOSE ENDS}

c. ne $[\mathrm{Kamau}]_{\mathrm{F}}$ woonire Nganga. ${ }^{99}$

It was Kamu that saw Nganga.

As we have seen in the previous chapters, the name Nganga is in focus in (a), but not in (b) (Remember that the verbal negation has the same effect as ne on the focus structure) and (c). This might lead us to think that the preserved high tone on Nganga is due to focus. However, we also find this high tone in the form with preverbal ne. There, Nganga also can be part of the focus, if the entire sentence is in focus. But this should be the same as in (b), where there is no high tone on Nganga. Even if we could formulate a generalization that we find a high tone on an object noun when it is in focus, it only would work in cases with no more than one postverbal element. When there is more than one element, there is no relation at all between high tones and focus. The first postverbal element will bear a final high tone on the final syllable if its lexical tone does, and the sentence final element will always undergo flattening, even if it is in focus. This means that in the double object examples that we have seen in the section on object focus above, where either one of the objects could be in focus when there was no preverbal ne, focus does not make a difference in the tonal form of the utterance. Therefore it seems like tone is affected by the form of the verb, and the form of the verb does interact with the focus structure, but there is no direct interaction of tone and focus. Also, it did not seem like there was any difference at all between sentences that have the same word order but different foci. This was tested by recording multiple versions of such sentences with identical word order, but as answers to different questions. For example, a transitive sentence was recorded as an answer with focus on the VP and narrow focus on the object, and a double object construction was recorded in two contexts with the different objects in focus. However, neither my informant nor I myself could tell any difference in the recordings.

Yet another phenomenon that could possibly be related to focus is that of the stable suffix, as described by Clements (1984a). The stable suffix appears to be a tonal appendix to verb forms with preverbal ne (Clements 1984a: 298). In these forms, the final vowel of the verb always seems to bear a rising tone. It is unclear, however, why this is so and whether this could be directly related to focus. Also, Clements' data does not make it clear whether the ne-forms of the verb that he discusses are instances of sentence focus or of truth-value focus. Therefore, we cannot know at this point whether the rising tone suffix appears in both of these forms or just in one of them. In connection with this, we also should remember the dialogue from Armstrong presented above in (123), where there was an explicit controversy about whether the utterance in question was true or not. In the final, strongly emphatic assertion with ne, Bergvall noted that "here $n e$ has strong stress; there may also be a lengthening of the $\mathbf{n}$ and an extended range of intonation to show contradiction. If this were an answer to 'Did you put it in the granary?', [...] there would be no extra stress, lengthening of $\mathbf{n}$, or extended tone-range." (Armstrong 1940: 297). This is one of the few indications found in the literature that intonation could be relevant for focus, as here two tpyes of focus, namely truth-value focus and sentence focus, might be distinguished by different possible intonation patterns.

Altogether, extensive systematic research that takes into consideration the tonal classes of nouns and verbs is needed to find out with certainty whether there are any direct correlations between tone and focus.

99 The tones on the verb are unclear in this example, and therefore have not been marked. It is clear, however, that there is no final high tone on Nganga. 


\section{Conclusion}

The aim of this study was to provide a broadened empirical basis for the range of possible focus constructions in Kikuyu and to propose a theoretical syntactic analysis of focus constructions involving the particle $n e$. After taking a close look at the existing proposals for the analysis of $n e$ in the literature, we were facing the question whether preposed focus constructions with ne were to be analyzed as cleft sentences, as proposed by Bergvall (1987), or as a syntactic focus phrase in the c-domain, as proposed by Clements (1984).

Based on new data, in which topicalization and a preposed focus were combined, I tried to argue that the fronted focus constructions cannot be analyzed as clefts. I then tried to develop a unified account of $n e$ for the preposed constructions with ne and for preverbal ne. This analysis was inspired by work done on Hungarian, which is generally assumed to have a fixed syntactic position for focus. The Kikuyu data can also be accounted for by assuming such a position. Furthermore, just as in Hungarian, there also seems to be a need for some sort of topic position preceding the focus position. If this analysis is correct, then Kikuyu is a discourse configurational language. ${ }^{100}$ This led to an extended phrase structure in the left periphery of the Kikuyu sentence, including a focus and a topic phrase. The account that I presented was also looked at in the light of new data, which included focus on the VP, the entire sentence, and the truth-value. Although more detailed analyses are necessary for a number of cases, it seems like the analysis could capture the phenomena observed in the data.

One question that was not fully answered was whether the copular use of ne can also be integrated into the unified account. This is certainly possible in terms of mere word order, but there seem to be some distributional restrictions that do not apply for the other occurrences of $n e$. Furthermore, the phenomenon of postverbal focus still lacks a detailed analysis. Nonetheless, it seems clear that there is a straightforward interaction between the use of the focus marker $n e$ and postverbal focus, since the latter can only occur when the former is absent.

The dimension of this thesis has mostly been limited to the synchronic study of Kikuyu. The analysis pursued here could benefit from additional cross-linguistic (in particular cross-Bantu) work, as well as from diachronic insights. It seems quite plausible that the preposed focus construction with $n e$ has developed from syntactic clefts, with $n e$ serving, in one way or another, a copular function. This type of development, from a copula to a focus marker, is quite common and has been illustrated, for example, for Rendille (Heine \& Reh 1984: 165-168). Assuming such a development would especially account for the relative clause properties found on the verb in preposed $n e$-focus constructions. ${ }^{101}$ If cross-linguistic and diachronic research would provide further evidence that the syntactic focus phrase has developed out of clefts, this would be interesting on a more general theoretical level, if one considers the proposal by Kiss (1998) discussed above, which analyzes English cleft constructions as involving a focus phrase as well.

Another question for further research is that of exhaustivity in preposed ne-focus constructions. The available tests in the literature on Hungarian are not very well suited for field work with an informant. Therefore, more practical tools, for example ones that use broader textual contexts, have to be developed in order to get reliable judgments. The question of exhaustivity, and of a possible difference in meaning between in-situ and preposed focus constructions also is of interest for a potential diachronic analysis, since it is unclear why Kikuyu would have developed two different types of focus constructions, in-situ and preposed, if these serve exactly the same purpose and express the same meaning.

\footnotetext{
${ }^{100}$ Certainly with respect to focus, and possibly also with respect to topic, if discourse evidence can be found that what I have represented as a topic phrase in the syntactic analyses really displays topic properties.

101 This also is the case in Rendille (Heine \& Reh 1984: 168).
} 


\section{CONCLUSION}

Finally, possible interactions of focus and tone are yet to found. Although it is hard to exclude the possibility completely, the evidence at the moment seems to indicate that there is no or not much interaction between them. However, further research is necessary to confirm this.

\section{Acknowledgements}

Since the work for this thesis originated in a class on linguistic fieldwork and has crucially depended on the native competence of a Kikuyu speaker, I first of all want to thank my informant Sam Kinuthia for his patience in enduring hours and hours of questioning about focus and question answer sequences in Kikuyu.

I am indebted to the teacher of this class, Manfred Krifka, who has taught me most of what I know about linguistics. Beyond teaching me a lot on how to do linguistics, he has inspired me to pursue the study of language further, and has given me more encouragement and support than I could have hoped for. In connection with this thesis, I am especially thankful for his advice and many helpful comments, as well as for all the time and effort he put into reading drafts and discussing them with me. Also, without his generous help in making the meetings with the informant possible, first at the Humboldt University and later at the ZAS, the research for this thesis could not have been carried out.

It was a very pleasant part of this endeavor that most of the data were collected with a group of people from the Humboldt University and the ZAS. I want to thank the participants of this group, namely Laura Downing, Sabine Zerbian, Markus Fischer, and Peggy Jacobs, for many good times and for helpful discussions and comments. I want to thank Laura and Sabine especially for their continuous interest in my work and for many exciting and fruitful discussions. Laura also read a draft of this thesis and gave very helpful feedback.

A number of people have been so kind to discuss parts of my work at different stages, and I very much appreciate their interest and comments: Katharina Hartmann and Renate Musan read my first short paper on focus in Kikuyu and discussed some of the issues with me. Yukiko Morimoto and Lisa Cheng took time to give me helpful comments on a draft of chapter 3 and 4.

I had the fortunate opportunity to present parts of this thesis at the SOAS in London at the workshop Bantu Grammar: Description and Theory, and I would like to thank the participants for discussion and comments.

I would like to thank my parents, Manfred and Angelika Schwarz, for their support throughout my studies, and also for always supporting me in whatever I wanted to do. And above all, thanks to Traci for unlimited support, for her patience, and for her continuous efforts to pull me away from my desk every once in a while.

\section{References}

Abraham, W. (ed.) (1990): Discourse Particles. Amsterdam: John Benjamins.

Abraham, W. \& Meij, S. de (eds.) (1986): Topic, Focus and Configurationality. Amsterdam: John Benjamins.

Aissen, Judith L. (1992): Topic and Focus in Mayan. Language, 68, 43-79.

Akmajian, Adrian (1970): On deriving cleft sentences from pseudo-cleft sentences. Linguistic Inquiry, 1, 149-168.

Armstrong, Lilias Eveline (1940): The Phonetic and Tonal Structure of Kikuyu. London: Oxford University Press.

Barlow, Ruffell A. (1927): The use of the copula with the Kikuyu verb. In: Festschrift Meinhof, (pp. 223-227). Glückstadt/Hamburg: J.J. Augustin.

Barlow, A. Ruffell (1951): Studies in Kikuyu Grammar and Idiom. Edinburgh: Blackwood \& Sons.

Benson, T. G. (ed.) (1964): Kikuyu-English Dictionary. London: Oxford University Press. 
Bergvall, Victoria L. (1983): Wh-Questions and Island Constraints in Kikuyu: A reanalysis. In: Kaye, J. \& Koopman, H. \& Sportiche, D. et.al. (eds.): Current Approaches to African Linguistics, Vol. 2. (pp. 245-260). Dordrecht: Foris Publications.

Bergvall, Victoria L. (1986): A typology of empty categories for Kikuyu and Swahili. In: Dimmendaal, G. (ed.): Current Approaches to African Linguistics, Vol. 3. (pp. 55-70). Dordrecht: Foris.

Bergvall, Victoria Lee (1987): Focus in Kikuyu and universal grammar. Unpublished Ph.D. Thesis, Harvard University.

Bergvall, Victoria L. (1987a): The Position and Properties of In Situ and Right-Moved Questions in Kikuyu. In: Odden, David (ed.): Current Approaches to African Linguistics, Vol. 4. (pp. 37-55). Dordrecht: Foris Publications.

Bresnan, Joan W. (1968): Remarks on Adsententials. MIT ms.

Brody, Michael (1990): Some Remarks on the Focus Field in Hungarian. UCL Working Papers, 2, 201-225.

Büring, Daniel (1997): The 59th Street Bridge accent: On the meaning of topic and focus. New York: Routledge.

Bynoe-Andriolo, Esla Y. \& Yillah, M. Sorie (1975): Predicate-clefting in Afro-European Creoles. Ohio State Working Papers in Linguistics, 20, 234-239.

Chomsky, N. (1970): Deep Structure, Surface Structure and Semantic Interpretation In: Jakobson, R. \& Kawamoto, S. (eds.): Studies in General and Oriental Linguistics. (pp. 5291). Tokyo: TEC.

Chomsky, N. (1976): Conditions on Rules of Grammar. Linguistic Analysis, 2, 303-351.

Chomsky, N. (1981): Lectures on Government and Binding. Dordrecht: Foris.

Chomsky, N. (1986): Barriers. Cambridge, MA: MIT Press.

Clements, G. N. (1980): A syntactic account of Kikuyu 'ni'. Paper presented at the Groningen Round Table on Linguistics, 4.

Clements, G. N.(1984): Binding Domains in Kikuyu. Studies in the Linguistic Sciences, 14, 3756.

Clements, G. N. (1984a): Principles of Tone Assignment in Kikuyu. In: Clements, G. N. \& Goldsmith, John (eds.): Autosegmental Studies in Bantu. (pp. 281-339). Dordrecht: Foris.

Clements, George N. \& Ford, K. C. (1979): Kikuyu Tone Shift and Its Synchronic Consequences. Linguistic Inquiry, 10, 179-210.

Clements, G. N. \& Ford, Kevin C. (1981): On the Phonological Status of Downstep in Kikuyu. In: Goyvaerts, Didier L. (ed.): Phonology in the 1980's. (pp. 309-357). Ghent: StoryScientia.

Clements, G. N. \& Goldsmith, John (eds.) (1984): Autosegmental Studies in Bantu. Dordrecht: Foris.

Collins, Peter (1991): Cleft and pseudo-cleft constructions in English. London: Routledge.

Delin, Judy \& Oberlander, Jon (1995): Syntactic constraints on discourse structure: The case of it-clefts. Linguistics, 33, 465-500.

Dimmendaal, G. (ed.) (1986): Current Approaches to African Linguistics, Vol. 3. Dordrecht: Foris.

Emonds, Joseph (1976): A transformational approach to English syntax. New York: Academic Press.

Fery, Caroline \& Sternefeld, Wolfgang (eds.) (2001): Audiatur Vox Sapientia. A Festschrift for Arnim von Stechow. Berlin: Akademie Verlag (= studia grammatica 52).

Ford, K. C. (1975): The Tones of Nouns in Kikuyu. Studies in African Linguistics, 6, 49-64.

Goyvaerts, Didier L. (ed.) (1981): Phonology in the 1980's. Ghent: Story-Scientia.

Groenendijk, Jeroen \& Janssen, T. \& Stokhof, M. (eds.) (1981): Formal Methods in the Study of Language. Amsterdam.

Güldemann, Tom (to appear): Present progressive vis-à-vis predication focus in Bantu: A verbal category between semantics and pragmatics. To appear in Studies in Language.

Güldemann, Tom (1996): Verbalmorphologie und Nebenprädikation im Bantu: Eine Studie zur funktional motivierten Genese eines konjungationalen Subsystems. Bochum: Brockmeyer. 


\section{REFERENCES}

Gussenhoven, Carlos (1983): Focus, mode and the nucleus. Journal of Linguistics, 19, 377-314.

Guthrie, M. (1967): The Classification of Bantu Languages. London: Dawsons of Pall Mall.

Heine, Bernd \& Reh, Mechthild (1984): Grammaticalization and Reanalysis in African Languages. Hamburg: Buske.

Höhle, Tilman N. (1992): Über Verum-Fokus im Deutschen. In: Jacobs, Joachim (ed.): Informationsstruktur und Grammatik. (pp. 112-141). Opladen: Westdeutscher Verlag.

Horvath, Julia (1986): FOCUS in the Theory of Grammar and the Syntax of Hungarian. Dordrecht: Foris Publications.

Horvath, Julia (1995): Structural Focus, Structural Case, and the Notion of Feature-Assignments. In: Kiss, Katalin É. (ed.): Discourse Configurational Languages. (pp. 28-64). Oxford: Oxford University Press.

Hyman, L. (ed.) (1979): Aghem Grammatical Structure. Los Angeles: USC. (= Southern California Occasional Papers in Linguistics 7)

Hyman, Larry (1999): The Interaction between Focus and Tone in Bantu. In: Rebuschi, Georges \& Tuller, Laurice (eds.): The Grammar of Focus. (pp. 151-177). Amsterdam, Philadelphia: John Benjamins (= Linguistics Today 24).

Inkelas, Sharon \& Zec, Draga (eds.) (1990): The phonology-syntax connection. Chicago: University of Chicago Press.

Jackendoff, R. (1972): Semantic Interpretation in Generative Grammar. Cambridge, MA: MIT Press.

Jacobs, Joachim (ed.) (1992): Informationsstruktur und Grammatik. Opladen: Westdeutscher Verlag.

Jacobs, Joachim (1984): Funktionale Satzperspektive und Illokutionssemantik. Linguistische Berichte, 91, 25-58.

Jakobson, R. \& Kawamoto, S. (eds.) (1970): Studies in General and Oriental Linguistics. Tokyo: TEC.

Johnson, M. R. (1978): A Semantic Analysis of Kikuyu Tense and Aspect. Unpublished Ph.D. Thesis, Ohio State University.

Johnson, Marion R. (1980): A semantic description of temporal reference in the Kikuyu verb. Studies in African Linguistics, 11, 269-320.

Kanerva, Jonni (1990): Focus and phrasing in Chichewa Phonology. New York: Garland.

Kanerva, Jonni M. (1990a): Focusing on Phonological Phrases in Chichewa. In: Inkelas, Sharon \& Zec, Draga (eds.): The phonology-syntax connection. (pp. 145-161). Chicago: University of Chicago Press.

Kaye, J. \& Koopman, H. \& Sportiche, D. et. al. (eds.) (1983): Current Approaches to African Linguistics, Vol. 2. Dordrecht: Foris.

Kim, Chin-Wu \& Stahlke, Herbert (eds.) (1971): Papers in African Linguistics. Edmonton/ Champaign: Linguistic Research, Inc.

Kiss, Katalin É. (ed.) (1995): Discourse Configurational Languages. Oxford: Oxford University Press.

Kiss, Katalin É. (1987): Configurationality in Hungarian. Budapest: Akadémiai Kiadó.

Kiss, Katalin É. (1998): Identificational Focus versus Information Focus. Language, 74, 245-273.

Kiss, Katalin É. (2002): The syntax of Hungarian. Cambridge: Cambridge University Press.

König, E. (1991): The meaning of focus particles. A comparative perspective. London, New York: Routledge.

Krifka, Manfred (1992): A Compositional Semantics for Multiple Focus Constructions. In: Jacobs, Joachim (ed.): Informationsstruktur und Grammatik. (pp. 17-53). Opladen: Westdeutscher Verlag.

Krifka, Manfred (2001): For a Structured Meaning Account of Questions and Answers. In: Fery, Caroline \& Sternefeld, Wolfgang (eds.): Audiatur Vox Sapientia: A Festschrift for Arnim von Stechow. (pp. 287-319). Berlin: Akademie Verlag. (= studia grammatica 52).

Lambrecht, Knud (1994): Information structure and sentence form: Topic, focus, and the mental representation of discourse referents. Cambridge: Cambridge University Press. 
McCawley, James D. (1968): Lexical Insertion in a transformational grammar without deep structure. Papers from the Fourth Regional Meeting of the Chicago Linguistics Society.

Mugane, John. M. (1997): A paradigmatic grammar of Gikuyu. Stanford: CSLI Publications.

Myers, Amy (1971): Assertion and Presupposition in Kikuyu. In: Kim, Chin-Wu \& Stahlke, Herbert (eds.): Papers in African Linguistics. (pp. 135-140). Edmonton/ Champaign: Linguistic Research, Inc.

Odden, David (ed.) (1987): Current Approaches to African Linguistics, Vol. 4. Dordrecht: Foris.

Ortiz de Urbina, Jon (1995): Residual verb second and verb first in Basque. In: Kiss, Katalin É. (ed.): Discourse Configurational Languages. (pp. 99-121). Oxford: Oxford University Press.

Pratt, Mary (1972): Tone in some Kikuyu verb forms. Studies in African Linguistics, 3, 325-377.

Prince, Ellen F. (1978): A comparison of wh-clefts and it-clefts in discourse. Language, 45, 883906.

Puskás, Genoveva (2000): Word order in Hungarian: The syntax of A'-positions. Amsterdam, Philadelphia: John Benjamins.

Rebuschi, Georges \& Tuller, Laurice (eds.) (1999): The Grammar of Focus. Amsterdam, Philadelphia: John Benjamins (= Linguistics Today 24).

Rebuschi, Georges \& Tuller, Laurice (1999): The Grammar of Focus: An Introduction. In: Rebuschi, Georges \& Tuller, Laurice (eds.): The Grammar of Focus. (pp. 1-22). Amsterdam, Philadelphia: John Benjamins.

Rooth, M. (1985): Association with Focus. Unpublished Ph.D. Thesis, University of Massachusetts at Amherst.

Rooth, M. (1992): A Theory of Focus Interpretation. Natural Language Semantics, 1, 75-116.

Ross, J. R. (1967): Constraints on Variables in Syntax. Unpublished Ph.D. dissertation, M.I.T.

Rudin, C. (1986): Aspects of Bulgarian Syntax: Complementizers and Wh-Constructions. Columbus: Slavica.

Schachter, Paul (1973): Focus and relativization. Language, 49, 19-46.

Schwarzschild, Roger (1999): GIVENness, AvoidF and other Constraints on the Placement of Accent. Natural Language Semantics, 7, 141-177.

Selkirk, Elisabeth O. (1984): Phonology and Syntax. Cambridge, MA: MIT Press

von Stechow, Arnim (1990): Focusing and backgrounding operators. In: Abraham, W. (ed.): Discourse Particles. (pp. 37-84). Amsterdam: John Benjamins.

von Stechow, A. \& Uhmann, S. (1986): Some remarks on focus projection. In: Abraham, W. \& Meij, S. de (eds.): Topic, Focus and Configurationality. Amsterdam: John Benjamins.

Szabolcsi, Anna (1981): The semantics of Topic-Focus Articulation. In: Groenendijk, Jeroen \& Janssen, T. \& Stokhof, M. (eds.): Formal Methods in the Study of Language. (pp. 513-540). Amsterdam.

Tsimpli, Ianthi M. (1995): Focusing in Modern Greek. In: Kiss, Katalin É. (ed.): Discourse Configurational Languages. (pp. 176-206). Oxford: Oxford University Press.

Watters, J. (1979): Focus in Aghem. In: Hyman, L. (ed.): Aghem Grammatical Structure. Los Angeles. 


\section{Kontaktadressen der Autoren}

Markus Fischer

Reichenbacher Str. 166

10999 Berlin

e-mail: markus.fischer@rz.hu-berlin.de

oder: fischer74@t-online.de

Florian Schwarz

Department of Linguistics

University of Massachusetts,

Amherst 01003

e-mail: florian@linguist.umass.edu 